\title{
Copyright
}

by

Kristy Lynne Towry

2002 
The Dissertation Committee for Kristy Lynne Towry Certifies that this is the approved version of the following dissertation:

\section{Control in a Teamwork Environment - The Impact of Social Ties on the Effectiveness of Mutual Monitoring Contracts}

\section{Committee:}

Steven J. Kachelmeier, Supervisor

Urton L. Anderson

Shane S. Dikolli

Lisa L. Koonce

Arthur B. Markman

David E. Platt 


\title{
Control in a Teamwork Environment - The Impact of Social Ties on the Effectiveness of Mutual Monitoring Contracts
}

\author{
by \\ Kristy Lynne Towry, B.S., M.B.A. \\ Dissertation \\ Presented to the Faculty of the Graduate School of \\ The University of Texas at Austin \\ in Partial Fulfillment \\ of the Requirements \\ for the Degree of
}

Doctor of Philosophy

The University of Texas at Austin

May, 2002 


\section{Dedication}

To Mama and Daddy 


\section{Acknowledgements}

This dissertation has benefited from the efforts of a tremendous committee. It is with most sincere gratitude that I acknowledge Urton L. Anderson, Shane S. Dikolli, Lisa L. Koonce, Arthur B. Markman, and David E. Platt. They, along with the entire faculty and staff of the University of Texas at Austin Accounting Department, have been generous with their time, energy, and patience throughout my doctoral studies. I also appreciate the support of the other Ph.D. students at UT, particularly Haidan Li and Alex Yen, who entered this program with me and have since become great friends and trusted colleagues. I am fortunate to receive constant encouragement and support from my family and friends, who help keep my feet firmly planted in the real world.

Finally, I have the best dissertation chair in the world. Without a doubt, Steve Kachelmeier is the greatest influence on my academic career, and any success I achieve will be largely because of his guidance. Beginning with our research methods class and continuing through a million impromptu meetings in his office, Steve has demonstrated to me the meaning of being a great scholar and a special friend. Thank you. 


\title{
Control in a Teamwork Environment - The Impact of Social Ties on the Effectiveness of Mutual Monitoring Contracts
}

\author{
Publication No.
}

Kristy Lynne Towry, Ph.D.

The University of Texas at Austin, 2002

Supervisor: Steven J. Kachelmeier

This study examines control in a teamwork setting, experimentally investigating two financial incentive systems that have been proposed in the agency theory-based analytic literature. Both systems rely on mutual monitoring, the ability of team members to observe each other's actions. However, the systems differ on whether team members report observations of their peers' efforts to management (vertical incentive system) or directly control the actions of each other (horizontal incentive system). Findings suggest that the effectiveness of these systems depends on the level of team identity. Specifically, the effectiveness of a vertical incentive system is degraded by a strong team identity. On the other hand, a horizontal incentive system becomes more effective in the presence of a strong team identity. 


\section{Table of Contents}

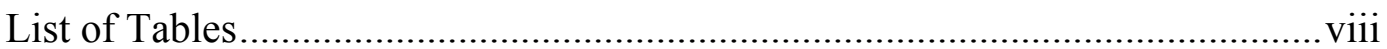

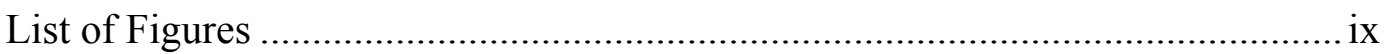

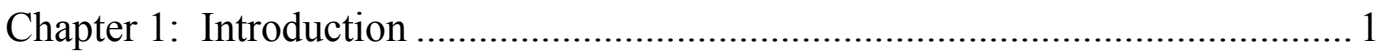

Chapter 2: Agency Theory in a Teamwork Environment ..................................... 9

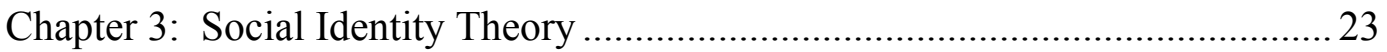

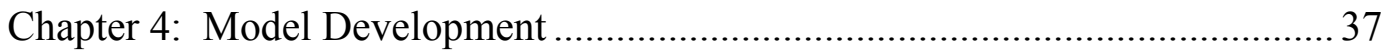

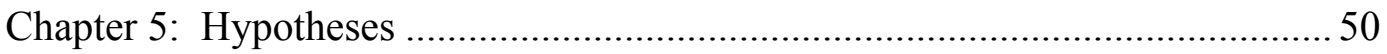

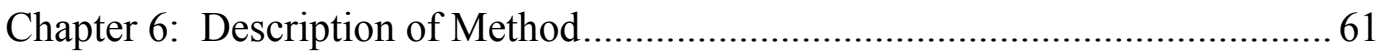

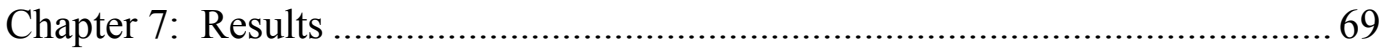

Chapter 8: Summary and Conclusions ……………………............................... 106

Appendix A - Experimental Materials............................................................... 110

Appendix B - Instructional Slides ................................................................... 122

Appendix C - Post-Experimental Questionnaire .................................................. 127

Appendix D - Communication Transcript Samples ……………………............ 130

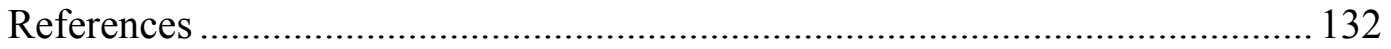

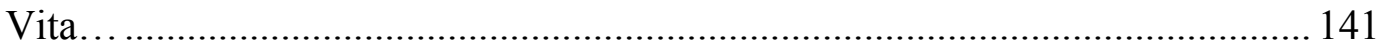




\section{List of Tables}

Table 1 - Conditional Probability Distribution for Output ...................................... 47

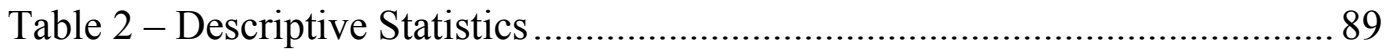

Table 3 - Tests for Normality ............................................................................... 91

Table 4 - ANOVA for Hypothesis 1 .................................................................. 92

Table 5 - Alternate Analysis of Hypothesis 1......................................................... 93

Table 6 - ANOVA for Hypothesis 3 ……………….......................................... 94

Table 7 - Alternate ANOVA for Hypothesis 3 …………………….................. 95

Table 8 - Contingent Decision Making Under the Vertical System...................... 96

Table 9 - Contingent Decision Making Under the Horizontal System.................. 97

Table 10 - Trend Analysis Using the Friedman Test.............................................. 98

Table 11 - Trend Analysis Using Wilcoxon Signed Ranks Test...........................99 


\section{List of Figures}

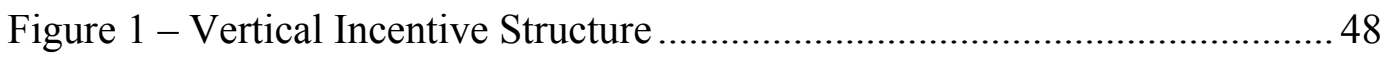

Figure 2 - Horizontal Incentive Structure …………………………………….... 49

Figure 3 - The Effect of Team Identity on Incentive Effectiveness ......................58

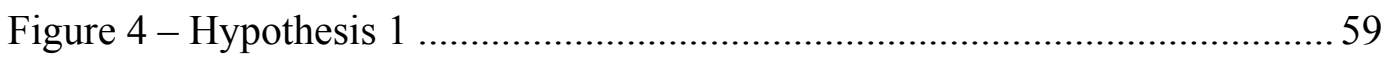

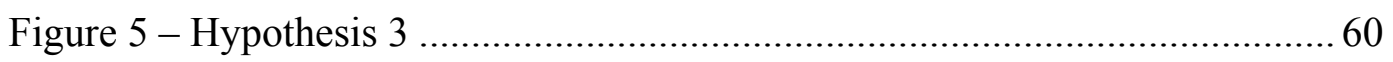

Figure 6 - Room Layout for Instructional Phase .................................................... 65

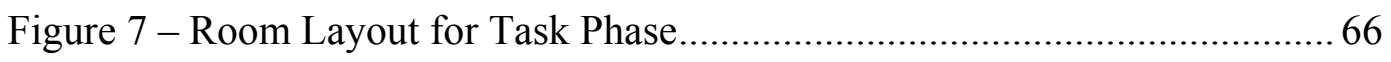

Figure 8 - Resource Decision Form...................................................................... 67

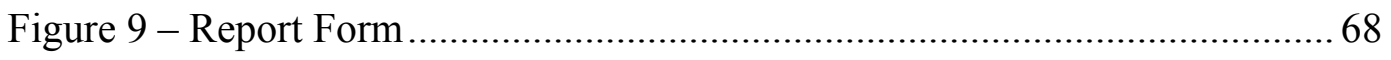

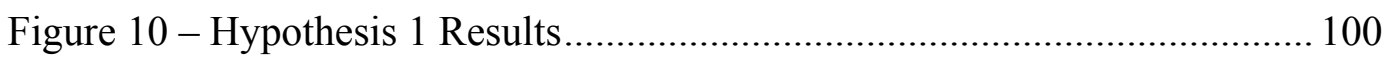

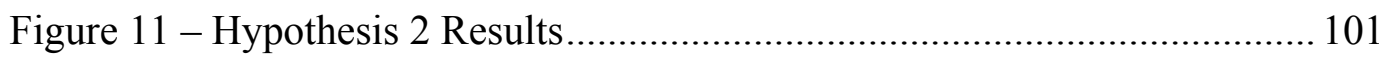

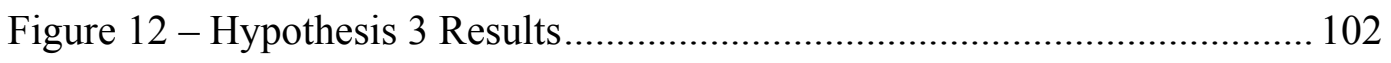

Figure 13 - Contingent Decision Making Under the Vertical System ................ 103

Figure 14 - Contingent Decision Making Under the Horizontal System ............ 104

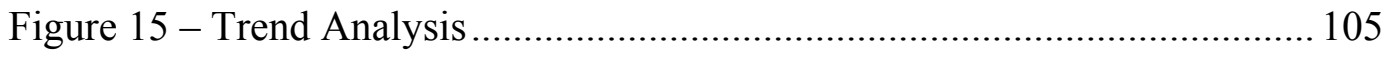




\section{Chapter 1: Introduction}

The use of teams in the workplace has increased dramatically over the last several decades (Cohen and Bailey 1997). ${ }^{1}$ For example, Hewitt Associates, based on their 1995 research on salary growth, report that $65 \%$ of surveyed companies use teams in some capacity. Similarly, the IMA (Institute of Management Accountants) reports in its 1999 Practice Analysis that $73 \%$ of survey respondents work at companies where management accountants are involved in cross-functional teams.

The trend toward greater use of teams began in Japanese companies, and it is now widely accepted that teamwork is critical for achieving success. Firms report a number of benefits of teams, including greater participation and involvement, increased attention to process improvements, and improved employee satisfaction (Wellins et al. 1994). Many young companies (e.g., Southwest Airlines (Kelley 2000), Whole Foods (Fishman 1996), and Cisco Systems (Gillmor 2000)) use teams as a central organizing principle, but even older, more established companies herald the benefits of teamwork. For example, General Mills, Inc. has reported that productivity is as much as $40 \%$ higher in

\footnotetext{
${ }^{1}$ Firms use teams in a number of different ways. Lawler and Cohen (1992) classify teams into three major categories - parallel teams, project teams, and work teams. Parallel teams involve workers who are temporarily removed from their regular duties to participate in some interim activity. Project teams are also temporary, but the participants on these teams generally remain in their regular assignments for the duration of the project. In contrast to these first two categories, work teams - the primary focus of this paper - are permanent groups engaged in producing a product or service. Examples of work teams include production teams and administrative support teams (Abosch and Reidy 1996). Of the companies using teams, Hewitt Associates (1995) report that about $77 \%$ use work teams.
} 
factories using a team-based as compared to a traditional approach (Dumaine 1990).

In response to the increased use of teams, researchers in a number of disciplines have begun to examine factors related to team effectiveness. Accountants and economists have modeled managerial control systems, with a particular emphasis on contracting and financial incentives. With basic assumptions rooted in individual rationality and self-interested behavior, such models tend to view a team simply as a collection of individuals, united only by interdependent tasks or incentives. Research in social psychology and related fields, on the other hand, recognizes that a team is more than a collection of interdependent individuals. This literature has examined the social ties that often develop among coworkers, suggesting that a real team exists only when the members have a sense of oneness, or team identity.

This study builds on both lines of research, proposing that insights from each may be useful in understanding team behavior. Specifically, in evaluating the potential usefulness of alternate incentive systems, it is important to consider the level of team identity. In this regard, I show that the incentive system interacts with the team identity, such that the effectiveness of an incentive system may be either enhanced or degraded by a strong team identity, depending on specific characteristics of the system.

This study examines two types of incentive systems, consistent with two fundamental approaches that have emerged in the analytic literature on multiagent settings. Both approaches rely on peer monitoring, the idea that while the 
principal (manager) cannot observe the actions of team members, the team members may be able to observe each other's actions. The use of peer monitoring is common in practice. In fact, psychology research shows that peer monitoring is a somewhat automatic process, conducted for the purpose of comparing oneself to others (Kunda 1999, 298). However, peer monitoring alone may not affect the behavior of workers. It must be incorporated, either formally or informally, into the incentive system. The analytic modeling literature has identified two general approaches for doing so.

Under the first approach, the agents monitor one another and report observations to the principal, who compensates the agents based on these reports. Because of its emphasis on hierarchical communication and control, this system will be referred to as the vertical incentive system. A prototypical example is Ma (1988). Peer evaluations are commonly used for career development purposes. For example, a number of firms have adopted "360 evaluation" systems, in which each worker evaluates the performance of superiors, subordinates and peers (Edwards and Ewen 1996). Notably, though, there has been a reluctance to report these evaluations upwardly or to use them as a formal basis for compensation. For example, a 1995 Saville and Holdsworth survey found that only $7 \%$ of large companies included peer evaluations in their formal appraisal systems (Thatcher 1996). In fact, a number of authorities (e.g. W. Edwards Deming, Peter Drucker, and Tom Peters) warn expressly against using peer evaluations in this way (Coates 1998). Thus, the use of vertical reports of peer observations for incentive 
contracting purposes, as conceptualized in economic theory, is not common in practice. $^{2}$

The second approach does not involve vertical reporting. Instead, the principal creates self-managing teams, basing each agent's pay on the team's joint output, and providing team members with a means of controlling one another, through formal sanctions, peer pressure, or enforceable side contracting. A prototypical example is Arya, Fellingham and Glover (hereafter AFG) (1997). Because of its emphasis on peer-enacted control, this system will be referred to as the horizontal incentive system. Unlike the vertical approach, the horizontal approach corresponds to a practice commonly observed in the real world. The popular press has discussed the role of peer pressure and social norms in helping Japanese companies achieve success (Nahavandi and Aranda 1994). Likewise, North American firms have shifted control from supervisors to self-managing teams (Dumaine 1990), often using team-based compensation (DeMatteo et al. 1998) and lateral control regimes (Lazega 2000). A recent study by the Center for Effective Organizations at The University of Southern California reports that $68 \%$ of Fortune 1000 companies use self-managed teams in some capacity (Dumaine 1994).

Analytically, these two approaches (vertical vs. horizontal) are two means to the same end, in that similar results can be obtained mathematically under the two systems. The premise of this study is that this analytic similarity is an

\footnotetext{
2 Very recently, several large consulting firms have begun to market their peer evaluation systems for compensation purposes, and businesses have begun to experiment with tying pay to peer reports. It is unclear, however, whether these implementations will be successful (Edwards and Ewen 1996), and this remains a subject of controversy among human resources professionals.
} 
oversimplification, because actual results under the two systems depend on the degree to which team members have established a team identity. Specifically, a strong team identity is likely to differentially affect effort levels under the two incentive systems because of its impact on strategy choice. Members of highly identified teams are more attuned to the possibility of mutually beneficial outcomes and will coordinate their strategies to achieve these outcomes. Under the horizontal approach, this will lead to the desirable outcome of greater effort, whereas under the vertical approach, this will lead to the undesirable, collusive outcome of lower effort and false reporting.

This research is important to managers wishing to maximize the effectiveness of work teams and to managerial accountants and assurance providers who design and evaluate managerial control systems. It contributes to their efforts in several ways. First, a considerable body of analytic modeling research has focused on the use of incentives to motivate desired behavior by employees, including recent efforts to design systems specifically for the teamwork environment. This research contributes to this stream of literature by providing evidence that the incentive system cannot be considered in a vacuum. Instead, it shows that psychological factors - specifically, the strength of team identity - play an important role in determining the effectiveness of various incentive systems. In doing so, this paper answers recent calls for research that melds theory from both economics and psychology to provide insights into accounting issues (Haynes and Kachelmeier 1998; Moser 1998; Waller 1995; Waller 2001). 
Second, this study addresses the measurement and contracting challenge presented by the teamwork setting. When accurate and verifiable measures of individual contributions are not available, incentive contracting may not be useful for encouraging employees to direct their efforts toward management's goals. Instead, the use of team incentives may result in free-riding. One solution to this problem is the use of the unconventional measure of peer observations. Such a measure is "soft" in the sense that it is not directly verifiable and does not meet the stringent measurement requirements to be included in the accounting library (Demski 1997). It may nonetheless be useful for incentive contracting purposes, and this study provides evidence on how such a measure can be used most effectively.

Third, this research provides evidence on the types of incentive systems that are most likely to be effective for different types of teams. Prior studies have emphasized the antecedents of team identification, showing that various team characteristics (e.g., the functional diversity of members, the team's status in the organization, and the members' time commitment to team activities) affect the degree to which members establish a team identity (Scott 1997). By focusing on the consequences of team identification, this study aids in developing the causal linkages among team characteristics, incentives, and performance.

Finally, this study provides insight into why firms have enthusiastically embraced compensation plans based on team output (the horizontal approach), but have been reluctant to tie pay to peer reports (the vertical approach). Part of this 
reluctance may be because the strong team identity that emerges in many teamwork settings undermines the incentive effects of the vertical approach.

Graduate business students participated in a 2 X 2 (Incentive System X Team Identity) between-subjects factorial design. Each experimental session involved eight participants, randomly assigned to four two-person teams. Team members assumed the roles of two division managers working for the same company, with compensation dependent upon their decisions. Each person's primary responsibility was to choose the level of effort (or more broadly, the level of resources) his/her division would commit to the production process. The first manipulated factor is the incentive system, capturing the two models of interest (vertical vs. horizontal). The second factor is the level of team identity, manipulated through a random assignment of participants into color groups. Each session of eight participants included two four-person color groups. In the high identity condition, four two-person teams were formed by pairing each participant with a participant from his/her color group. The low identity condition also involved four two-person teams, but with each participant paired with a participant from the other color group. The experimental case further enhanced (reduced) the salience of team identity in the high (low) identity condition.

The primary dependent variable is the level of effort chosen. I hypothesize and find a significant interaction between the incentive system and the level of team identity. Specifically, under the horizontal approach, a strong team identity leads to increased effort levels. However, under the vertical approach, a strong team identity leads to decreased effort levels. Further tests 
provide evidence that this effect is a result of both a cognitive change, leading team members to focus on joint vs. individual outcomes, and an increase in communication. Moreover, the incentive systems themselves differentially reinforce team identity, in that after repeated interaction, the level of team identity becomes higher for teams using the horizontal incentive system than for those using the vertical incentive system.

The remainder of this dissertation is organized as follows. Chapter 2 presents a review of the multi-agent literature from economics and accounting. Chapter 3 presents a review of the psychology-based literature on Social Identity Theory. In Chapter 4, I develop a model of team production with mutual monitoring. This model is combined with the psychology literature to develop hypotheses in Chapter 5. Chapter 6 describes the experimental methodology used to test these hypotheses. Chapter 7 presents the results and statistical analysis. Finally, Chapter 8 provides a summary and concluding remarks. Four appendices are included. Appendix A is a copy of the experimental materials. Appendix B shows the instructional slides presented during the experimental sessions. Appendix C presents the post-experimental questionnaire. Appendix D provides sample transcripts of the communication that occurred between teammates. 


\section{Chapter 2: Agency Theory in a Teamwork Environment}

\section{The Multi-Agent SetTing}

The analytic literature on contracting has begun to explore the implications of team settings. Most of the models are based on the principalagent paradigm, with the basic model (Holmstrom 1979) modified to include multiple agents. The literature has identified at least four ways in which the principal can improve his/her contracting position by taking advantage of the multi-agent setting.

First, if the agents share some common uncertainty, then each agent's output provides information about the other agent's state uncertainty (Holmstrom 1982). In this case, relative performance evaluations are valuable to the principal (e.g., Arya and Glover 1996a; Frederickson 1992; Gibbons and Murphy 1990; Holmstrom 1982; Mookherjee 1984). Second, if the agents are risk averse, then the multi-agent setting allows for risk sharing among agents, reducing the principal's agency costs (Ramakrishnan and Thakor 1991; Villadsen 1995). Third, in the multi-agent setting, incentives can be designed to encourage information sharing, helping, and other cooperative acts (Itoh 1991; Tirole 1988; Villadsen 1995). Finally, while the principal cannot observe the agents' actions, the agents may be able to observe each other, and the principal may achieve gains by encouraging mutual peer monitoring (e.g., AFG 1997; Ma 1988). It is this final feature of the multi-agent setting - the opportunity for mutual monitoring upon which this study focuses. The mutual monitoring literature can be divided 
into two basic approaches - the vertical approach and the horizontal approach. The literature related to each approach is discussed below.

\section{THE VERTICAL INCENTIVE SYSTEM}

Agency theorists have developed an extensive literature on incentive contracts that rely on vertical communication (agent to principal) in a multi-agent setting (Arya and Glover 1996b; Demski and Sappington 1984; Demski et al. 1988; Fischer \& Hughes 1997; Ma 1988; Ma et al. 1988). ${ }^{3}$ While the assumptions and forms of these vertical incentive contracts vary, the general model is one in which each agent observes the other agent's action and truthfully reports it to the principal. ${ }^{4}$ The agents are essentially whistle blowers, who pass along to the principal any information they gather about their co-workers. The vertical approach relies heavily on the assumption that the agents will choose their strategies independently, because any coordination among them will likely reduce the reliability of their reports.

The principal's maximization problem in a typical multi-agent analysis is analogous to that in a single-agent analysis - the principal maximizes his/her own utility, subject to the agents' individual rationality and incentive compatibility constraints. A key difference between the single-agent and multi-agent settings,

\footnotetext{
${ }^{3}$ Similar schemes, involving reporting of private information, may also be used in a single-agent setting, but the multi-agent setting often provides additional gains to the principal. For example, in a private information setting, Demski and Sappington (1984) show that the agents' rents are reduced whenever their private information is even imperfectly correlated. Similarly, in an unobservable action setting, Ma (1988) shows that the principal is able to achieve the first-best contracting result whenever the agents are able to perfectly observe each other's efforts.

4 These reports may be in the form of direct communication from the agents to the principal or may be indirect (e.g., the principal makes an inference based on the agents' choices among lotteries).
} 
however, is the form of the incentive compatibility constraint. In the single-agent setting, the incentive compatibility constraint requires that the agent select the action that maximizes his/her utility. In multi-agent studies using the vertical approach, the incentive compatibility constraint typically requires that the agents play a Nash equilibrium in their subgame.

A problem that often occurs under the vertical approach is the potential for tacit collusion (e.g., Demski and Sappington 1984; Mookherjee 1984). This problem occurs whenever the incentive system fails to uniquely implement the principal's desired solution. That is, while the incentive compatibility constraint requires that the agents play a Nash equilibrium, this Nash equilibrium may not be unique. In fact, it almost certainly is not unique, and in many cases it is Pareto dominated (from the agents' point of view) by an equilibrium that is undesirable to the principal. The implementation literature has therefore explored ways to ensure that the agents not only play a Nash equilibrium in their subgame, but that they play the specific Nash equilibrium desired by the principal. Methods for ensuring this unique implementation include tightening the incentive compatibility constraint to require the play of dominant strategies (Demski and Sappington 1984), increasing the size of the strategy set through the use of multistage mechanisms (e.g., Fischer and Hughes 1997; Ma 1988; Ma et al. 1988), and using a number of simple accounting-based mechanisms (e.g., Arya and Glover 1995; Arya and Glover 1996a; Arya and Glover 1996b; Arya, Glover and Hughes 1997). Many of the studies reviewed in this chapter are part of this implementation literature. 
Ma (1988) is a prototypical example of the vertical approach. Ma (1988) investigates a moral hazard problem, adopting the production setting introduced by Mookherjee (1984). He proposes a solution to the tacit collusion problem (discussed above) both in a setting where the two agents can monitor one another and in a setting where the agents' actions are unobservable to one another. The mutual monitoring setting is particularly relevant to the present study. In this setting, Ma (1988) shows that the principal's desired outcome can be uniquely implemented as a perfect equilibrium. Specifically, Ma (1988) proposes a twostage mechanism. In the first stage, both agents select their actions. In the second stage (before outcome is realized), one of the agents reports to the principal the actions taken by both the agents, and the other agent verifies this report. The key element of the solution is that if the second agent challenges the first agent's report, s/he accepts an output-based lottery, which is valuable only if the first agent actually did lie. The unique perfect equilibrium under this setting has both agents choosing the principal's desired actions, the first agent submitting a truthful report, and the second agent verifying that report. Ma's solution to the tacit collusion problem is particularly appealing because it is a first-best solution the risk averse agents take on no risk in equilibrium, because pay is based on reports of actions, and not on stochastic outcomes.

While Ma's (1988) mechanism solves the tacit collusion problem, it is important to note that off-equilibrium collusion is still possible. Specifically, the agents can improve their outcomes by choosing low levels of effort and agreeing to lie to the principal. This is not a tacit collusion problem, as defined by the 
literature, because it is off the equilibrium path - each agent has strict incentives to report truthfully. However, under some circumstances, agents may reach this collusive outcome, as proposed in Chapter 5. The opportunity for off-equilibrium collusion is a feature common to mutual monitoring studies using the vertical approach to incentive contracting.

Fischer and Hughes (1997) extend Ma (1988) to what they claim is a more realistic setting, in which the agents can only imperfectly monitor one another's actions. In the Fischer and Hughes (1997) model, each agent receives a private signal after actions are taken but before outcomes are realized. This signal may be interpreted as an imperfect observation of the other agent's effort. The contracting mechanism provides each agent with incentives to truthfully report to the principal the signal received, and compensation is a function of the signals reported and the output produced. Because compensation depends in part on the output produced, the agents take on some risk, for which they must be compensated. Therefore, unlike Ma (1988), Fischer and Hughes (1997) do not provide a first-best solution. However, Fischer and Hughes (1997) are able to almost costlessly solve the tacit collusion problem, "knocking out" all equilibria that Pareto dominate the principal's desired equilibrium. As is true with Ma's (1988) solution, an off-equilibrium opportunity for collusion still exists. The agents can improve their outcomes by agreeing to report falsely to the principal.

Arya and Glover (1996b) address the tacit collusion problem in a slightly different setting, one in which the two agents are not ex ante symmetric. Instead, one agent is a division manager and the other is a verifier (or auditor). While this 
setting is not completely analogous to the team setting of the current study, certain insights from Arya and Glover's (1996b) model are applicable to the team setting as well. Their paper provides an interesting blend of unobserved action (moral hazard) and private information (adverse selection). The division manager has private information regarding the division's cost function. The verifier is subject to moral hazard, in that s/he can choose to work or to shirk in fulfilling the verification duties, and this choice is unobservable by the principal. (If the verifier works, s/he will learn the true cost incurred by the division manager. However, if s/he shirks, s/he receives an uninformative signal of costs.) Arya and Glover (1996b) show that in the one-period game, the tacit collusion problem is so severe that it is impossible to construct a tacit collusion-proof mechanism. In the one-period setting, therefore, the verification process is valueless to the principal. However, when the model is extended to multiple periods, Arya and Glover (1996b) solve the tacit collusion problem through the use of historical cost reports. Notably, off-equilibrium collusion is still possible, involving the division manager reporting that costs are high and the verifier shirking on the verification duties and verifying the division manager's report.

While the papers discussed to this point explicitly assume the agents can observe each other's actions, other papers relate to mutual monitoring in a more indirect manner. These studies generally describe a private information (adverse selection) problem, rather than an unobservable action (moral hazard) problem. In the typical private information problem, the two agents have private information regarding their divisions' productivities, and a direct revelation 
mechanism is used to induce the agents to truthfully reveal this information to the principal. If the private information is correlated, this setting is conceptually similar to a setting in which each agent can imperfectly observe the other's action, because after an agent observes his/her own private information and the other agent's output, s/he can make an inference about the other agent's effort. (If the private information is perfectly correlated, each agent can perfectly discern the other's effort once the output is observed.)

An example of the indirect approach is Demski and Sappington's (1984) seminal model of contracting in a setting where multiple agents have correlated private information. Demski and Sappington (1984) show that the principal extracts rents from the agents whenever their information is correlated. The principal accomplishes this feat by requiring each agent to predict the other's output (by picking a lottery contingent on the other agent's output). This prediction is an implicit report, a revelation of each agent's private information, and the principal captures the agents' rents when the information is revealed. In fact, if the agents are risk neutral and the information is even slightly correlated, then the agents earn zero rents.

Demski and Sappington (1984) readily acknowledge the problem of tacit collusion. Their solution is to tighten the incentive compatibility constraint to require the agents to play subgame dominant strategies. As this is a costly solution, Demski and Sappington (1984) show that a less costly mechanism for solving the tacit collusion problem is asymmetric, with one agent constrained to play a Nash equilibrium and the other constrained to play only subgame dominant 
strategies. As is true for the models addressing mutual monitoring in a more direct manner, there is still an opportunity for off-equilibrium collusion, whereby agents agree to coordinate their reports and outputs to their mutual advantage.

Ma et al. (1988) also address the tacit collusion problem in a setting where the agents have correlated private information regarding their productivities. In this setting, the principal's preference is that each agent matches his/her output level to his/her productivity level (producing low output when productivity is low, and producing high output when productivity is high). This is similar to Demski and Sappington's setting, but Ma et al. (1988) take a different approach to the problem. Their solution is to induce one agent to police the other. The principal increases the message space available to the agents, allowing one agent to signal the principal if $\mathrm{s} / \mathrm{he}$ believes the other agent is cheating (choosing low output when his/her productivity is actually high). By taking advantage of this policing activity, the principal is able to costlessly eliminate the tacit collusion problem, though off-equilibrium collusion is still a possibility.

The papers discussed here, as well as others not related to mutual monitoring (e.g., Demski et al. 1988; Glover 1994), have focused on solving the tacit collusion problem. While these papers suggest a number of methods for solving the tacit collusion problem, they are not aimed at eliminating opportunities for off-equilibrium collusion. This lack of attention to offequilibrium outcomes is not surprising, because models using the vertical approach to mutual monitoring contracts rely on the fundamental assumption that agents will independently choose their strategies to maximize their individual 
utilities. Side contracting among the agents, explicit or implicit, is not allowed. Under this assumption, off-equilibrium outcomes are not a concern to the principal, because these outcomes could not be sustained without some type of enforcement mechanism. Models taking a horizontal approach, as discussed in the next section, make a different assumption. These studies assume that agents will coordinate their strategies and enforce their agreements through either formal or informal mechanisms.

\section{THE HORIZONTAL INCENTIVE SYSTEM}

The second way in which the principal can take advantage of the opportunity for mutual monitoring is through the use of a horizontal incentive system, relying on team self-management and peer-based control (e.g., AFG 1997; Barron \& Gjerde 1997; Itoh 1993; Kandel and Lazear 1992; Prendergast 1999; Radner 1986; Ramakrishnan and Thakor 1991; Tirole 1988; Varian 1990; Villadsen 1995). In contrast to the vertical approach, a horizontal incentive system does not involve reporting to the principal. Instead, the principal assumes that the agents will explicitly or implicitly coordinate their actions. Therefore, the principal creates an incentive system that induces the agents to agree (among themselves) to the actions desired by the principal and to enforce these agreements through the use of formal sanctions, peer pressure, or enforceable side contracting (either explicit or implicit).

Tacit collusion is generally not a concern when the incentive system is based on the horizontal approach. Recall that under the vertical approach, the incentive compatibility constraint typically requires that the agents play a Nash 
equilibrium in their subgame. The potential for tacit collusion in this setting stems from the possibility that multiple equilibria will exist, and that the equilibrium preferred by the agents will not be the one preferred by the principal. The incentive compatibility constraint often takes a different form under the horizontal approach, eliminating the potential for tacit collusion. For example, Villadsen (1995) (discussed below) suggests that if agents can side contract, and if utility is transferable among agents, the incentive compatibility constraint requires only that agents maximize their joint utility. The principal delegates to the agents the choice of how to divide effort among themselves. This delegation is typical of the horizontal approach, and it requires a shift from a fundamental assumption made under the vertical approach - the assumption that the agents cannot make enforceable side contracts among themselves.

Tirole (1988) challenges the assumption that side contracting is not possible. He criticizes the "grand contract" approach, under which all members of an organization are assumed to be linked under one grand contract, with all behavior and interaction specified by that contract. Tirole (1988) claims that this approach is unrealistic, arguing instead for a multi-contract approach that recognizes the sociological nature of the work environment. He suggests that in practice, members of organizations are likely to side contract in various ways, making use of both monetary and non-monetary side payments.

Itoh (1993) provides support for Tirole's argument, and shows that side contracts can actually improve the principal's welfare. Itoh (1993) demonstrates that when agents can mutually monitor each other, incentive schemes that 
acknowledge and exploit the agents' ability to make and enforce side-agreements often can be implemented at lower costs than those that assume no side contracting. As discussed earlier, when side contracting is allowed, the incentive compatibility constraint is altered. Under Itoh's (1993) "full-side contracting assumption," the incentive compatibility constraint requires that the agents implement Pareto optimal effort choices, rather than Nash equilibria. The reduction in costs under this assumption is the result not of risk sharing or coinsurance, but of improved coordination of actions. ${ }^{5}$ Interestingly, Itoh (1993) shows that the value of side contracting is limited to situations involving mutual monitoring, demonstrating that if agents can observe each other's outputs but not their efforts, the principal cannot improve his/her position by allowing for side contracting.

In a related paper, Ramakrishnan and Thakor (1991) seek to specify conditions under which side contracting is beneficial or detrimental to the principal. They focus on the conditional correlation between the two agents' outputs, showing that there is a critical point under which the principal will prefer a "cooperative organization of tasks." This cooperative organization is closely related to the notion of side contracting, as it involves mutual monitoring and joint determination of efforts and payoffs.

Similarly, Villadsen (1995) distinguishes between beneficial and detrimental collusion among agents. In her analysis, the opportunity for collusion is exogenous, determined by organizational and environmental factors outside the

\footnotetext{
${ }^{5}$ Itoh (1993) also discusses vertical (revelation-based) incentive systems, arguing that such systems "fall apart" when agents can side contract.
} 
model. She argues that if collusive opportunities exist, the principal must create an incentive system that either prevents collusion (a collusion-proof mechanism) or exploits it (a cooperative mechanism). She demonstrates that the cooperative mechanism is generally preferable to the collusion-proof mechanism, because it allows for more efficient sharing of effort and risk. Hence, side contracting can be beneficial to the organization if it is specifically accounted for in the incentive system design.

The papers discussed thus far in this section explore explicit side contracting by the agents. AFG (1997), on the other hand, propose an incentive system based on implicit side contracting. That is, the agents' ability to enforce agreements arises not from formal contracts and enforcement mechanisms, but from the incentive system itself. Specifically, AFG (1997) suggest that by altering incentives in the second period of a two-period model, the principal can induce agents to mutually monitor and to punish one another for shirking. This punishment takes the form of a tit-for-tat strategy, whereby each agent works in Period 1, and then works again in Period 2 only if the other agent worked in Period 1. Thus, as is the case when side contracts are explicit, AFG's (1997) control concept is horizontal in nature - the agents choose the actions preferred by the principal, because other agents will punish them if they choose otherwise.

AFG (1997) and the other papers discussed to this point suggest formal mechanisms that enable agents to control one another. In the case of AFG (1997), control stems from the incentive system itself, whereas other papers assume explicit enforcement mechanisms. Horizontal control can also be achieved 
through informal mechanisms, such as the use of peer pressure. Kandel and Lazear (1992) discuss peer pressure in a partnership setting, seeking to provide a rigorous framework for studying this somewhat intuitive concept. They conceptualize peer pressure as one team member's credible threat to punish another for effort below the desired level. Under this definition, AFG's (1997) tit-for-tat strategy is an example of horizontal control based on peer pressure.

While peer pressure may serve the useful purpose of allowing the agents to horizontally control one another, Barron and Gjerde (1997) suggest that peer pressure imposes a cost as well. They assume that this cost is borne by both the provider and the recipient of the peer pressure, and that the principal must compensate the agents for these extra costs in the "peer pressure environment." Thus, Barron and Gjerde (1997) show that introducing peer pressure into the work environment alters the optimum incentive system. This alteration provides an explanation for the empirical observation that incentives are often muted relative to the predictions of agency theory. Barron and Gjerde's (1997) notion that peer pressure can impose costs is supported by a number of studies on "concertive control" (Barker 1993; Ezzamel and Willmott 1998; Lazega 2000; Sewell 1998). These studies document that self-managed teams often establish strict norms of behavior and harsh disciplinary practices. While self-managed teams have been advocated as a positive alternative to inflexible and dehumanizing hierarchical systems, Barker (1993) argues that they often have the unintended effect of creating hostility among team members. 


\section{VERTICAL VS. HORIZONTAL INCENTIVE SYSTEMS}

As discussed above, a fundamental difference between the approaches of the horizontal and vertical incentive systems is related to the agents' ability to make and enforce side contracts. Under the vertical incentive system, agents are assumed to make their decisions independently, as they have no mechanism, formal or informal, for enforcing agreements among themselves. Under the horizontal approach, on the other hand, the principal assumes that the agents can agree upon their actions and enforce these agreements through formal or informal mechanisms. This distinction is at the heart of this study.

In Chapter 5, I argue that team identity (a concept introduced in Chapter 3) differentially influences the effectiveness of the two incentive systems. The basis of this argument is in the side contracting issue. Specifically, I argue that members of highly identified teams will become more attuned to joint rather than individual outcomes, and will actively coordinate their decisions to maximize joint outcomes. This coordination implies some type of side contracting, in that it involves an agreement between the agents as to the actions each will take. Thus, as team identity increases, side contracting will become more likely, and the effectiveness of the horizontal system will increase relative to the vertical incentive system. This is the primary hypothesis of the paper, developed more fully in Chapter 5. 


\section{Chapter 3: Social Identity Theory}

\section{Side Contracting Predictions From Social PSychology}

As developed in the prior chapter, a key difference between the horizontal and vertical systems relates to assumptions about side contracting. The vertical system assumes that team members choose their strategies independently, with no coordination or side contracting between the agents. In contrast, the horizontal incentive system relies on the assumption that the agents will cooperate, coordinating their actions through implicit or explicit side contracts. Therefore, to predict the effectiveness of either system in eliciting high levels of effort, one must understand the likelihood of coordinated behavior among the agents. The analytic models of the preceding chapter treat the level of coordination as an exogenous factor, and do not delve into the processes through which such coordination emerges. Social psychology research, on the other hand, provides a theory for predicting when team members will coordinate their actions. In this chapter, I introduce the theory, and review the related theoretical and empirical literature. In Chapter 5, I apply the theory to the incentive systems of interest to this study, and make specific predictions regarding the effectiveness of vertical and horizontal incentive systems.

\section{SELF-CATEGORIZATIONS}

The concepts of team identity, cohesion, and esprit de corps are somewhat intuitive. From sports teams to production teams, organizations seem convinced that teams that "hang together" achieve greater results than those that are simply 
collections of individuals working separately. A number of consulting firms (e.g., Teambuilding, Inc.; Team Builders Plus; Center for Creative Leadership) specialize in training aimed at teambuilding, a term related to the notion that a team can be more than the sum of its parts. To investigate this intuition more rigorously, I use a body of theory from social psychology collectively known as Social Identity Theory (Abrams and Hogg 1990).

Social Identity Theory, in general, describes the psychological processes that occur when a person self-identifies as a group member. ${ }^{6}$ A social identity results from a self-categorization process, through which an individual cognitively groups himself/herself with others, based on perceived similarities (Turner 1987a; Hogg 1987). ${ }^{7}$ Tajfel and Turner (1986) describe this process as a transition, through which a person stops thinking like a unique individual and instead begins to think like a representative of a group. As described by Brewer and Schneider (1990), there is "a fundamental depersonalization of the selfconcept" (170).

Evidence from psychology experiments suggests that self-categorization and the accompanying psychological phenomena are quite basic human processes. Scholars have explored the necessary and sufficient conditions for selfcategorization, or the formation of a "psychological group." (For a review, see

\footnotetext{
${ }^{6}$ Note that in a team setting, the terms team identity and social identity are synonymous.

${ }^{7}$ Strictly speaking, self-categorization theory (Turner 1987a) and Social Identity Theory (Abrams and Hogg 1990) emerge from distinct traditions of social psychological research. While selfcategorization theory examines the causes, processes, and consequences of psychological group formation, Social Identity Theory focuses more on ingroup/outgroup comparisons and intergroup behavior. However, because these bodies of literature are so interrelated, there is an accepted tendency to view them as one composite body of theory. I take such an approach, including selfcategorization theory under the broad umbrella of Social Identity Theory.
} 
Turner 1987b.) Because of their focus on the minimal conditions required for psychological group formation, these studies are collectively described as applying the "minimal group paradigm." They have examined the roles of conditions such as interdependence, interpersonal attraction, and physical proximity in invoking the self-categorization process. Notably, none of these factors appear to be necessary for self-categorization to occur. On the contrary, simply dividing people into groups, even on an explicitly random basis, is sufficient for inducing self-categorization (Locksley et al. 1980).

While individuals readily group themselves and others into various social categories, it is important to note that these categorizations do not always dominate the individual's self-concept. Tajfel and Turner (1986) distinguish between a personal identity and a social identity, arguing that only one of these identities can be dominant at a time. Thus, while an individual may have categorized himself/herself with others, this cognitive grouping (or social identity) will only affect behavior to the extent that it dominates the personal identity in the individual's self-concept. Shortly (in the "Antecedents of Social Identity" section), I will discuss the factors that determine the degree to which a social identity is adopted.

\section{ORGANIZATIONAL STUDIES IN SOCIAL IDENTITY}

Early work on social identity and self-categorizations focused primarily on issues of ethnic identity and discrimination, but this theory has more recently been applied in an organizational context (e.g., Ashforth and Mael 1989; Hogg and Terry 2000). Most organizational applications of Social Identity Theory are 
theoretical in nature, with only limited empirical research conducted to test the implications of this theory for organizational issues. Ashforth and Mael (1989) propose a three-pronged agenda for future applications of Social Identity Theory to organizational research. First, they acknowledge that individuals in organizations have multiple (often conflicting) identities, and suggest that research should focus on identification with salient subgroups (e.g., teams, functional roles, etc.) as well as with the overall organization. Second, they propose that organizational scholars should conduct research to identify both the antecedents and consequences of organizational identification. Finally, Ashforth and Mael (1989) call for further research on the effect of organizational identification on the internalization of the organization's goals and values.

Lembke and Wilson (1998) respond to the first of Ashforth and Mael's (1989) three proposals, suggesting that Social Identity Theory is a particularly appropriate theory for understanding one particular aspect of identification in organizations - identification with teams. Lembke and Wilson (1998) criticize prior research on team processes, arguing that traditional approaches to understanding teams (e.g., McGrath 1984) fail to consider the cognitive changes that are associated with team formation. Social Identity Theory, on the other hand, would suggest that a key component of team processes is the formation of a psychological team, a salient shared categorization of team members.

Ashforth and Mael's (1989) second proposed avenue of research is an examination of the antecedents and consequences of social identification, as discussed in the following two sections. 


\section{ANTECEDENTS OF SOCIAL IDENTITY}

As described earlier, self-categorization is a natural human process, conducted automatically and with relatively little prompting. As a result, each individual simultaneously holds a number of self-categorizations (Ashforth and Mael 1989). For example, employees assigned to cross-functional teams may simultaneously self-categorize themselves with fellow team members and with individuals filling similar functional roles (engineering, accounting, etc.) on other teams. The adoption of a social identity may be described in terms of the salience of these self-categorizations. Specifically, when one particular self-categorization becomes more salient than others (and more salient than the individual's personal identity), then a person is described as having adopted that particular social identity. ${ }^{8}$ What factors determine when an individual adopts a particular social identity? (Or alternatively, what makes a particular self-categorization salient?) A number of factors have been suggested.

Turner (1987a) proposes that situational cues are important for determining the relative salience of competing self-categorizations. For example, the degree to which an accountant on a cross-functional team identifies with other team members vs. other accountants may be in part determined by whether his/her office is physically located adjacent to other team members or to other accountants. Lembke and Wilson (1998) posit that the degree of team identity will also depend on the perceived status of the team. This proposal is supported

\footnotetext{
${ }^{8}$ While the concept of adopting a particular social identity may initially be interpreted as a discrete choice, Lembke and Wilson (1998) argue that social identification is not an "all or nothing" phenomenon; instead, the extent of social identification is a matter of degree.
} 
by empirical evidence - in a field study of the U.K. social worker strike of the 1970s, Breakwell (1983) reports that as the power of a group decreased, group members began to identify with various subgroups, fragmenting the larger group in a psychological attempt to achieve higher status. Ashforth and Mael (1989) also propose several antecedents of identification, including the distinctiveness of the group's values and practices, the salience of outgroups, and the clarity of the group's boundaries.

In one of the very few empirical investigations of social identity in a team setting, Scott (1997) explores the antecedents of team identification. She conducted a field study of 42 product and process development teams employed at a large manufacturing firm. Her results suggest that the level of team identity is positively related to the proportion of time that members spend on team-related activities and to the project leader's status in the organization, and is negatively related to the level of functional diversity on the team. Thus, a cross-functional team engaged in a temporary or part-time project is less likely to establish a strong team identity than is a full-time production team.

The studies discussed above document the characteristics that are likely to influence the level of social identity. The following section, in turn, discusses the consequences of social identity.

\section{CONSEQUENCES OF SOCIAL IDENTITY}

I am aware of only one study addressing the effects of social identity in an accounting setting. King (2002) demonstrates that a sense of social identity among auditors mitigates their tendency to over rely on clients' non-binding 
communication. More specifically, King (2002) experimentally investigates interactions among auditors and their clients, finding that clients use "cheap talk" to create trust in their auditors. King (2002) refers to this increased level of trust as a "self-serving bias," an unconscious bias created by psychology-based phenomena. The clients are able to capitalize on the auditors' trust by committing higher levels of fraud. King's (2002) results suggest that the auditors' selfserving bias can be mitigated by increasing the salience of the auditors' group membership, and by encouraging the development of social norms. The results of King's (2002) study are not directly applicable to the current study, because they do not focus on a team setting, where gains are possible through coordinated behavior. King's (2002) study nonetheless provides evidence of the important role social identity plays in affecting behavior in accounting settings.

Work in social psychology has explored the processes through which social identity affects behavior. When a particular social identity is adopted, several effects occur. First, members of the social category (the ingroup) are perceived as more heterogeneous than members of other categories (the outgroup) (Lorenzi-Cioldi and Doise 1990). Second, members of the ingroup are mutually attracted to one another and show favoritism for members of the ingroup over those of the outgroup (Brewer 1979). Finally, and most importantly for the current study, the unit of analysis for decision making shifts away from the individual and toward the group as a whole (Tajfel and Turner 1986).

When an individual adopts a social identity, s/he cognitively represents the social group as one entity rather than as a collection of separate entities. This 
change of perspective affects how information is interpreted and how decisions are made (Lembke and Wilson 1998). In a team setting, for example, the shift from an individual to a team perspective will change team members' beliefs about how their actions affect outcomes (Wech et al. 1998). In a highly identified team, team members are likely to believe that they can influence outcomes through collective vs. individual actions. The result is that team members begin to see their actions and outcomes as being interrelated with others on the team. Thus, in making choices, they are more likely to coordinate their actions and to focus on joint rather than individual outcomes (Brewer 1979).

The effect of social identity on decision making has been observed in the context of social dilemmas. ${ }^{9}$ These social dilemma experiments are particularly relevant for the current study, because both the horizontal and vertical incentive systems being investigated have features that relate to social dilemmas. Specifically, in a social dilemma, it is individually rational for each person to defect (behave opportunistically), but each person is better off if all choose to cooperate than if all choose to defect (Dawes 1980). As will be explained in Chapter 4, the horizontal and vertical incentive systems demonstrate a similar tension between individual rationality and social welfare.

Brewer (1979) first suggested that social identification affects behavior in social dilemmas, and this suggestion was followed by several empirical investigations of the premise. One of the earliest is a study by Kramer and

\footnotetext{
${ }^{9}$ While the papers presented here are all experimental, some related field studies have found similar results. For example, Everett et al. (1992) report that on women's swimming teams, team cohesion (a concept not identical to but closely related to social identity) results in a lower incidence of social loafing (the withholding of effort as individual effort becomes less identifiable).
} 
Brewer (1984), who conducted three experiments investigating a commons dilemma problem involving a replenishable resource. ${ }^{10}$ The group as a whole was provided with a resource pool of points, and participants were given two goals: 1) to individually accumulate as many points as possible from the resource pool, and 2) to make the resource pool last as long as possible, in order to maximize the number of periods over which points could be accumulated. During each period of the experiment, each participant was allowed to deduct (or "harvest") up to 10 points from the resource pool. Following the deductions the pool was replenished at a variable rate averaging 1.1. Kramer and Brewer (1984) report that the depletion rate was lower when participants' mutual membership in some superordinate group (either naturally occurring or experimentally manipulated) was made salient to them. ${ }^{11}$

Several factors limit the generalizability of Kramer and Brewer's (1984) results. For example, the participants could not interact or communicate with one another. Nor could they directly observe the harvesting decisions of other participants. (In fact, half of the participants in their studies were bogus participants, group members who were presumably participating from a remote location, but who were actually pre-programmed dummies.) It is reasonable to conjecture that these factors may interact with the primary independent variable of interest, social identity (as represented by salient group membership). Thus,

\footnotetext{
10 The replenishable resource task was patterned after that developed by Messick et al. (1983).

11 The superordinate group designation was made salient through instructional wording in two experiments. In the third experiment, salience was achieved through a "common fate" manipulation. Participants accumulated points throughout the experiment, which were converted to currency at the conclusion of the session. To make the group designation salient, a common conversion rate was determined for all members of the group, based on a random draw at the end of the session.
} 
the conclusions of this study may not generalize to settings involving social interaction, communication, and mutual observation.

Brewer and Kramer (1986) continued this stream of research in an experimental investigation of the interaction between decision framing and social identification in a social dilemma. ${ }^{12}$ They presented their participants with social dilemmas that were economically equivalent but that were framed in two different ways. In the commons dilemma condition, the problem was framed as a replenishable resource problem, similar to that used by Kramer and Brewer (1984). In the public goods condition, by contrast, participants were asked to make contributions to (rather than harvest from) the common pool.

Based on prospect theory (Kahneman and Tversky 1984), Brewer and Kramer (1986) predicted that participants confronted with a commons dilemma would behave more cooperatively than those confronted with a public goods problem. The evidence supports this prediction. However, Brewer and Kramer (1986) also report several important interactive effects among decision frame, social identity, and group size. Of most importance, in large groups, the effect of social identity on the level of cooperation was different under the two decision frames. The behavior of participants in the commons dilemma condition was consistent with prior evidence - social identity (manipulated as salient group membership) led to higher levels of cooperation (lower depletion of the resource). However, participants in the public goods condition actually cooperated less when their mutual membership in a superordinate group was made salient. Brewer and

\footnotetext{
12 Similarly to Kramer and Brewer (1984), social identity was induced using a common fate manipulation.
} 
Kramer (1986) cannot fully explain this paradoxical result, but they argue that it demonstrates the very complex relationships that exist among the variables investigated in their study. As with their earlier work, personal interaction, communication, and decision observation were not allowed, limiting the generalizability of their results.

Wit and Wilke (1992) investigated the effect of social identity on behavior in several types of social dilemmas (prisoner's dilemma, chicken dilemma, and trust dilemma). They report that salient group membership resulted in higher levels of cooperation in all three games. ${ }^{13}$ These experiments differed from those performed by Kramer and Brewer (1984) and Brewer and Kramer (1986), in that all of the participants were real - there were no bogus participants at remote locations. However, as in the earlier experiments, personal interaction, communication, and decision observation were not allowed. Notably, Wit and Wilke's (1992) experiment involved only a one-shot game, not multiple decisions over time.

While the social dilemma research discussed to this point focused primarily on the behavioral effects of social identity on cooperative behavior, De Cremer and van Gugt (1998) aimed at understanding the psychological processes through which these effects occur. In a public goods experiment, they report that social identity increased contributions, and that this effect was mediated by selfefficacy (the perception that one's actions have a significant effect on the group's outcome) rather than by mutual trust. This experiment was conducted in a

\footnotetext{
${ }^{13}$ Similarly to Kramer and Brewer (1984) and Brewer and Kramer (1986), social identity was induced using a common fate manipulation.
} 
manner similar to those conducted by Kramer and Brewer (1984), in the use of dummy group members and the prohibition of interaction, communication, and observation.

Clearly, there is ample evidence on the effect of social identity on cooperation in social dilemmas. However, as described above, the setting for much of this research has omitted many of the institutional features common in firms and of interest to the current study. ${ }^{14}$ Most importantly, the current research deals specifically with teams and the use of mutual monitoring in incentive contracting. Prior studies, on the other hand, do not allow participants to interact or to monitor one another's decisions. Further, the current research is aimed at understanding the role of communication in affecting decisions in a teamwork setting, whereas prior research did not allow for communication among the participants.

The current study extends these basic findings on the effects of social identity to the setting of a teamwork environment, exploring the impact of team identity on the effectiveness of two types of financial incentive systems. Thus, while prior studies have documented the characteristics that influence the level of team identity, I report on the consequences of team identity, adding links in the causal chain from team and environmental characteristics to incentive effectiveness.

\footnotetext{
14 These abstractions from the organizational environment are important to the extent that other factors interact with social identity in affecting behavior. Such interactions are reasonable for such variables as mutual observability and communication. For example, if participants are able to observe each other's decisions, social norms and opportunities for retribution may be sufficient to induce cooperative behavior regardless of the level of social identity. Social identity might thus increase cooperation only in the absence of mutual observability.
} 


\section{A Note ON TEAM COHESION}

While this study uses the construct of team identity to analyze the effect of social ties on the effectiveness of financial incentive systems, an alternate construct, team cohesion, could have been used instead. Festinger (1950) defined group cohesion as "the resultant forces which are acting on the members to stay in a group" (p. 274). While a number of different definitions have been proposed, the most important component of team cohesion is a mutual attraction among team members. The key difference between team identity and team cohesion is that team identity is an attraction to the concept of the group itself, whereas cohesion is interpersonal in nature. That is, an individual could be highly identified with a group, based solely on a salient shared categorization, without knowing individual members of the group. However, for cohesion to exist, the members of the group must know and be attracted to one another.

In a team setting, team identity and team cohesion are likely to be closely related. This is because one of the consequences of team identity is that team members see other members of the team as more attractive. A number of studies have examined the effect of social identification on interpersonal attraction, demonstrating that this attraction is a direct result of the self-categorization process. (For a review, see Hogg 1987.) Thus, the factors that lead to highly identified teams will indirectly lead to highly cohesive teams as well.

As discussed earlier, the literature on social identification has only recently been applied to an organizational setting. However, there is a rich history of psychology studies examining the relationship between team cohesion 
and team effectiveness. While there is intuitive appeal to a link between cohesion and performance, empirical evidence on this link is mixed. (For a review, see Mullen and Copper, 1994). A number of studies have demonstrated situations where team cohesion is not related or is even negatively related to team performance. While the current study's theory is based on social identification, not cohesion, the study's findings may provide insight into the mixed results in the cohesion literature as well. As developed later, I propose that social identity may have either a positive or negative impact on the effectiveness of a financial incentive system (and thus on team performance), depending on some specific attributes of the system. If the behavioral implications of team cohesion and team identification are similar, then the mixed results in the cohesion literature may be at least in part due to a similar interaction between cohesion and the incentive system. 


\section{Chapter 4: Model Development}

\section{THE MODEL}

In this section, I introduce a model of team production, including the opportunity for mutual monitoring. I then demonstrate how each type of incentive system (vertical vs. horizontal) may be used in this setting. Consider two risk neutral and effort averse agents ( $a$ and $b$ ) engaged in joint production over $n$ periods. The analytic papers (AFG 1997 and Ma 1988) used as a basis for this model assume risk aversion. In fact, if the agents were risk neutral there would be a trivial solution to the problem (selling the firm to the agents.) In this experimental setting, however, the agents' risk preferences are not related to the hypothesized effects, and therefore, I assume risk neutrality for ease of exposition and operationalization. I control for risk preferences by basing experimental payments on the expected values of the stochastic distributions.

I will first focus on the single-period setting, and then extend the discussion to $n$ periods. Joint production in this context means that each agent $i$ selects an effort level $e_{i} \in\{$ shirk, work $\}$ and that output $x \in\{$ high, low $\}$ is a function of these effort choices. Specifically, $x=f\left(e_{a}, e_{b}, \theta\right)$, where $\theta$ is a random variable representing uncertainty in the production process. As reflected in $\theta$, output is stochastically related to the agents' effort levels, resulting in the conditional probability distribution depicted in Table 1. Note that real-world teams engaged in joint production are likely to experience gains from synergy. However, the use of mutual monitoring is not affected by whether or not such 
gains exist. Therefore, to simplify the experimental setting, the conditional probability distribution used here is linear and additive in effort, incorporating no synergies into the production process.

For the remainder of this document, I suppress $\theta$ and focus on the resultant conditional probability distribution, $p\left(x_{j} \mid e_{a}, e_{b}\right)$, the probability that output is $j$, given the levels of effort selected by the two agents. This distribution demonstrates that the two agents are ex-ante symmetric. Therefore, if only one agent works, there is a 50\% probability of achieving the high output, regardless of which agent is working. The principal cannot observe the actions of the agents. However, the agents are able to observe each other's actions perfectly, so there is an opportunity for mutual monitoring.

Each agent $i$ maximizes expected utility $u_{i}=g\left(e_{i}, m_{i}\right)$, which is increasing in monetary wages $\left(m_{i}\right)$ and decreasing in effort $\left(e_{i}\right)$. This function is additively separable in its two operands. As is common in many experimental studies, I make the simplifying assumption that utility can be measured in dollars. Therefore, the utility function can be represented as $u_{i}=m_{i}-c\left(e_{i}\right)$, where $c\left(e_{i}\right)$ is a function converting effort levels to costs. ${ }^{15}$ Assume that the principal prefers each agent to work $(w)$ rather than shirk $(s) .{ }^{16}$ However, $c(w)>c(s)$ due to effort aversion, so ceteris paribus, the agents will both prefer shirking. Next, I will explore the use of two types of incentive systems to induce the agents to work in this setting.

\footnotetext{
15 As discussed by Baiman [1982], agency theory defines effort as a task that is controlled by the agent, results in disutility, and is correlated positively with output.

${ }^{16}$ In this study, I treat the principal and the incentive system exogenously. Thus, all analysis is directed to the two agents' subgame.
} 


\section{THE VERTICAL INCENTIVE SYSTEM}

The vertical incentive system used in this paper is based loosely on the model proposed by Ma (1988). Under this scheme, the principal bases agent $i$ 's pay on his/her effort level, as explicitly reported by the other agent. ${ }^{17}$ But how does the incentive scheme ensure that the agents report truthfully? One costless method (similar to that proposed by Ma) is the use of lotteries. Specifically, in accusing another agent of shirking, the accusing agent agrees to accept an outputbased lottery that is valuable only if the other agent did in fact shirk. Unfortunately, this solution relies on a basic assumption not met in my model. Ma $(1988,558)$ assumes that each unique pair of actions by the two agents leads to a unique probability distribution of outputs. As mentioned earlier, this is not the case in the current model, because when only one agent works, the symmetric distribution of outputs does not depend on which agent is working.

As a simpler alternative to achieve the same objective, the firm could employ an auditor to ensure truthful reporting. The auditor would be called only if one agent accused the other of shirking. The accusing agent would then be rewarded (penalized) if the auditor determined that his/her accusation was truthful (false). One apparent disadvantage of this method is that the principal would have to pay the auditor, making it a costly solution. However, the unique subgame perfect Nash equilibrium is for each agent to work and to report truthfully the other agent's effort. Therefore, in equilibrium the auditor is never called, and the off-equilibrium possibility of an audit is sufficient to induce truthful reporting by

\footnotetext{
17 In Ma's (1988) original model, the incentive scheme is asymmetric, with one agent reporting both agents' efforts, and the other verifying the first agent's report.
} 
both agents. In this study, I do not specify a method for ensuring truthful reporting, but instead generalize this aspect of the model. That is, I assume that if an agent accuses the other of shirking, the accusing agent will receive a positive utility payment $(\beta)$ if the other agent actually did shirk and a negative utility payment $(\gamma)$ if the other agent actually worked.

Under this incentive scheme, agent $i$ 's wages $m_{i}$ have two additive components - effort pay and reporting pay. Formally, $m_{i}=E_{i}+R_{i}$, where:

$$
\begin{aligned}
& E_{i} \text { (effort pay) }= \begin{cases}\hat{u}_{i}+c(w) & \text { if } r_{i}=\text { work } \\
\hat{u}_{i}+c(s)-\delta & \text { if } r_{i}=\text { shirk }\end{cases} \\
& R_{i} \text { (reporting pay) }= \begin{cases}\beta & \text { if } r_{j}=\text { shirk and } e_{j}=\text { shirk } \\
\gamma & \text { if } r_{j}=\text { shirk and } e_{j}=\text { work } \\
0 & \text { otherwise (i.e., if } r_{j}=\text { work) }\end{cases} \\
& r_{i} \in\{\text { shirk, work }\} \text { is agent } i \text { 's effort, as reported by agent } j \\
& \delta \geq \beta>0 ; \gamma<0^{18} \\
& i \neq j
\end{aligned}
$$

Intuitively, effort pay represents wages for effort as reported by the other agent, and each agent will be paid his/her reservation utility $\hat{u}_{i}$ (plus an amount equal to the disutility of effort) if the report indicates that $s /$ he has worked. If the report indicates that $\mathrm{s} /$ he shirked, a penalty of $\delta$ is assessed. Reporting pay is the wage component that induces truthful reporting, because it pays a bonus (penalty) to the agent who accuses his/her teammate of shirking if that report is truthful

\footnotetext{
${ }^{18}$ The requirement that $\delta \geq \beta$ is more a practical requirement than a technical requirement. If $\beta>$ $\delta$, then a collusive opportunity would exist for the agents to increase their payoffs by agreeing to each shirk and then report truthfully. This collusive outcome (not a Nash equilibrium) is easily avoided by adding this constraint.
} 
(false). In this study, the following specific parameters are used, resulting in the extensive form game tree found in Figure 1.

$$
\begin{aligned}
& \hat{u}_{i}=\$ 10.00^{19} \\
& c(s)=\$ 0.00, c(w)=\$ 10.00 \\
& \beta=\$ 10.00 \\
& \delta=\$ 10.00 \\
& \gamma=\quad \$ 20.00 .
\end{aligned}
$$

This game can be solved by backward induction, resulting in the unique subgame perfect Nash equilibrium in which each player works and each player reports truthfully. This will result in each agent receiving his/her reservation utility of $\$ 10.00$. Further, if this game is repeated a finite number of times, the unique subgame perfect Nash equilibrium in the $n$-period game will have the agents working and reporting truthfully in each period (Gibbons 1992, 84). This is a first-best result, because the agents do not take on any risk (at equilibrium, the agents will receive exactly their reservation utilities each period, regardless of the output produced). ${ }^{20}$

While economic theory predicts the Nash equilibrium strategy of working and truth telling, an examination of Figure 1 reveals that this solution is not Pareto optimal. Both agents can improve their outcomes if they coordinate their actions,

\footnotetext{
${ }^{19}$ It is not necessary that the participants' reservation utilities exactly equal $\$ 10$. In the laboratory, it is only important that the reward structure achieve Smith's (1982) dominance precept, meaning that it must dominate any subjective, non-monetary costs or values that the subjects hold for participating in the experiment.

20 The distinction between first-best and second-best solutions is important, because agency costs are greater when the agents take on risk (as they do in a second-best solution). However, risk preferences are not the focus of this laboratory study, and so I control for risk preferences by basing experimental payments on the expected values of the stochastic distributions.
} 
each shirking and then falsely reporting that the other has worked. This collusive outcome is not a Nash equilibrium, because both agents have strict incentives to report truthfully. However, Social Identity Theory suggests some circumstances favoring such an outcome. This idea will be explored in the next chapter, but first I will introduce the second type of incentive system - the horizontal incentive system.

\section{THE HORIZONTAL INCENTIVE SYSTEM}

The horizontal incentive system presented here is based on that of AFG (1997). Their approach is to have the principal tie each agent's pay to the team output. A fundamental issue with team output-based pay is the opportunity for social loafing (the withholding of effort as individual effort becomes less identifiable) (Kidwell and Bennett 1993). To prevent social loafing, AFG (1997) rely on the ability of the agents to monitor each other's efforts and to punish each other for shirking. This threat of punishment is a type of peer pressure, as conceptualized by Kandel and Lazear (1992). In general, punishment can take on many forms, ranging from informal social sanctions to more formalized disciplinary procedures. In the AFG (1997) two-period model, the threat to punish takes the form of a tit-for-tat strategy. That is, each agent works in the first period and then works in the second period only if the other agent worked in the first period.

The principal provides output-based team incentives in Period 1, meaning that each agent's compensation is increasing in team output and that each agent prefers both agents working to both shirking. Specifically, 


$$
m_{i}= \begin{cases}\hat{u}_{i}+c(w)+\lambda_{1} & \text { if } x=\text { high } \\ \hat{u}_{i}+c(w)+\lambda_{I}-\frac{\lambda_{1}}{p(l o w \mid w, w)} & \text { if } x=\text { low }\end{cases}
$$

where

$$
\begin{aligned}
& \lambda_{1}=\frac{[c(w)-c(s)][p(\text { low } \mid w, w)]}{p(l o w \mid s, s)-p(l o w \mid w, w)}+\varepsilon, \text { and } \\
& \varepsilon=\text { an arbitrarily small increment. }
\end{aligned}
$$

The subscript on $\lambda$ refers to the period. This scheme is designed to ensure that each agent earns exactly his/her reservation wage in expectation when both agents work. The conditional probability distribution and the definitions and values of $\hat{u}_{i}, c(s)$, and $c(w)$ are the same as presented earlier for the vertical incentive system. The constraint on $\lambda_{1}$ assures that each agent prefers both agents working to both shirking, and requires that $\lambda_{I}=\$ 5.00+\varepsilon$. I set $\varepsilon=\$ 1.00$. Using these parameters, if output is high (low), each agent receives compensation of $\$ 26.00$ (\$2.00), resulting in the extensive form game, presented in expected value terms, in Panel A of Figure 2.

This single-period game is essentially a risky prisoner's dilemma, in that the unique Nash equilibrium is for each agent to shirk, while a Pareto optimal outcome is for each agent to work. If this game were repeated finitely, the unique Nash equilibrium for the multiple-period game would have both agents shirking in each period, because each agent could use backward induction to "unravel" the problem. However, the principal can induce the agents to work in Period 1 by changing the incentive structure in Period 2. 
In Period 2, the principal uses individual incentives rather than team incentives, meaning that the constraint on $\lambda_{2}$ assures that each agent at least weakly prefers working, given that the other agent is working. In doing so, the principal creates multiple equilibria in the Period 2 subgame. In at least one of these equilibria, agent $i$ is worse off than in the other equilibria. Agent $j$ can therefore threaten to punish agent $i$ for not working in Period 1 by playing this "bad equilibrium" in Period 2. The threat is credible, because punishing behavior in Period 2 is part of an equilibrium. Because each agent has the ability to punish within an equilibrium, the problem no longer unravels due to backward induction. Thus, a punishment strategy can be maintained in a Nash equilibrium, using the following compensation parameters in the second period:

$$
m_{i}= \begin{cases}\hat{u}_{i}+c(w)+\lambda_{2} & \text { if } x=\text { high } \\ \hat{u}_{i}+c(w)+\lambda_{2}-\frac{\lambda_{2}}{p(l o w \mid w, w)} & \text { if } x=\text { low }\end{cases}
$$

where

$$
\lambda_{2}=\frac{[c(w)-c(s)][p(l o w \mid w, w)]}{p(l o w \mid w, s)-p(l o w \mid w, w)} .
$$

Using values defined earlier, $\lambda_{2}=\$ 10.00$, resulting in the extensive form game represented in Figure 2, Panel B. In this final period subgame, all four cells represent Nash equilibria, so either agent can credibly threaten to move from the (work, work) equilibrium to punish deviant behavior in the prior period. Thus, the punishment strategy is a Nash Equilibrium in the two-period game. Further, it is a Nash Equilibrium in the $n$-period game formed by repeating the 
two-period game $n / 2$ times. ${ }^{21}$ Nikias (2001) provides experimental evidence that under certain conditions, participants do play punishment strategies when faced with the AFG (1997) incentive scheme.

A natural question arises at this point. Why doesn't the principal use the Period 2 (individual) incentives in all periods? That is, the incentives in Period 2 do not induce social loafing, because they assure that each agent at least weakly prefers to work given that the other agent is working. Further, by increasing $\lambda_{2}$ by an arbitrarily small amount, the principal could assure that each agent strictly prefers to work given that the other agent is working. Therefore, the principal could use these incentives in all periods and induce working as equilibrium behavior. The reason the principal would not want to do this in a conventional principal-agent setting is related to risk aversion. The individual incentives of Period 2 impose greater risk on the agents than do the team incentives of Period 1. For example, using the parameters of this study, in Period 1, if output is high (low), each agent receives compensation of \$26.00 (\$2.00), whereas in Period 2, high (low) output results in compensation of $\$ 30.00(-\$ 10.00)$. While I have assumed risk neutrality for simplification, real-world agents would likely be risk averse, requiring greater compensation under higher-risk incentives. Therefore, the principal would want to use the higher-risk individual incentives only as needed to provide for a punishment opportunity, as described by AFG (1997).

\footnotetext{
21 This punishment strategy can take any of several forms, including a tit-for-tat strategy, a grimtrigger strategy, or some other type of penal code. From a technical perspective, the punishment strategy could be sustained as a Nash equilibrium in an $n$-period game by using the individual (punishment phase) incentives only in period $n$. However, to increase the salience of the opportunity for punishment, I use the individual incentives in all even-numbered periods.
} 
While the outcome of each agent playing the tit-for-tat or some other punishment strategy is a Nash equilibrium, it is not unique. For example, the undesirable (from the principal's perspective) outcome in which both agents shirk each period is also an equilibrium. However, the Nash equilibrium in which both agents use a punishment strategy Pareto dominates all other Nash equilibria. What can the principal do to ensure that the agents achieve the desirable (and Pareto optimal) result of working each period? The answer to this question likely relates to the level of team identity, as developed in the next chapter.

In summary, agency theorists have proposed two different approaches through which the principal can take advantage of peer observations - the vertical approach and the horizontal approach. While similar results theoretically can be obtained from either approach, the following chapter explores why the social psychological concept of team identity is likely to differentially affect outcomes under the two systems. 
Table 1 - Conditional Probability Distribution for Output

Effort Levels

Both Shirk

Agent 1 Shirks / Agent 2 Works

Agent 1 Works / Agent 2 Shirks Both Work
Probabilities of Output Levels

$\underline{\text { High }}$ $25 \%$ $50 \%$ $50 \%$ $75 \%$

Note: Three assumptions are made regarding this conditional distribution -

1) First-order stochastic dominance.

2) The "non-moving support" condition (the stipulation that the support of $x$ (output) is the same for any combination of efforts by the two agents (Holmstrom 1979)).

3) Symmetry - this assumption is not required, but is made for simplicity. 
Figure 1 - Vertical Incentive Structure

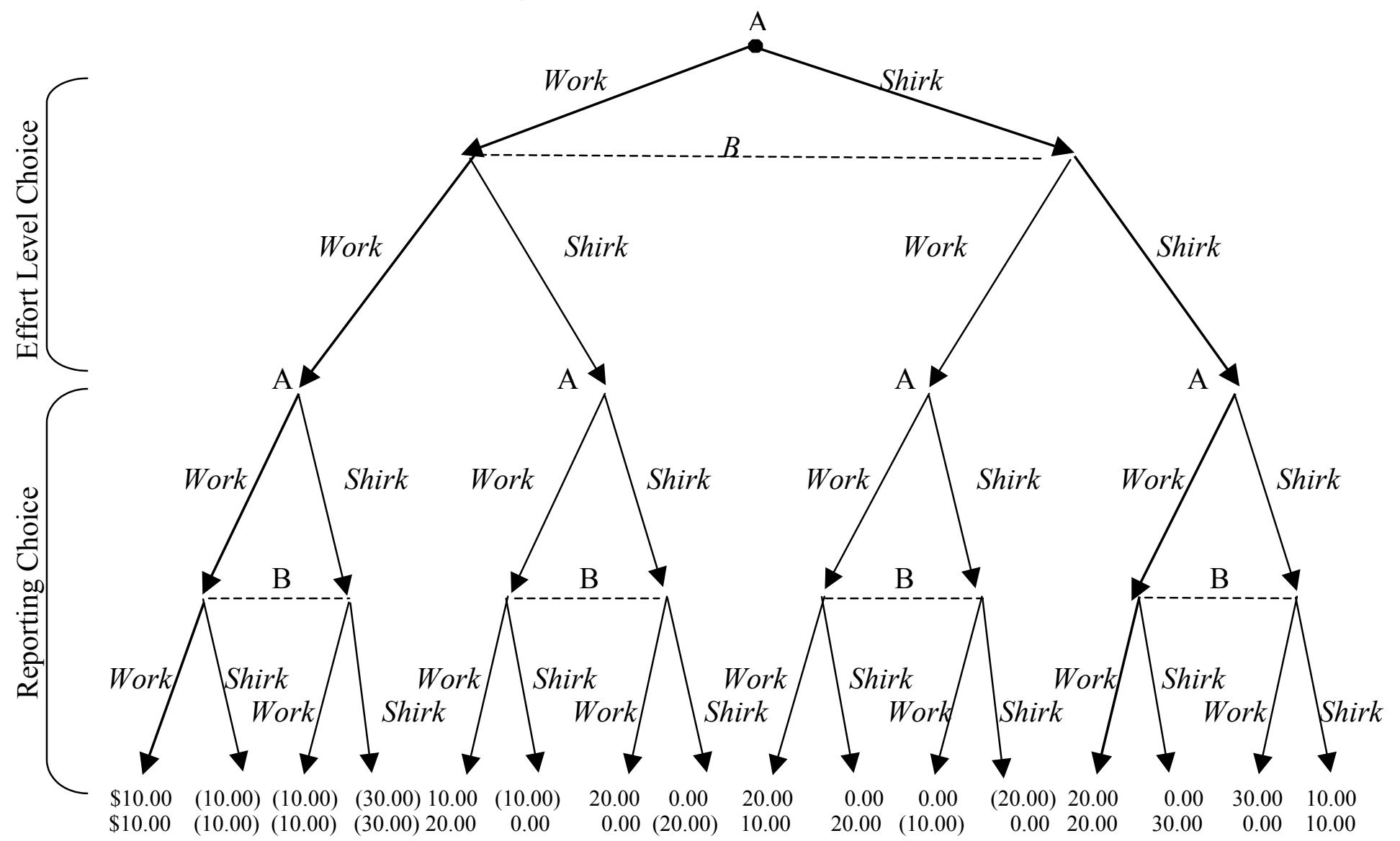


Figure 2 - Horizontal Incentive Structure

Panel A: Period 1

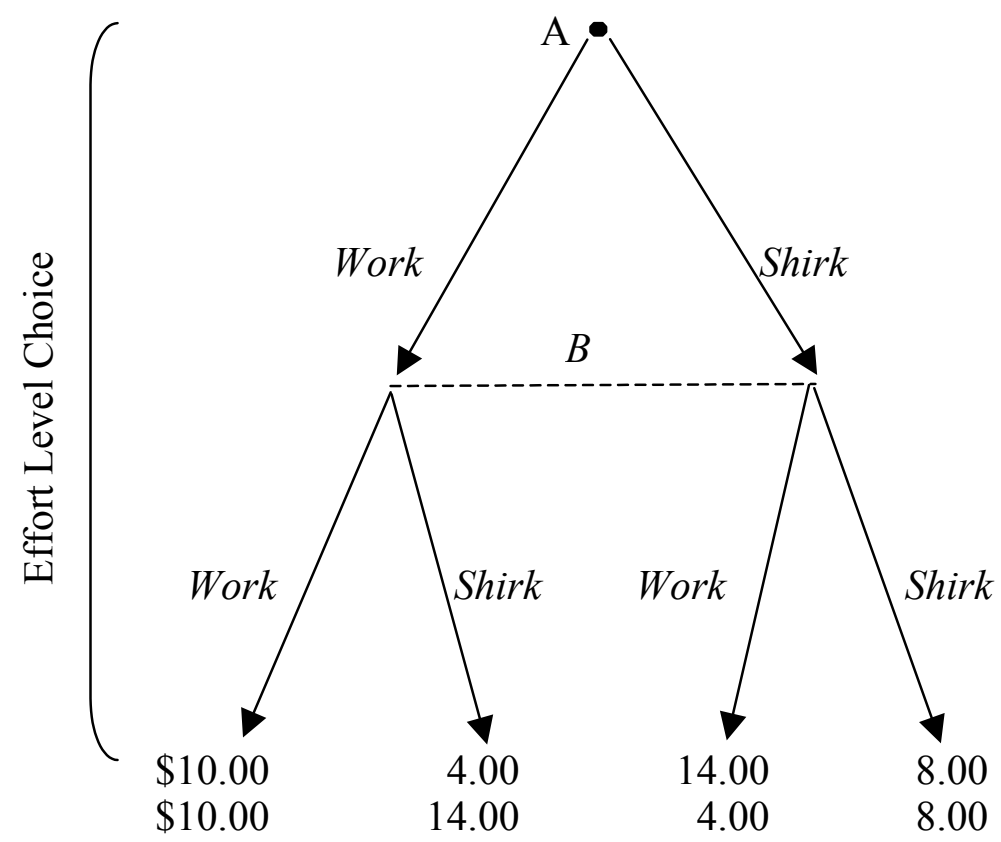

Panel B: Period 2

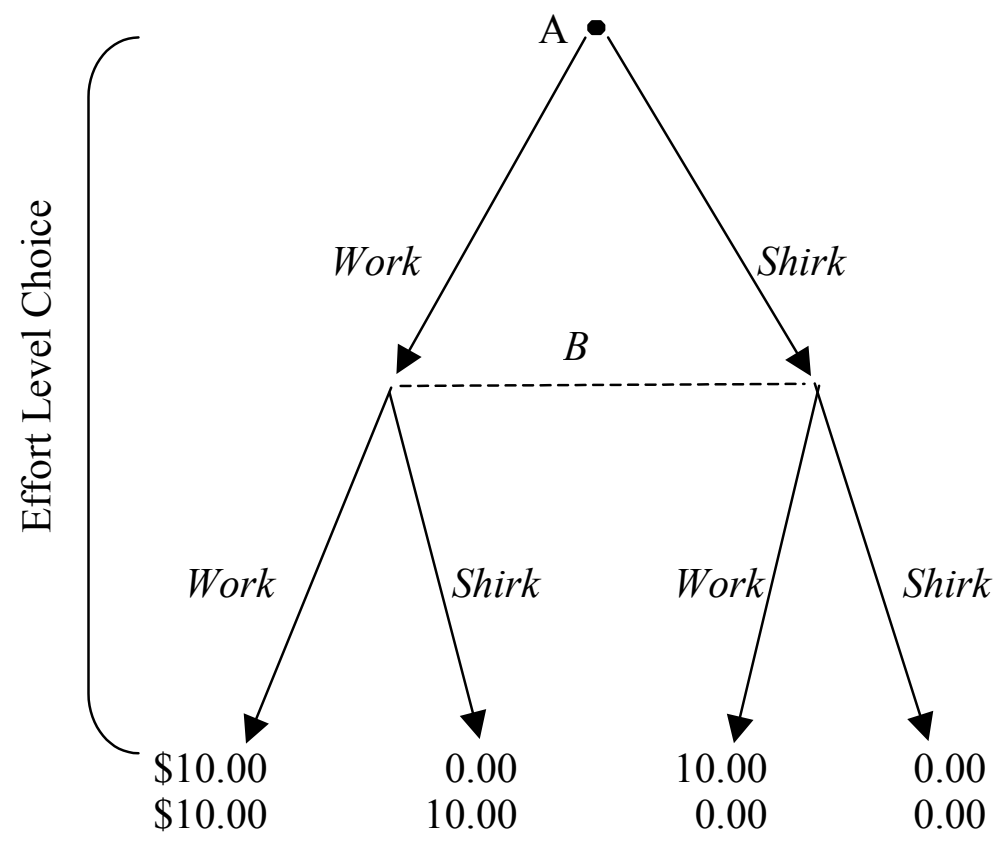




\section{Chapter 5: Hypotheses}

\section{HYPOTHESES 1 AND 2 - THE EFFECT OF TEAM IDENTITY ON INCENTIVE EFFECTIVENESS}

As suggested earlier, my primary prediction is an interaction between the incentive system and the level of team identity, such that the effectiveness of an incentive system may be either enhanced or degraded by a strong team identity. This prediction is hypothesized formally in $\mathrm{H} 1$, following a description of the process resulting in this interaction. The process is illustrated in Figure 3.

The reasoning originates with a self-categorization process, by which members of highly identified teams cognitively group themselves with their teammates. As a result, the team, rather than the individual, becomes the primary cognitive unit of analysis. In considering strategy choices, the team members will become more attuned to the interrelatedness of their actions, focusing on the ways in which they can jointly affect outcomes. This change in cognitive focus will lead them to choose strategies that are mutually beneficial (or cooperative) in nature. Thus, the cognitive change that defines team identity will have a direct effect on the level of cooperation achieved. In other words, highly identified teams are more likely than other teams to reach Pareto optimal outcomes.

Team identity also operates through an indirect effect, resulting from the efforts of highly identified teams to actively coordinate their strategies. Coordination is enhanced by communication (Cooper et al. 1992), so it follows that highly identified teams will engage in greater communication, leading to an increased probability of arriving at cooperative (Pareto optimal) outcomes. 
Thus, I predict that team identity, operating through both direct (cognitive) and indirect (communication-mediated) effects, will lead to greater cooperation. However, cooperation means different things under the two incentive systems. Recall that under the vertical incentive system, pay is based on reported effort. This opens the possibility for collusion between the two agents - they can each shirk and report that the other worked. This collusive outcome is not a Nash equilibrium, because each agent has strict incentives to report truthfully. However, the collusive outcome is Pareto superior (from the agents' point of view) to the principal's preferred outcome of working and truthful reporting. Under the vertical incentive system, therefore, agents who cooperate (i.e., collude) are likely to choose lower effort levels than those who choose their strategies independently.

The horizontal incentive system, on the other hand, bases pay on team output and offers no opportunities for collusion. Indeed, under this system, the principal assumes that the agents will side contract to the principal's advantage. There are a number of equilibria (e.g., both agents shirk each period) in the multiple-period game, but the cooperative (Pareto optimal) outcome is the one preferred by the principal. In this equilibrium, each agent plays a punishment strategy, with the result that each agent works each period. Under the horizontal incentive system, therefore, agents who cooperate are likely to choose higher effort levels than those who choose their strategies independently.

In summary, team identity should lead to greater cooperation, which can have either a positive or negative effect on effort, depending on the incentive 
system in place. This is the primary hypothesis, pictured in Figure 4 and stated in the alternate form.

H1: The incentive system will interact with team identity, such that the effectiveness (in terms of the level of effort elicited) of the horizontal incentive system will be enhanced by a strong team identity, while the effectiveness of the vertical incentive system will be degraded by a strong team identity.

The second hypothesis focuses on the process resulting in the predicted interaction between team identity and the incentive system. Specifically, $\mathrm{H} 2$ tests the two paths through which team identity is expected to influence the effectiveness of the incentive system - the direct, or cognitive, path, and the indirect, or communication-mediated, path.

H2: $\quad$ Team identity will have both a direct and an indirect effect on the effectiveness of the incentive system (with communication acting as a mediating variable).

Note that while $\mathrm{H} 1$ predicts that the total effect of team identity on effort will depend on the incentive system, $\mathrm{H} 2$ dissects the total effect into its components. Therefore, $\mathrm{H} 2$ implicitly predicts that each of the component effects will depend on the incentive system.

\section{Distinguishing This STUdy From Prior Social DilemMa Literature}

As discussed earlier in the review of the social identity literature, several studies have examined social identity in social dilemma settings, finding that highly identified groups achieve greater levels of cooperation in these games. One might question, therefore, the need for an experiment in the current study, asking why the results of prior studies wouldn't automatically apply to the team incentives setting. Thus, it is important to distinguish the contributions of this 
study from the more generic social dilemma literature. There are several important institutional features represented in the current study, leading to differences between the economic incentives and environmental characteristics in this study vs. prior studies. Any of these differences may affect the results. Therefore, the social dilemma literature provides some guidance as to what one might expect in the current setting, but does not provide an unambiguous answer as to the impact of social identity on the effectiveness of horizontal and vertical incentive systems.

Perhaps the most important way in which the current study is distinguished from the prior literature is in its reliance on mutual monitoring. Prior studies on social identity in a social dilemma setting (e.g., Kramer and Brewer 1984; Brewer and Kramer 1986) did not allow participants to observe each other's actions. In fact, as mentioned earlier, many of these studies used dummy participants, presumably participating from remote locations. Thus, the question remains as to whether social identity will increase cooperative behavior when team members have the ability to monitor one another. Specifically, it may be that social norms of behavior are invoked whenever participants' actions are observed by one another, and that social identity will have no incremental effect on behavior.

A second distinguishing feature of the current study is that it allows for communication. Prior investigations of social identity in social dilemma settings have restricted all interactions among participants, including opportunities for communication. A team setting generally creates significant opportunities for 
communication, and so in the current study, participants are allowed to communicate in writing to one another. Prior studies (unrelated to social identity) report that allowing pre-play communication among participants increases cooperation in social dilemmas (Ledyard 1995). It may be that such communication and social identity serve as substitutes, not complements, for one another. Specifically, communication and social identity each provide mechanisms by which individual team members may focus their attention on team outcomes rather than individual outcomes. It is possible that when team members have the opportunity to communicate with one another, the level of team identity will have no incremental effect on the level of cooperation achieved.

While prior studies have examined the effect of communication on cooperation in social dilemmas, these studies have viewed communication as an exogenous variable, comparing the level of cooperation when communication is allowed to when it is prohibited. This study, on the other hand, explores the endogenous nature of the communication, suggesting that the level of communication will be determined, at least in part, by the level of social identity. Thus, this study contributes to the prior literature on social identity in social dilemma settings by providing evidence on the mechanisms through which social identity affects the level of cooperation.

Finally, and aside from the mutual monitoring and communication issues discussed above, there are features of these incentive systems themselves that distinguish them from standard social dilemmas. For example, the vertical incentive system results in a two-stage game, involving effort choices followed by 
reporting choices. In this game, the cooperative outcome involves each person shirking and then falsely reporting that the other has worked. This is different from a standard social dilemma, because at the time of reporting, each person knows exactly how much $\mathrm{s} / \mathrm{he}$ is individually sacrificing by choosing to lie for a teammate. (Using the parameters described in Chapter 4, once a person has chosen to shirk, his/her teammate must knowingly give up a reporting bonus of 10 points in order to make the cooperative strategy choice.) From an economic perspective, the fact that the vertical system is a two-stage game should not affect behavior. However, from a behavioral perspective, the two-stage mechanism might increase the salience of individual rationality, reducing the likelihood that social identity will have an effect on behavior. Thus, the vertical system provides a boundary condition for testing the effect of social identity on cooperation in social dilemmas.

The horizontal incentive system also differs in key ways from standard social dilemmas. In fact, the multi-period game that results from this system is not a social dilemma, per se. As described earlier, a social dilemma is characterized by a situation where the unique Nash equilibrium is not Pareto optimal. This is not the case in the horizontal system, as the outcome that has each person playing a tit-for-tat strategy is both a Nash equilibrium and a Pareto optimal outcome. However, this solution depends entirely on the multi-period nature of the game, with "enforcement periods" used to sustain cooperation in earlier periods. These earlier periods, standing alone, are essentially risky prisoner's dilemmas. ${ }^{22}$ The

${ }^{22}$ A prisoner's dilemma is simply a two-person version of a social dilemma, which is usually taken to involve more than two participants. 
enforcement periods create an interesting twist. While these enforcement periods serve the specific purpose of increasing cooperative behavior, by creating opportunities for retribution, there is some possibility that their usefulness will be undermined by social identity. That is, if a strong team identity reduces participants' willingness to punish one another for not cooperating, it may have the indirect effect of reducing cooperative behavior, a result opposite of that found in prior research on social identity in social dilemmas.

\section{HYPOTHESIS 3 - THE EFFECT OF THE INCENTIVE SYSTEM ON SOCIAL IDENTITY}

In the discussion to this point, the incentive system and the level of team identity have been considered independent and exogenous factors, reflecting that they are the two factors that are experimentally manipulated. However, after repeated interaction, a different type of relationship can arise between these two constructs. Specifically, the type of incentive system is likely to affect the level of identity that a team achieves, because the two incentive systems emphasize different aspects of the agents' relationship. The horizontal system is geared toward a team mentality. That is, the principal remains unaware of individual contributions and each person's compensation is based on the team's total output. The vertical system, on the other hand, eschews the cooperative spirit of a team. Instead, team members tattle on one another. Individual compensation is based on peer reports, and team members receive bonuses for making unfavorable reports on their peers. For these reasons, the type of incentive system is expected 
to affect the team members' feelings about one another, and thus the level of team identity. This leads to the final hypothesis, pictured in Figure 5.23

H3: After repeated interaction, individuals compensated according to the horizontal incentive system will experience a higher level of team identity than will individuals compensated according to the vertical incentive system.

${ }^{23}$ Note that the horizontal axis of this graph represents team identity as manipulated. The upward sloping lines indicate that this manipulation is expected to have a lasting effect - even after repeated interaction, teams formed from two members of the same color group will have greater ending team identity than those formed from different color groups. 
Figure 3 - The Effect of Team Identity on Incentive Effectiveness

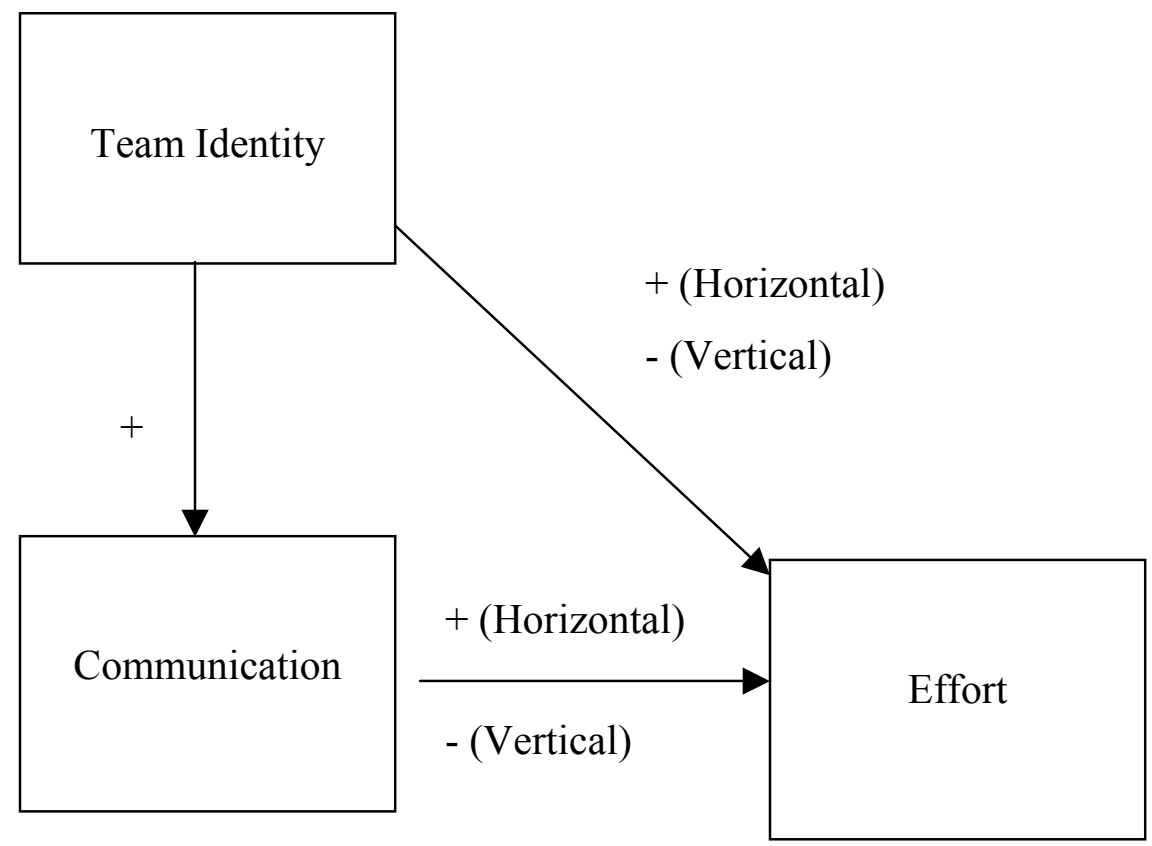


Figure 4 - Hypothesis 1

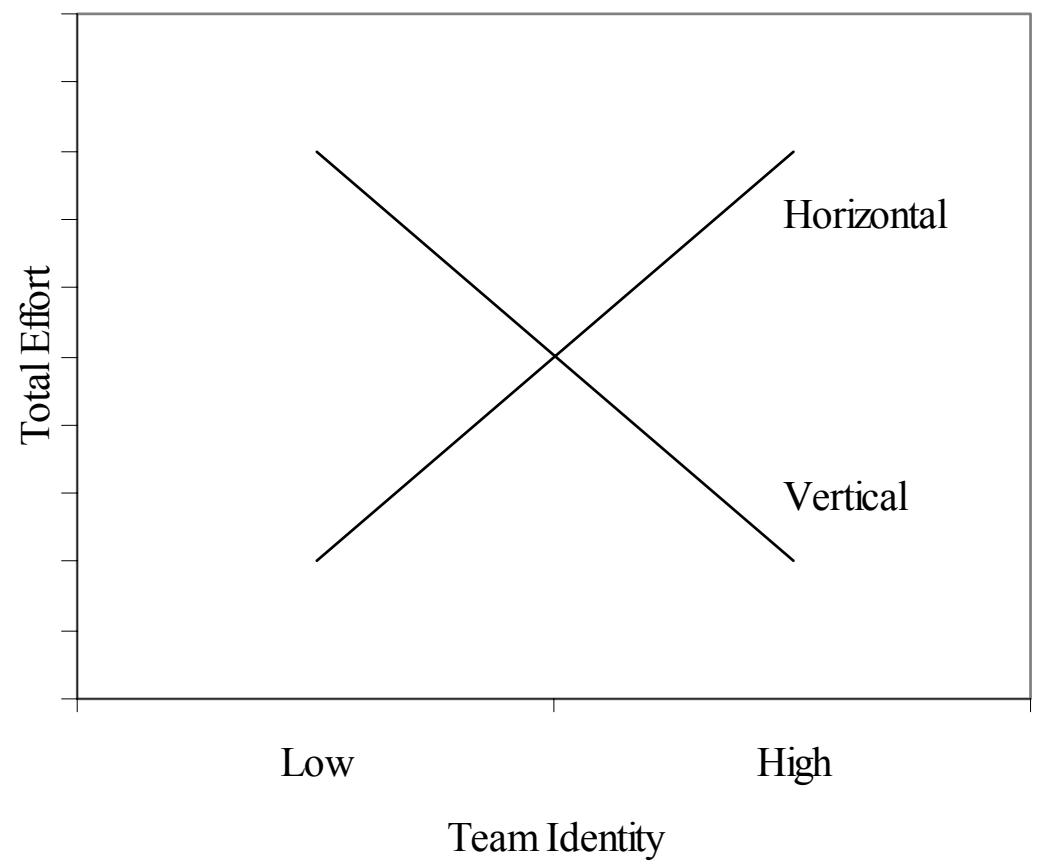

Note that Hypothesis 1 does not predict the placement of these two lines, but rather the slopes. That is, the horizontal incentive system line should be sloped upward, and the vertical incentive system line should be sloped downward. 
Figure 5 - Hypothesis 3

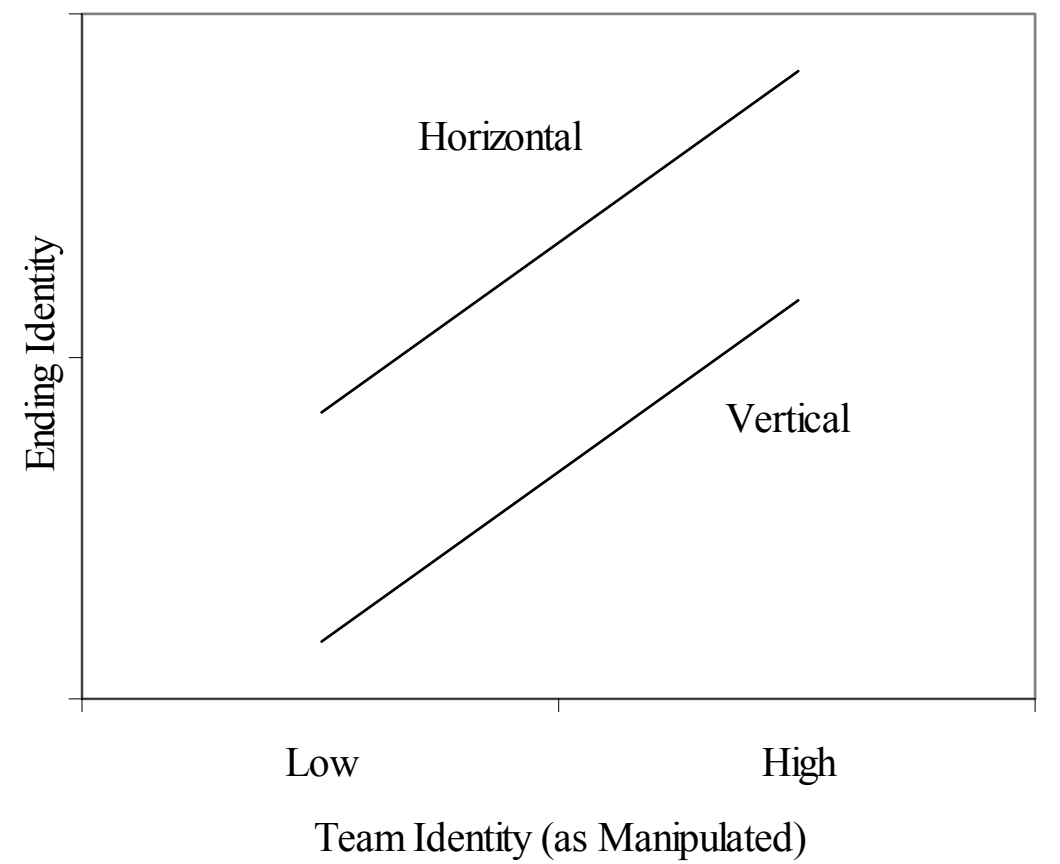

Note that the horizontal axis represents beginning team identity, as manipulated in the experimental session, whereas the vertical axis represents ending team identity, as assessed on the post-experimental questionnaire. 


\section{Chapter 6: Description of Method}

This experiment uses a 2X2 (Incentive System X Team Identity) betweensubjects factorial design. Sixteen experimental sessions were held, each involving eight participants recruited from graduate business classes at The University of Texas at Austin. As participants arrived, they were randomly assigned to two groups of four, with each group identified by a different color. For the instructional phase, each participant was seated with members of his/her color group at a table draped in the group color. Figure 6 presents the room layout for the instructional phase of the experimental session.

The wording of the instructions, along with the assigned seating by color and the use of colored props (table drapes, name placards, partition coverings, etc.), were designed to increase the salience of the color groups, thereby facilitating the participants' self-categorizations into these color groups. ${ }^{24}$ The presence of two color groups in each session promoted this process, as prior research has shown that a social identity is reinforced by in-group / out-group comparisons (Abrams and Hogg 1990). A partition separated the two color groups during the instructional phase, but this partition was placed such that each participant could view members of the other group simply by leaning back. The administrator could be seen by members of both color groups.

\footnotetext{
24 The instructions in the low and high identity conditions differed in two respects. First, they specified whether each person would be paired with a member of his/her own color group or the other color group. Second, the teammate was referred to as "your teammate" in the high identity condition vs. "the other person" in the low identity condition.
} 
While still seated with their color groups, participants read a scenario (see Appendix A), in which they were instructed to assume the roles of two division managers making effort (or more generally, resource allocation) decisions. The scenario described the incentive system, manipulated to represent the two systems of interest. Participants were told that they would be compensated in cash, based on their decisions and the incentive system in place. Because risk preferences were not relevant to the hypotheses of this study, the stochastic element was eliminated, and each incentive system was presented in expected value terms.

One objective of this study is to explore how communication spontaneously arises in low and high identity teams. In order to investigate the level of communication, participants were told that they could communicate with their teammates in writing. To prevent a potential demand effect, this instruction was provided verbally, instead of through the formal written instructions. That is, because of the endogenous nature of the communication variable, it was important that the communication-related instructions be subtle, so as not to cue participants that they should communicate. One concern with verbal instructions of this type is that the administrator might inadvertently (through the use of body language or intonation) encourage greater communication in some experimental conditions than in others. To alleviate this concern, the administrator was unaware of the experimental condition at the time of verbal instructions..$^{25}$

Color groups were used to implement the first manipulated factor of team identity. Teams of two were required for the actual experimental task. In the

25 Experimental materials, which differed by condition, were handled only by laboratory assistants, and not by the administrator providing verbal instructions. 
high identity condition, each team was formed by pairing two members from the same color group, whereas in the low identity condition, each team was formed by pairing two members from different color groups. ${ }^{26}$ For a real-world analogue to this manipulation, suppose that the color groups represent functional roles (accounting, engineering, etc.). The high identity teams then represent crossfunctional teams, whereas the low identity teams represent uni-functional teams.

After the participants read the instructions and the experimenter reviewed them (Appendix B presents the instructional slides), the members of each team were seated at opposite ends of a table, where they completed the experimental task. For this portion of the experimental session, partitions were placed so that teammates could observe each other, but not other teams. (Figure 7 presents the room layout for this phase of the experimental session.) Each person's task was to choose the level of resources that his/her division would provide. Participants were asked to choose high or low resources, rather than to choose work or shirk, because of the concern that the latter labels might invoke a value judgment and response (Haynes and Kachelmeier 1998). The two members of each team made these decisions simultaneously, circling high or low on Resource Decision Forms (see Figure 8). The experimenter then showed each participant the form completed by his/her teammate, capturing the notion of mutual monitoring. The Resource Decision Form was also the primary tool for intra-team communication, as participants were told that in addition to circling "high" or "low" on the form,

\footnotetext{
${ }^{26}$ While it may seem improbable that ad-hoc assignments to color groups would engender a sense of group identity, psychology studies on this "minimal group paradigm" are quite robust. Favoritism for in-groups over out-groups, even for explicitly random groups, has been demonstrated in numerous studies (Turner 1987b).
} 
they could write whatever else they would like. In the vertical incentive system, each participant also submitted a Report Form (see Figure 9), revealing (either truthfully or not) the level of effort selected by his/her teammate.

Each session included 20 periods. ${ }^{27}$ Finally, participants completed a post-experimental questionnaire (see Appendix C), including demographic questions as well as questions aimed at capturing process-related variables.

27 For the vertical system, this entailed 20 replications of the one-period game, while for the horizontal system, it entailed 10 replications of the two-period game. 
Figure 6 - Room Layout for Instructional Phase
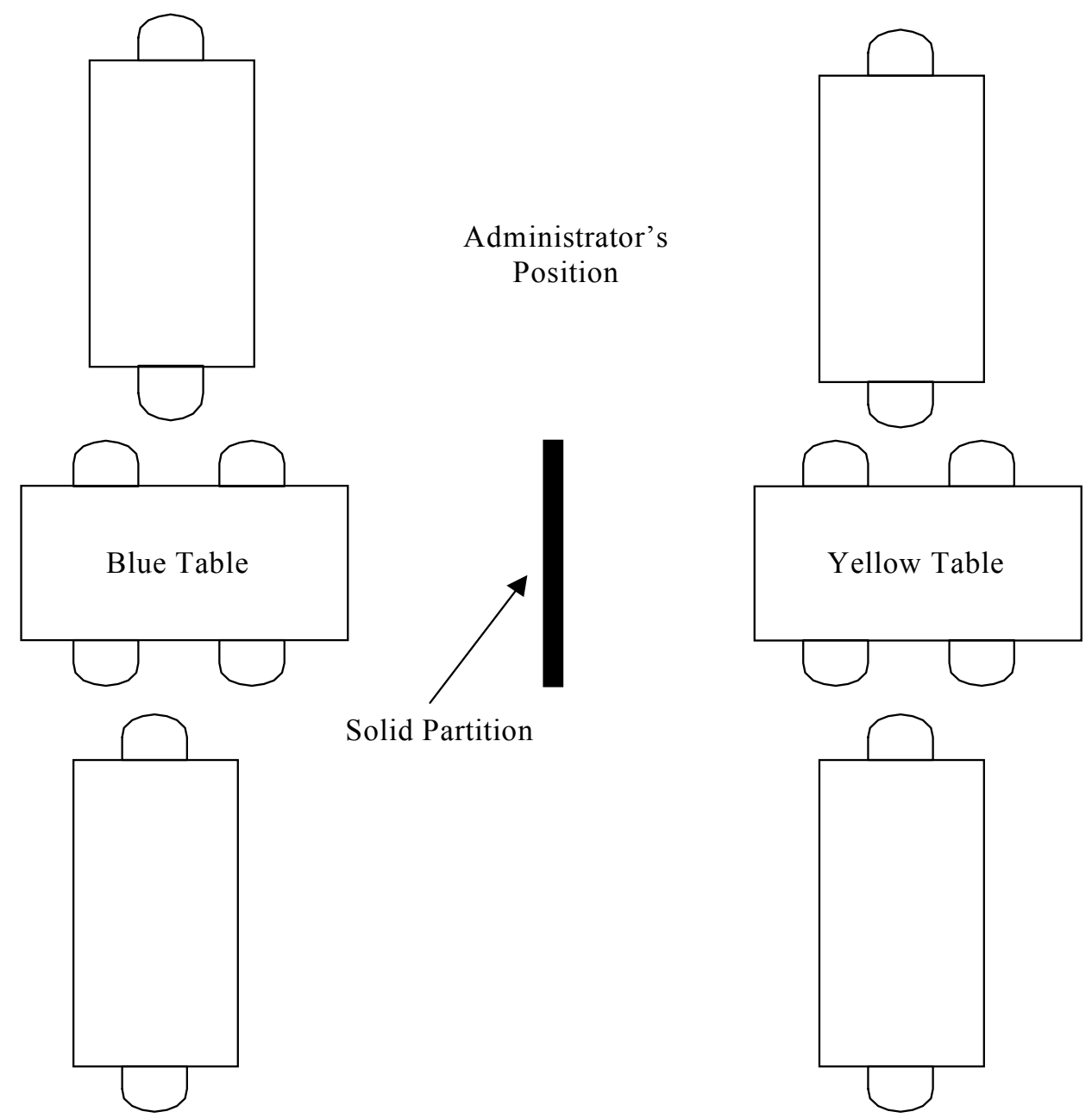
Figure 7 - Room Layout for Task Phase

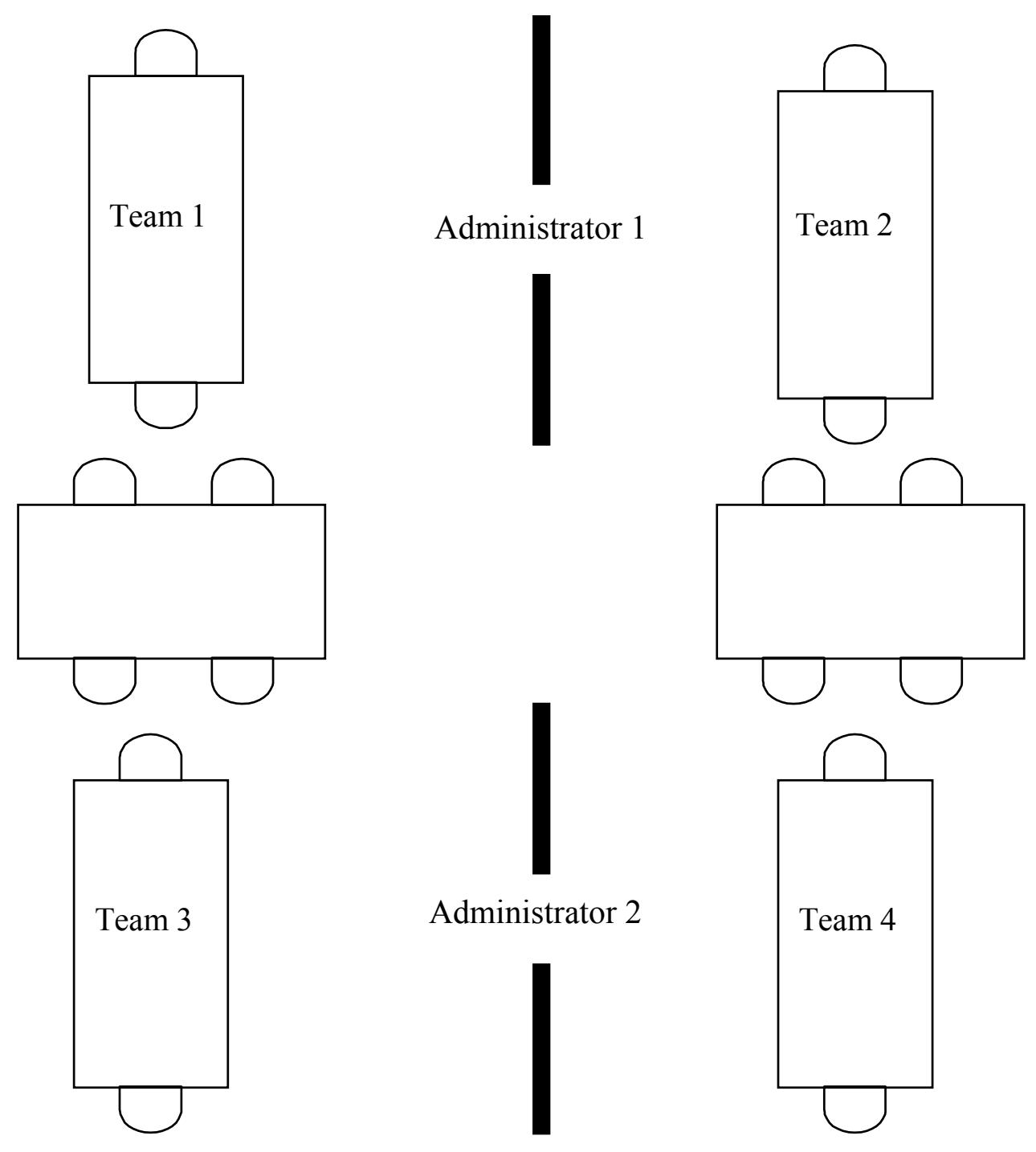


Figure 8 - Resource Decision Form

\section{Resource Decision Form}

Circle the level of resources that you will provide.

HIGH LOW 
Figure 9 - Report Form

PANEL A - LOW IDENTITY

\begin{tabular}{|l|}
\hline Report Form \\
Circle the level of resources that you will report for the other participant. \\
HIGH LOW \\
\hline
\end{tabular}

\section{PANEL B - High Identity}

\section{Report Form}

Circle the level of resources that you will report for your teammate.

HIGH

LOW 


\section{Chapter 7: Results}

In this chapter, I present analysis for the three primary hypotheses, as well as supplemental analyses on contingent decision making and trends over time.

\section{DESCRIPTIVE STATISTICS, STATISTCAL ASSUMPTIONS, AND MANIPULATION CHECKS}

The analysis presented here represents the decisions of 128 participants, who each spent approximately one hour on the study. Average compensation for participants in the vertical condition was $\$ 26.97$. The horizontal system does not offer profitable opportunities for off-equilibrium collusion. Therefore, participants in this condition were paid an extra $\$ 10.00$ to equalize average pay across conditions. ${ }^{28}$ The adjusted average compensation under the horizontal system was $\$ 28.43$.

Table 2 presents descriptive statistics. The primary statistical processes used in this study, Analysis of Variance (ANOVA) and Structural Equationsbased Path Analysis, assume that all measured variables are normally distributed. Therefore, the Kolmogorov-Smirnov test for normality was conducted for the primary variables - effort, communication, and ending team identity. ${ }^{29}$ This procedure tests the null hypothesis that the distribution is normally distributed, so a non-significant result suggests that the assumption of normality is met. The results of this test are presented in Table 3.

\footnotetext{
28 This adjustment was announced at the conclusion of the session.

29 The specific measures used for these constructs are discussed below in conjunction with the hypothesis tests.
} 
For all four of the experimental conditions, the Kolmogorov-Smirnov test fails to reject the null hypothesis that the total effort variable is normally distributed. Thus, the assumption of normality is met for this variable. The communication variable, on the other hand, differs significantly from a normal distribution in three of the four conditions. Therefore, the statistical tests using this variable (see Hypothesis 2 below) will be carefully checked for robustness. The ending team identity variable violates the assumption of normality in only one of the four conditions (vertical, high identity). This is a relatively minor violation, and the method of ANOVA is known to be robust to violations of normality (Maxwell and Delaney 1989, 109). Therefore, the statistical tests using this variable (see Hypothesis 3 below) are not seriously compromised.

Another assumption of the method of ANOVA is homogeneity of variances across experimental conditions. Thus, the Levene test (Levene 1960) is conducted to assess the homogeneity for total effort and ending team identity, the two primary variables for which ANOVAs are conducted. The results of this test indicate violations of this assumption for both total effort $(F=3.09, p=0.03)$ and ending team identity $(F=4.85, p<0.01)$. ANOVA is robust to violations of this assumption, particularly when the cell sizes are equal and not extremely small (less than 5) (Maxwell and Delaney 1989, 110). Therefore, statistical tests of these variables should be robust. However, as described in the tests of Hypothesis 2 and Hypothesis 3 below, alternate measures and specifications confirm the robustness of statistical inferences related to these variables. 
Because the manipulation of team identity in the experiment is fairly subtle, it is important to verify that this manipulation had the intended effect on participants' perceptions. Thus, a question in the post-experimental questionnaire (Appendix C) served as a manipulation check for the team identity variable. A Likert scale question asked each person to assess the degree to which $\mathrm{s} / \mathrm{he}$ had considered the person s/he was paired with to be a "teammate" (at the beginning of the experiment). Participants in the high identity condition reported significantly higher numbers $(F=7.69, p<0.01)$, indicating that the manipulation of the team identity construct was successful.

\section{HYPOTHESIS 1}

$\mathrm{H} 1$ predicts an interaction between the level of team identity and the incentive system. The dependent variable is the effectiveness of the incentive system. This construct is operationalized as "total effort," the cumulative number of times team members selected the high level of resources over the course of the experiment. (Each period, a team received a score of zero if neither member picked high resources, one if only one member picked high resources, and two if both members picked high resources.) Because under the horizontal incentive system, the even periods are essentially enforcement periods, aimed at eliciting high effort in odd periods, this analysis considers only odd periods. ${ }^{30}$ Therefore, this variable can take on any value between 0 and 20, with 20 representing a team for which each member selects high during all 10 odd periods. Figure 10 provides graphical results, and Table 4 presents the results of the $2 \mathrm{X} 2$ ANOVA.

\footnotetext{
${ }^{30}$ An alternate specification of effort, using all 20 periods, is analyzed later.
} 
The hypothesized interaction between team identity and the incentive system is highly significant $(F=9.38, p<0.01)$. Furthermore, simple effects analysis (in Panel B) reveals that under the vertical incentive system, high identity teams chose lower levels of effort than low identity teams $(F=3.52$, one-tailed $p$ $=0.03$ ), but that under the horizontal incentive system, high identity teams chose higher levels of effort than low identity teams $(F=6.03$, one-tailed $p<0.01)$. Thus, the effectiveness of the vertical incentive system is degraded by a strong sense of team identity, while the effectiveness of the horizontal incentive system is enhanced by a strong sense of team identity, supporting the primary hypothesis of this study.

Several tests were conducted to test the robustness of these conclusions. Recall that the Levene test suggested heterogeneity of variance for the total effort variable. Therefore, as suggested by Conover and Iman (1981), a second ANOVA is conducted, using the rank of effort as the dependent variable. The results of this ANOVA also reveal a significant interaction ( $F=11.04, p<0.01)$. Further, the Mann-Whitney non-parametric test verifies the simple effects analysis (vertical one-tailed $p=0.02$, horizontal one-tailed $p<0.01$ ).

Next, the tests were repeated using all periods of data, rather than only odd periods. This specification also results in a significant incentive system $\mathrm{X}$ team identity interaction $(F=9.57, p<0.01)$. Simple effects analysis of this alternate measure of total effort finds that under the vertical incentive system, high identity teams chose lower levels of effort than low identity teams $(F=3.57$, one-tailed $p$ 
$=0.03$ ), but that under the horizontal incentive system, high identity teams chose higher levels of effort than low identity teams $(F=9.90$, one-tailed $p<0.01)$.

Finally, the method of generalized estimating equations (or GEE) developed by Diggle et al. (1994) was used to test H1. This logistic regression procedure is designed specifically for analyzing longitudinal (or within-subjects) data where the outcomes are categorical rather than continuous. While the cumulative effort measure used for the primary analysis approaches normality (and is not significantly different from normal, as presented in Table3), the effort choice is technically a categorical variable. Thus, it is appropriate to test the robustness of the ANOVA with a logistic regression procedure. The results of this analysis are presented in Table 5. The GEE analysis confirms the results of the primary analysis, finding a significant interaction between the incentive system and the level of team identity $(Z=2.64, p<0.01)$.

Based on these supplemental tests for robustness, I conclude that Hypothesis 1 is supported, and that team identity increases the effectiveness of horizontal incentive systems, while degrading the effectiveness of vertical incentive systems.

\section{HYPOTHESIS 2}

$\mathrm{H} 2$ is aimed at unraveling the process by which team identity influences the effectiveness of incentive systems. As represented in Figure 3, this hypothesis suggests that the relationship occurs through both direct (cognitive) and indirect (communication-mediated) effects. This model is tested using a structural equations-based path analysis, which simultaneously estimates each link in the 
model. This method overcomes the issue of multicollinearity, which could lead to biased estimates if multiple regression were used to test both direct and indirect effects. The primary measure of fit of the model is a chi-squared statistic, which tests the null hypothesis that the proposed model is a good fit for the data. This statistic is not statistically significant $\left(\chi^{2}=0.15, p=0.70\right)$, indicating that the model is indeed a good fit of the data. This evidence is corroborated by the Tucker-Lewis Index, also known as the Non-normed Fit Index. This value indicates the proportion of improvement of the model over a null model. The value of 1.30 , indicating a $130 \%$ increase, is well above the generally accepted cutoff value of 90\% (Kline 1998, 131).

The independent and dependent variables for this analysis are the same as those used in the ANOVA for H1. However, an additional mediating variable level of communication - is added to the analysis. Recall that participants were allowed to share written communication with their teammates. The level of communication is captured by counting the number of words written by each team. ${ }^{31}$ (Sample communication transcripts are presented in Appendix D.)

The standardized path coefficients for this model are presented in Figure 11. $\mathrm{H} 2$ predicts that the incentive system will moderate the relationship between team identity and effort, on both its direct and indirect (communication-mediated) paths. In other words, there will be interactions between the incentive system and both team identity and communication. While it is relatively straightforward to test interactions in regression and analysis of variance techniques, it is more

\footnotetext{
${ }^{31}$ While I did not conduct a formal content analysis of the communication transcripts, casual observation of the content suggests no differences among the experimental conditions. The vast majority of communication was aimed at problem solving and coordination.
} 
complicated to do so under path analysis. When at least one of the independent variables is discrete, as is the case here, the generally accepted approach is the multi-sample approach, using nested model comparisons (Rigdon et al. 1998).

I first assess the direct relationship between team identity and effort. A path model is created to reflect the model presented in Figure 3. This model is called the unrestricted model. A second model (called the restricted model) is then created. This model restricts the coefficient on the team identity-effort path to be equal for the two incentive systems. (Note that in the unrestricted model, this coefficient is allowed to vary across the two incentive systems.) The presence of an interaction is assessed by statistically comparing the fit of the unrestricted and restricted models. This comparison indicates that the unrestricted model is a significantly better fit $\left(\chi^{2}=6.06, p=0.01\right)$ than the restricted model, suggesting the presence of a statistically significant interaction. In other words, the direct effect of team identity on effort is different under the horizontal and vertical incentive systems.

Note that this result is fundamentally different from that presented for H1. While $\mathrm{H} 1$ tested for an interaction between team identity and the incentive system, that test was aimed at identifying only the total effect, and did not subdivide it into its direct and indirect (communication-mediated) components. The analysis presented in this section, by contrast, is aimed at unraveling these two components. Thus, the significant interaction here suggests a moderating influence of the incentive system on the direct effect of team identity on effort. Under the horizontal incentive system, a strong team identity increases the level 
of effort $(t=2.80$, one-tailed $p<0.01)$, whereas under the vertical incentive system, the direct effect of team identity is not statistically significant $(t=-1.08$, one-tailed $p=0.14$ ). However, there is weak evidence of a direct effect, even under the vertical system. Recall that the level of effort is assessed for odd periods only. If all 20 periods of data are used instead, this direct effect is marginally significant $(t=-1.30$, one-tailed $p=0.10)$.

Recall that the direct effect is the result of a change in cognitive focus, whereby team members focus on how they can jointly, rather than individually, affect outcomes. I attempted to capture this difference in cognitive focus through a self-report, asking in the post-experimental survey whether participants had been more concerned with maximizing their individual payoff or the team's payoff. Participants in the high identity condition reported no greater focus on the team's payoff than did those in the low identity condition $(F=0.003, p=0.96)$. This lack of results is not entirely surprising, however, given the robust finding that people have poor self-insight into their own judgment processes (Slovic and Lichtenstein 1971).

I now address the indirect (communication-mediated) effect of team identity on effort. As hypothesized, high team identity leads to a significant increase in communication $(t=2.55$, one-tailed $p<0.01)$. There is also a communication $\mathrm{X}$ incentive system interaction $\left(\chi^{2}=3.16, p=0.07\right)$, meaning that the subsequent effect of communication on effort depends on the incentive system in place. Under the vertical incentive system, communication is negatively associated with effort $(t=-1.82$, one-tailed $p=0.04)$, suggesting that 
team members used communication to collude with one another, leading them to reduce their effort levels. Under the horizontal incentive system, however, communication has no significant relationship with effort ( $t=0.45, p=0.65$ ). One possible explanation for this lack of association is that the relative simplicity of the system allowed participants to coordinate their strategies without the need to communicate. Results from the post-experimental survey show that participants found the horizontal system less complex than the vertical incentive system $(t=1.40$, one-tailed $p=0.08)$. Together, these results suggest that under the vertical incentive system, the relationship between team identity and the effectiveness of the incentive system (in terms of the level of effort elicited) is partially mediated by increased communication. However, no such mediating relationship is found under the horizontal incentive system.

One might argue that the importance of communication for determining the level of cooperation lies not in the amount of communication but in whether communication occurs at all. That is, an important determinant of the amount of communication may be related to individual differences, as some people are direct and "to the point," whereas others are more verbose. Thus, communication might alternately be operationalized as a dichotomous (yes / no) variable, instead of as the number of words. To test the robustness of the model to this specification choice, $\mathrm{I}$ conducted a logistic regression, using the level of identity $(0=$ low, $1=$ high) as the independent variable, and a dichotomous communication variable as the dependent variable. This regression finds a significant relationship between the level of identity and whether or not communication occurred $\left(\chi^{2}=9.22, p<\right.$ 
0.01). Further, a two-way ANOVA finds that this dichotomous communication variable interacts with the incentive system to affect effort $(F=16.97, p<0.01)$. Specifically, the presence of communication (regardless of the amount of communication) increases effort under the horizontal system $(F=3.19$, one-tailed $p=0.04)$, but decreases effort under the vertical system $(F=16.32$, one-tailed $p$ $<0.01$ ). Thus, the findings using a dichotomous communication variable are stronger than those using the number of words, supporting an indirect (communication-mediated) effect of team identity on effort for both the horizontal and vertical incentive systems.

Recall that the Kolmogorov-Smirnov test for normality finds that the communication variable is not normally distributed. One accepted method to correct for non-normality in path analysis is to conduct a bootstrapping process, and to use the Bollen-Stine $p$-value rather than the usual maximum likelihood $p$ value to assess the model fit (Bollen and Stine 1993). Bootstrapping is a resampling procedure, whereby multiple samples (in this case, 2,000) are drawn with replacement from the original dataset. The model is then re-estimated for each of these samples. Out of the 2,000 samples drawn, the model fit 1,442 of these samples better than the original sample. The Bollen-Stine $p$-value (calculated as $1,442 / 2,000$ ) of 0.72 is used to assess the model, and results in the conclusion that the model is indeed a good fit.

In summary, the model predicted in $\mathrm{H} 2$ is fully supported under the vertical incentive system. Specifically, under the vertical incentive system, the effort reducing effect of team identity has both a direct and an indirect 
(communication-mediated) component. Under the horizontal incentive system, the effort increasing effect of team identity also appears to have direct and indirect components. Under this condition, while high identity did lead to increased communication, the subsequent effect of communication on effort was driven by the mere presence of communication and not by the amount of communication.

\section{HYPOTHESIS 3}

While the analysis to this point views team identity and the incentive system as two exogenous and independent constructs, $\mathrm{H} 3$ predicts that after repeated interaction, individuals compensated under the horizontal incentive system will experience a higher level of team identity than will individuals compensated under the vertical incentive system. (That is, team identity has an endogenous component in addition to its exogenous manipulation.) The dependent variable for this test is ending team identity, the result of a question on the post-experimental survey. This question asked each participant to report on a Likert scale the degree to which s/he perceived the person with whom $\mathrm{s} /$ he was paired to be a teammate (at the end of the session). This response is averaged for each pair, and the results are shown in Figure 12.

A two-way (team identity $\mathrm{X}$ incentive system) ANOVA is reported in

Table 6. Team identity (representing the manipulated high or low identity condition) is included because this manipulation is expected to have a lasting effect. That is, a team that begins the process with a high team identity is likely to maintain a relatively high level of identity, regardless of the incentive system in 
place. This is indeed the case, as teams in the high identity condition selfreported higher ending levels of team identity than teams in the low identity condition $(F=6.23$, one-tailed $p<0.01)$.

A main effect for the incentive system $(F=2.11$, one-tailed $p=0.07)$ also exists, suggesting that after repeated interaction, teams operating under the horizontal incentive system experienced higher levels of team identity than did teams operating under the vertical incentive system. Therefore, $\mathrm{H} 3$ is supported. While the incentive system $\mathrm{X}$ team identity interaction term for this ANOVA is not significant $(F=1.70, p=0.20)$, it is nonetheless important to point out that the incentive system main effect is driven by the low identity condition. The small difference in ending team identity between the two systems in the high identity condition (6.06 - horizontal, 6.00 - vertical) is likely due to a ceiling effect. That is, even in the low identity condition, participants under the horizontal system reported relatively high levels of ending team identity (5.56 out of a possible 7.00). Thus, there is little room for an incremental level of ending team identity in the high identity condition.

As an alternate method of evaluating $\mathrm{H} 3$, and to more directly test for a ceiling effect, I conduct a similar ANOVA using the change in self-reported team identity as the dependent variable. ${ }^{32}$ The results of this ANOVA, reported in Table 7, indicate an interaction between the level of team identity and the

\footnotetext{
32 In the post-experimental questionnaire, in addition to reporting their feelings at the end of the experiment, each participant was asked to recall on a Likert scale the degree to which $\mathrm{s} / \mathrm{he}$ had perceived the person with whom s/he was paired to be a teammate at the beginning of the session. This is the same question used as a manipulation check. A self-report such as this may not be entirely reliable due to demand effects, and therefore the results using this measure must be interpreted with caution.
} 
incentive system $(F=3.27, p=0.07)$. Simple effects analysis reveals that as predicted, for low identity teams (i.e., teams formed from people in different color groups), the change in the level of identity is more positive under the horizontal incentive system than under the vertical incentive system $(F=4.22$, one-tailed $p$ $=0.02$ ). There is, however, evidence of a ceiling effect - for high identity teams (i.e., teams formed from people within the same color group), the change in the level of team identity does not significantly differ between the two incentive systems $(F=0.80, p=0.37)$.

\section{SUPPLEMENTAL ANALYSIS - CONTINGENT DECISION MAKING}

The analytical models behind both the vertical and the horizontal incentive systems assume that team members will make their decisions contingent upon the decisions of their teammates. For example, in the two-stage vertical incentive system, each team member's report is likely to depend on the level of effort chosen by his/her teammate. Similarly, under the horizontal incentive system, each person's choice in even periods (when the choice affects not his/her own payoff but only the teammate's payoff) is likely to depend on the teammate's choice in the prior odd period. While this type of contingent decision making is not formally hypothesized, in this section I provide supplemental analysis to investigate the degree to which it occurred.

\section{Vertical Incentive System}

Figure 13 depicts and Table 8 provides numerical details on the level of contingent decision making under the vertical incentive system. As discussed earlier, in the low identity condition, participants were more likely to pick high 
resources (57\% of choices) than low resources ( $43 \%$ of choices). Further, when one team member picked high resources, his/her teammate was almost certain to truthfully report this choice $-93 \%$ (or 53 / 57) of high resource choices were truthfully reported). On the other hand, in those situations when participants picked low resources, the teammates were less inclined to make favorable reports. About one-third of these teammates blew the whistle, truthfully reporting and collecting the 10-point reporting bonus. ${ }^{33}$ The Wilcoxon Signed Ranks test finds the proportion of favorable reports following a teammate's choice of high to be significantly greater than the proportion following a teammate's choice of low $(Z$ $=-1.65$, one-tailed $p=0.05) .{ }^{34}$ Thus, there is statistical evidence that participants in this condition (vertical incentive system, low identity) engaged in contingent decision making, demonstrating more willingness to report that a teammate chose high resources when the teammate did in fact make that choice.

In the high identity condition, by contrast, there is no statistical evidence that participants under the vertical incentive system engaged in contingent decision making. Despite the fact that the majority $(67 \%)$ of participants in the high identity condition chose low resources, the peer reports in this condition were almost always favorable. (Participants reported that their teammates had chosen high resources $87 \%$ of the time.) Moreover, the Wilcoxon Signed Ranks test shows that the participants' peer reports did not differ significantly according to the actual resource decisions made by their teammates $(Z=0.28, p=0.78)$.

\footnotetext{
${ }^{33}$ Notably, in the low identity condition, participants were more likely to lie than to blow the whistle on a shirking teammate. This represents a failure in the incentive system, which is designed to elicit truthful reporting.

34 This non-parametric test is used, because proportions do not satisfy the distributional assumptions of a standard t-test.
} 
Together, these analyses suggest that the degree of contingent decision making under the vertical incentive system depends on the level of team identity, with low identity participants basing their reports on their teammates' actual decisions and high identity participants making more uniformly favorable reports.

\section{Horizontal Incentive System}

Figure 14 depicts and Table 9 provides numerical details on the level of contingent decision making under the horizontal incentive system. Note that the analysis of contingent decision making under the horizontal incentive system is different from the analysis presented above for the vertical incentive system. This is because of the fundamental differences in structure between the two systems. Under the vertical incentive system, each period involved a two-stage game, with participants making resource decisions (Stage 1) followed by reporting decisions (Stage 2). Thus, the analysis of contingent decision making analyzed the effect of Stage 1 decisions on Stage 2 decisions. In contrast, each period in the horizontal incentive system involves only a one-stage game. However, even periods are used as enforcement periods, giving participants opportunities to punish each other for uncooperative behavior in prior periods. Therefore, the analysis of contingent decision making in the horizontal system investigates the effect of odd-period decisions on subsequent even-period decisions.

In the low identity condition, participants were about equally likely to select high $(51 \%)$ or low $(49 \%)$ resources in odd periods. Evidence suggests that their teammates' choices in subsequent even periods were contingent on the odd period choices. The Wilcoxon Signed Ranks test provides marginal evidence that 
participants were more likely $(Z=-1.28$, one-tailed $p=0.10)$ to pick low resources in even periods (thus punishing their teammates) when the teammates had picked low in the preceding odd period than when the teammates had picked high. Twenty-seven percent (or 13 / 49) of low resource choices in odd periods were followed by punishment (through a teammate's choice of low) in the subsequent even period. In contrast, only $6 \%$ (or $3 / 51)$ of high resource choices in odd periods were followed by punishment in the subsequent even period.

While there is evidence of contingent decision making, it is important to note that participants nonetheless seemed reluctant to punish their teammates. Most participants picked high resources in even periods, even following a choice of low in the previous odd period. An examination of the post-experimental survey suggests that these participants were simply considering the effects of their individual decisions, and were not focused on the interrelatedness of their strategies or on the possibility of affecting each other's choices through implicit side contracting and enforcement. Specifically, when asked to describe their decision processes, several participants reported that they chose low resources in odd periods, because the cost of high effort (10 points) exceeded the benefits ( 6 points). In even periods, they were individually indifferent to high or low, so they picked high, knowing that such a decision would benefit their teammates.

In the high identity condition, most participants $(80 \%)$ chose high resources in odd periods. The subsequent even-period choices were almost always high as well (96\%), even in those relatively infrequent cases when a teammate had chosen low in the previous odd period. Further, the Wilcoxon 
Signed Ranks test provides no evidence of contingent decision making $(Z=0.00$, $p=1.00$ ). That is, participants were no more likely to pick low resources following a teammate's choice of low than following a teammate's choice of high. This lack of contingent decision making is notable, given the success of the incentive system in eliciting cooperative behavior in high identity teams. That is, in the high identity condition, participants almost always chose high resources, even though it was highly unlikely that they would be punished for choosing low resources. Members of low identity teams were less likely than members of high identity teams to select high resources, despite a greater probability of being punished for selecting low resources.

The analysis presented in this section suggests that under both the vertical and horizontal incentive systems, members of low identity teams were more likely to engage in contingent decision making than were members of high identity teams. Despite this fact, high identity teams achieved greater cooperation (lower effort under the vertical system and higher effort under the horizontal system). This paradoxical result suggests an important implication for firms using teams. Specifically, social factors may sometimes play a more important role than formal sanctioning and control systems in eliciting cooperative behavior among team members. For example, for firms using self-managing teams, a focus on team building may provide greater benefits to the firm than an emphasis on the team members' control over such things as compensation, promotions, and workload distribution. Similarly, firms using vertical incentive systems may find that social 
ties reduce the effectiveness of these systems, even in the presence of strong formal mechanisms for inducing truthful reporting.

\section{SUPPLEMENTAL ANALYSIS - TREND ANALYSIS}

Figure 15 plots how the participants' effort levels varied over the course of the experiment. (Only odd period choices are shown in these pictures, because under the horizontal incentive system, even periods are enforcement periods.) The level of effort represents the average number of participants on each team who chose high resources in the given period (ranging from 0 to 2). The Friedman test (the non-parametric equivalent of a one-way repeated-measures ANOVA) is used to compare effort levels across periods in each of the four experimental conditions. The results of this test (presented in Table 10) indicate that in all four experimental conditions, there is no significant period effect. ${ }^{35}$ However, this lack of statistical evidence is likely attributable to limited statistical power, as casual observation of Figure 15 seems to indicate a downward slope in all four conditions. This casual observation is corroborated by statistical evidence when the four conditions are collapsed. The Friedman test comparing effort levels across periods in this collapsed data set detects a significant difference in effort across periods $\left(\chi^{2}=24.52, p<0.01\right)$. Further, when the Wilcoxon Signed Ranks test is used to compare Period 1 effort to Period 19 effort, Period 1 effort is significantly higher (or at least marginally so) than Period 19 effort in all four experimental conditions (see Table 11). The one-tailed $p$-values for the four

\footnotetext{
35 The $\chi^{2}$ statistic in the Friedman test is analogous to the $F$-statistic in a one-way ANOVA. A significant statistic would indicate some difference in effort levels across periods.
} 
conditions range from 0.04 to 0.10 . Thus, statistical evidence provides evidence of a downward trend in effort levels over the course of the experiment.

This downward trend is notable, because it is difficult to rationalize an explanation that would account for consistent decreases in effort over time across all conditions. Specifically, most underlying explanations for changes in behavior over time would logically have opposite effects under the two incentive systems. Take learning, for example. If participants are learning the strategies that lead to greater payoffs, one would expect increased cooperation over time, leading to higher effort under the horizontal incentive system and lower effort under the vertical incentive system. The downward sloping lines under the horizontal system are thus inconsistent with a learning explanation. One might alternately conjecture that the decrease in effort is due to a breakdown in cooperation. However, the results under the vertical system are inconsistent with this explanation, as a breakdown in cooperation would lead to less collusion and higher effort levels under this system.

It seems that different factors may be affecting behavior over time under the two systems. For example, in the relatively complex vertical incentive system, learning may play a larger role, leading to increased cooperation and decreased effort over time. (This explanation is consistent with post-experimental survey evidence that participants perceived the vertical system to be more complex than the horizontal system.) The current design cannot disentangle the different factors affecting behavior over time. However, the results provide evidence of complex relationships between the incentive systems and behavioral 
factors. These complex relationships may be the subject of future research, following the approach of the current study in examining interactions between economic and psychological variables. 


\section{Table 2 - Descriptive Statistics}

Panel A - Primary Variables

\begin{tabular}{|c|c|c|c|c|}
\hline & \multirow{2}{*}{\multicolumn{2}{|c|}{$\frac{\text { Horizontal }}{\text { Identity }}$}} & \multicolumn{2}{|c|}{ Vertical } \\
\hline & & & Iden & \\
\hline & Low & High & Low & High \\
\hline \multicolumn{5}{|l|}{ Mean (Std. Dev.) } \\
\hline $\begin{array}{l}\text { Total Effort } \\
\text { (\# of times "high" picked) }\end{array}$ & $\begin{array}{l}10.31 \\
(5.51)\end{array}$ & $\begin{array}{l}15.88 \\
(5.02)\end{array}$ & $\begin{array}{l}11.38 \\
(6.78)\end{array}$ & $\begin{array}{r}7.13 \\
(7.92)\end{array}$ \\
\hline $\begin{array}{l}\text { Communication } \\
\text { (\# of words) }\end{array}$ & $\begin{array}{r}18.19 \\
(52.40)\end{array}$ & $\begin{array}{r}68.94 \\
(99.28)\end{array}$ & $\begin{array}{c}13.88 \\
(38.06)\end{array}$ & $\begin{array}{r}51.19 \\
(74.87)\end{array}$ \\
\hline Points Earned & $\begin{array}{l}352.25 \\
(34.21)\end{array}$ & $\begin{array}{l}384.75 \\
(24.70)\end{array}$ & $\begin{array}{c}465.63 \\
(184.53)\end{array}$ & $\begin{array}{r}613.13 \\
(159.90)\end{array}$ \\
\hline $\begin{array}{l}\text { Ending Level of Team Identity } \\
\text { (self-reported) }\end{array}$ & $\begin{array}{r}5.56 \\
(1.25)\end{array}$ & $\begin{array}{r}6.06 \\
(1.42)\end{array}$ & $\begin{array}{c}4.41 \\
(2.32)\end{array}$ & $\begin{array}{r}6.00 \\
(1.52)\end{array}$ \\
\hline
\end{tabular}




\section{Panel B - Other Variables}

\begin{tabular}{|c|c|c|c|c|}
\hline & \multicolumn{4}{|c|}{ Incentive System } \\
\hline & \multirow{2}{*}{\multicolumn{2}{|c|}{$\begin{array}{c}\text { Horizontal } \\
\text { Identity } \\
\end{array}$}} & \multirow{2}{*}{\multicolumn{2}{|c|}{$\frac{\text { Vertical }}{\text { Identity }}$}} \\
\hline & & & & \\
\hline & Low & High & Low & High \\
\hline \multicolumn{5}{|l|}{ Mean (Std. Dev.) } \\
\hline $\begin{array}{l}\text { Beginning Level of Team Identity } \\
\text { (Manipulation Check) }\end{array}$ & $\begin{array}{c}4.34 \\
(1.65)\end{array}$ & $\begin{array}{c}5.44 \\
(0.96)\end{array}$ & $\begin{array}{r}4.59 \\
(1.31)\end{array}$ & $\begin{array}{r}5.03 \\
(0.94)\end{array}$ \\
\hline Desire for Future Interaction & $\begin{array}{c}5.22 \\
(1.37)\end{array}$ & $\begin{array}{r}5.97 \\
(1.42)\end{array}$ & $\begin{array}{r}5.75 \\
(1.34)\end{array}$ & $\begin{array}{c}5.81 \\
(1.34)\end{array}$ \\
\hline $\begin{array}{l}\text { Concern for Outcomes } \\
\text { (1=Individual to } 7=\text { Team })\end{array}$ & $\begin{array}{c}4.72 \\
(0.86)\end{array}$ & $\begin{array}{c}4.88 \\
(1.43)\end{array}$ & $\begin{array}{c}4.75 \\
(1.28)\end{array}$ & $\begin{array}{c}4.63 \\
(1.10)\end{array}$ \\
\hline Production Interdependence & $\begin{array}{c}5.78 \\
(1.35)\end{array}$ & $\begin{array}{r}5.40 \\
(1.26)\end{array}$ & $\begin{array}{r}6.00 \\
(0.82)\end{array}$ & $\begin{array}{r}5.38 \\
(1.36)\end{array}$ \\
\hline Complexity of Incentive System & $\begin{array}{c}3.38 \\
(1.48)\end{array}$ & $\begin{array}{c}2.94 \\
(1.24)\end{array}$ & $\begin{array}{c}3.56 \\
(0.83)\end{array}$ & $\begin{array}{c}3.53 \\
(0.79)\end{array}$ \\
\hline $\begin{array}{l}\text { Factors Considered: } \\
\text { Cooperate }\end{array}$ & $\begin{array}{r}5.75 \\
(0.63)\end{array}$ & $\begin{array}{r}6.06 \\
(0.79)\end{array}$ & $\begin{array}{c}6.00 \\
(1.10)\end{array}$ & $\begin{array}{r}5.94 \\
(0.85)\end{array}$ \\
\hline Do the right thing for your division & $\begin{array}{r}4.97 \\
(0.99)\end{array}$ & $\begin{array}{c}7.72 \\
(12.72)\end{array}$ & $\begin{array}{r}5.13 \\
(1.00)\end{array}$ & $\begin{array}{r}4.75 \\
(1.43)\end{array}$ \\
\hline Do the right thing for other division & $\begin{array}{r}4.06 \\
(1.05)\end{array}$ & $\begin{array}{c}4.22 \\
(1.45)\end{array}$ & $\begin{array}{c}4.47 \\
(1.20)\end{array}$ & $\begin{array}{r}4.25 \\
(1.76)\end{array}$ \\
\hline Do the right thing for firm & $\begin{array}{r}5.38 \\
(0.65)\end{array}$ & $\begin{array}{r}4.69 \\
(1.41)\end{array}$ & $\begin{array}{c}4.81 \\
(1.40)\end{array}$ & $\begin{array}{r}4.82 \\
(1.50)\end{array}$ \\
\hline Be honest & $\begin{array}{r}5.16 \\
(1.41)\end{array}$ & $\begin{array}{c}5.16 \\
(1.54)\end{array}$ & $\begin{array}{c}4.84 \\
(1.20)\end{array}$ & $\begin{array}{r}4.63 \\
(1.38)\end{array}$ \\
\hline
\end{tabular}


Table 3 - Tests for Normality

\begin{tabular}{|c|c|c|}
\hline Experimental Condition & $\underline{K-S Z}$ & $\begin{array}{c}p \text {-value } \\
\text { (two-tailed) } \\
\end{array}$ \\
\hline \multicolumn{3}{|l|}{ Horizontal, Low Identity } \\
\hline Total Effort & 0.62 & 0.84 \\
\hline Communication & 2.04 & $<0.01$ \\
\hline Ending Team Identity & 0.59 & 0.87 \\
\hline \multicolumn{3}{|l|}{ Horizontal, High Identity } \\
\hline Total Effort & 0.84 & 0.50 \\
\hline Communication & 1.03 & 0.24 \\
\hline Ending Team Identity & 1.23 & 0.11 \\
\hline \multicolumn{3}{|l|}{ Vertical, Low Identity } \\
\hline Total Effort & 0.64 & 0.81 \\
\hline Communication & 2.07 & $<0.01$ \\
\hline Ending Team Identity & 0.73 & 0.67 \\
\hline \multicolumn{3}{|l|}{ Vertical, High Identity } \\
\hline Total Effort & 1.03 & 0.24 \\
\hline Communication & 1.34 & 0.06 \\
\hline Ending Team Identity & 1.26 & 0.08 \\
\hline
\end{tabular}


Table 4 - ANOVA for Hypothesis 1

The Effect of Team Identity and Incentives on Effort

Analysis Using Effort in Odd Periods Only

Panel A: Main Effects

\begin{tabular}{lrrrr} 
Factor & Mean & $\begin{array}{r}\text { M-value } \\
\text { (two- } \\
\text { tailed) }\end{array}$ \\
\hline Team Identity & 1 & 6.89 & 0.17 & 0.68 \\
Incentive System & 1 & 236.39 & 5.76 & 0.02 \\
Incentive System X Team Identity & 1 & 385.14 & 9.38 & $<0.01$ \\
Error & 60 & 41.08 & &
\end{tabular}

Panel B: Simple Effects for Each Incentive System

Effect of Team Identity under

Vertical Incentive System

$\begin{array}{llll}1 & 144.50 & 3.52 & 0.07\end{array}$

Effect of Team Identity under

Horizontal Incentive System

$\begin{array}{llll}1 & 247.53 & 6.03 & 0.02\end{array}$


Table 5 - Alternate Analysis of Hypothesis 1 The Effect of Team Identity and Incentives on Effort

\section{Analysis Using GEE Procedure}

\begin{tabular}{|c|c|c|c|c|}
\hline Parameter & Estimate & $\begin{array}{c}\text { Standard } \\
\text { Error }\end{array}$ & $Z$ & $\begin{array}{r}p \text {-value } \\
\text { (two- } \\
\text { tailed) }\end{array}$ \\
\hline Intercept & 0.071 & 0.185 & 0.83 & 0.41 \\
\hline Incentive System & 0.176 & 0.185 & 2.07 & 0.04 \\
\hline Team Identity & -0.009 & 0.185 & -0.11 & 0.92 \\
\hline Incentive System X Team Identity & 0.225 & 0.185 & 2.64 & $<.01$ \\
\hline
\end{tabular}


Table 6 - ANOVA for Hypothesis 3

The Effect of the Incentive System on Ending Team Identity

\begin{tabular}{lrrrr} 
& & Mean & & $\begin{array}{c}p \text {-value } \\
\text { (two- } \\
\text { tailed) }\end{array}$ \\
\hline Factor & dof & Square & \multicolumn{1}{c}{$F$} & \\
Incentive System & 1 & 5.94 & 2.11 & 0.15 \\
Team Identity (Manipulated) & 1 & 17.54 & 6.23 & 0.02 \\
Incentive System X Team Identity & 1 & 4.79 & 1.70 & 0.20 \\
Error & 60 & 2.82 & &
\end{tabular}


Table 7 - Alternate ANOVA for Hypothesis 3

The Effect of the Incentive System on the Change Team Identity

Panel A: Main Effects

\begin{tabular}{|c|c|c|c|c|}
\hline Factor & $d o f$ & $\begin{array}{c}\text { Mean } \\
\text { Square }\end{array}$ & $F$ & $\begin{array}{r}p \text {-value } \\
\text { (two- } \\
\text { tailed) }\end{array}$ \\
\hline Incentive System & 1 & 4.52 & 1.21 & 0.28 \\
\hline Team Identity (Manipulated) & 1 & 1.27 & 0.34 & 0.56 \\
\hline Incentive System X Team Identity & 1 & 12.25 & 3.27 & 0.07 \\
\hline Error & 60 & 3.75 & & \\
\hline
\end{tabular}

Panel B: Simple Effects for Each Level of Identity

Effect of the Incentive System in the

Low Identity Condition

$\begin{array}{llll}1 & 15.82 & 4.22 & 0.04\end{array}$

Effect of the Incentive System in the

High Identity Condition

$1 \quad 3.00 \quad 0.80$

0.37 
Table 8 - Contingent Decision Making Under the Vertical System

\section{High Identity \\ Effort Choice}

Low

High

Low Identity

Effort Choice

Low

High

\section{$\underline{\text { Teammate's Report }}$}

\begin{tabular}{|c|c|c|}
\hline Low & High & Total \\
\hline $13 \%$ & $54 \%$ & $67 \%$ \\
\hline$\underline{0 \%}$ & $33 \%$ & $33 \%$ \\
\hline $13 \%$ & $87 \%$ & $100 \%$ \\
\hline
\end{tabular}

\section{$\underline{\text { Teammate's Report }}$}

\begin{tabular}{|c|c|c|}
\hline Low & High & Total \\
\hline $14 \%$ & $29 \%$ & $43 \%$ \\
\hline $4 \%$ & $53 \%$ & $\underline{57 \%}$ \\
\hline $8 \%$ & $82 \%$ & $100 \%$ \\
\hline
\end{tabular}


Table 9 - Contingent Decision Making Under the Horizontal System

\begin{tabular}{lrrr} 
High Identity & & \\
Odd Period Choice & & \multicolumn{3}{l}{ Teammate's Next Choice } \\
\cline { 2 - 4 } Low & Low & High & Total \\
High & $2 \%$ & $18 \%$ & $20 \%$ \\
& $\underline{2 \%}$ & $\underline{78 \%}$ & $\underline{80 \%}$ \\
& $4 \%$ & $96 \%$ & $100 \%$
\end{tabular}

Low Identity

Odd Period Choice $\quad$ Teammate's Next Choice

Low

Low High Total

$13 \% \quad 36 \% \quad 49 \%$

High

$\underline{3 \%} \quad \underline{48 \%} \quad \underline{51 \%}$

$16 \% \quad \overline{84 \%} \quad 100 \%$


Table 10 - Trend Analysis Using the Friedman Test An Omnibus Test of Differences in Effort Across All Periods

\begin{tabular}{|c|c|c|}
\hline Experimental Condition & $\chi^{2}$ & $\begin{array}{c}p \text {-value } \\
\text { (two-tailed) }\end{array}$ \\
\hline Horizontal, Low Identity & 8.63 & 0.47 \\
\hline Horizontal, High Identity & 5.23 & 0.81 \\
\hline Vertical, Low Identity & 10.46 & 0.31 \\
\hline Vertical, High Identity & 12.26 & 0.20 \\
\hline All Conditions Combined & 24.52 & $<0.01$ \\
\hline
\end{tabular}


Table 11 - Trend Analysis Using Wilcoxon Signed Ranks Test A Test Comparing Efforts in Period 1 and Period 19

\begin{tabular}{|c|c|c|}
\hline Experimental Condition & $\mathrm{Z}$ & $\begin{array}{c}p \text {-value } \\
\text { (two-tailed) }\end{array}$ \\
\hline Horizontal, Low Identity & -1.26 & 0.21 \\
\hline Horizontal, High Identity & -1.41 & 0.16 \\
\hline Vertical, Low Identity & -1.51 & 0.13 \\
\hline Vertical, High Identity & -1.79 & 0.07 \\
\hline All Conditions & -2.95 & $<0.0$ \\
\hline
\end{tabular}


Figure 10 - Hypothesis 1 Results

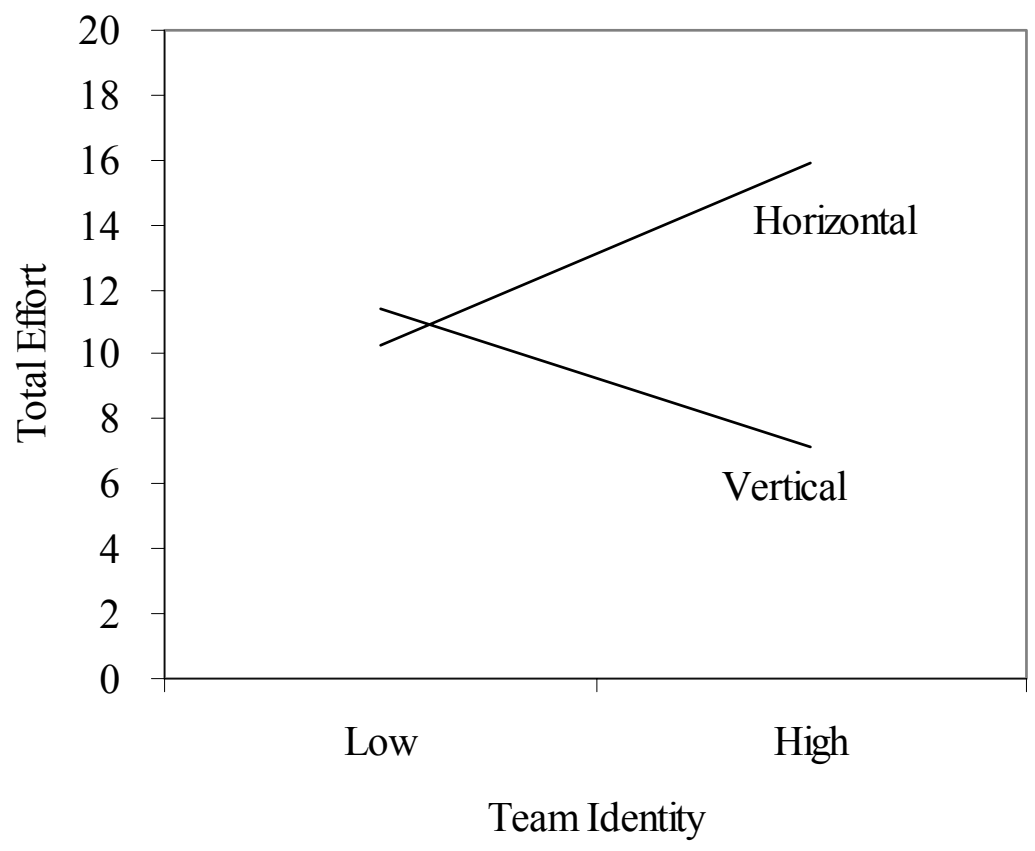


Figure 11 - Hypothesis 2 Results

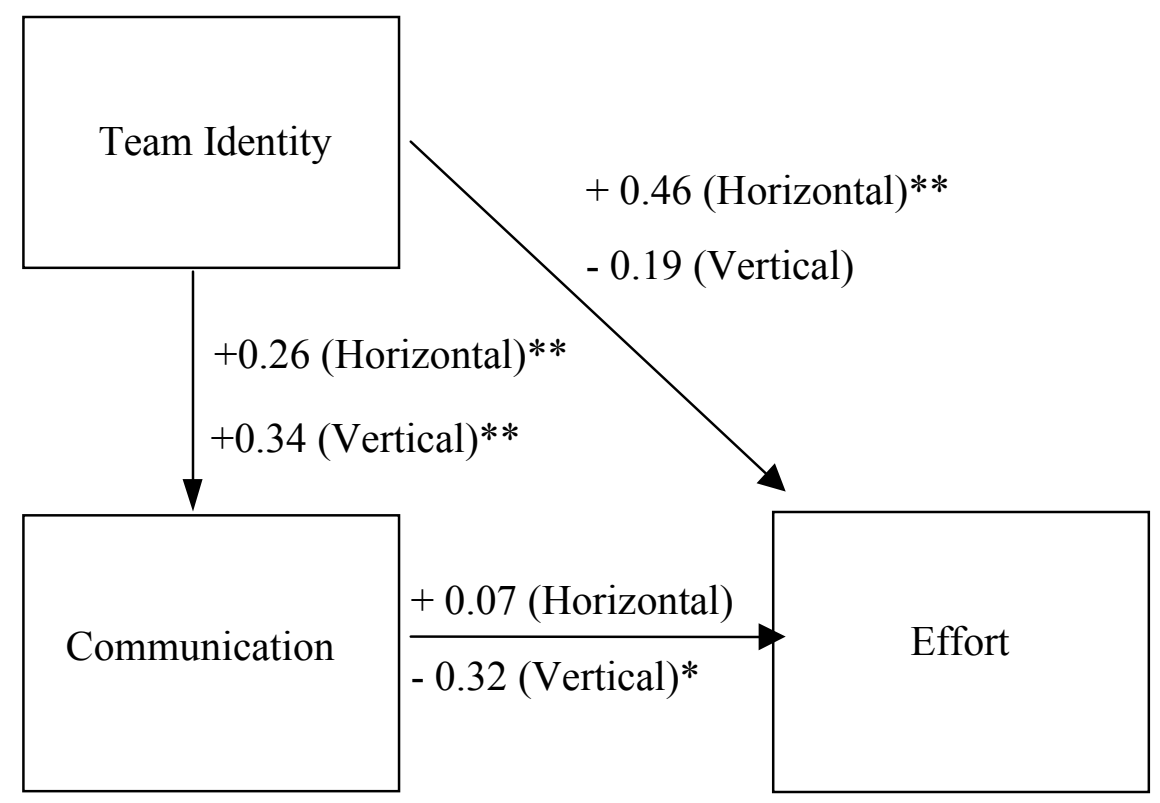

Overall Goodness of Fit: $\quad \chi^{2}=0.15, p=0.70$

(tests the null that the model is a good fit).

$* *$ Significant at $<.01$

* Significant at $<.05$ 
Figure 12 - Hypothesis 3 Results

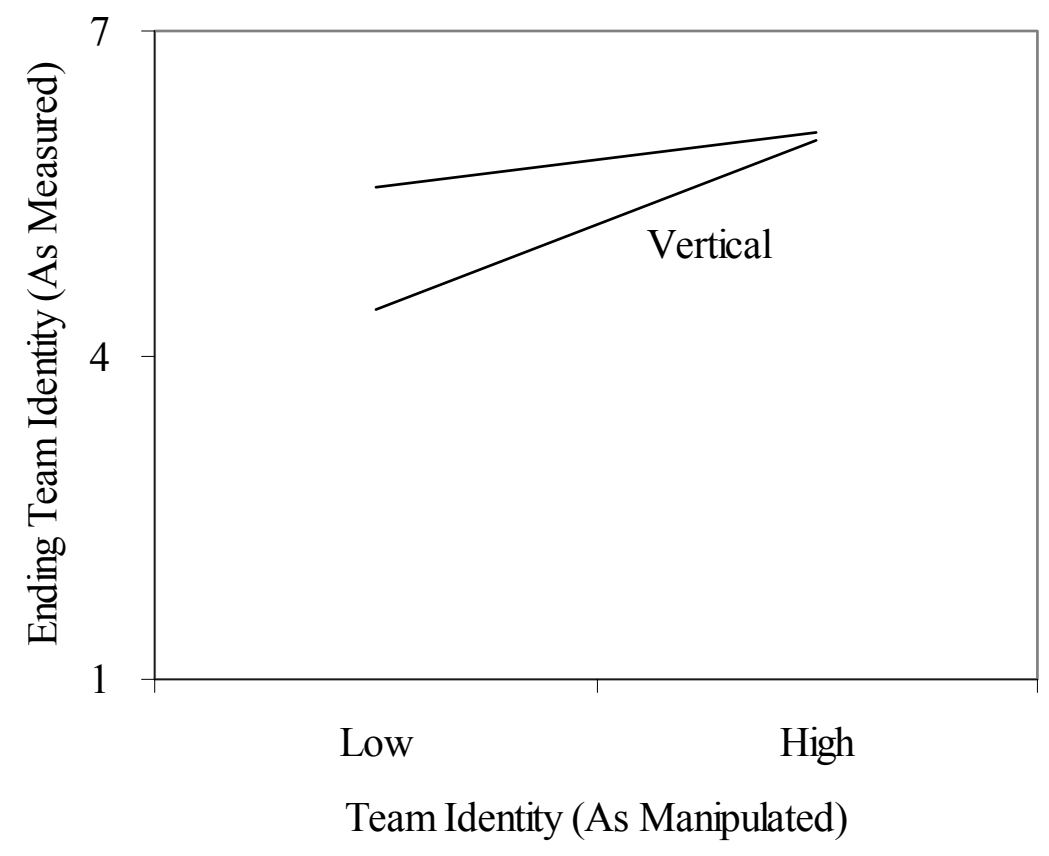


Figure 13 - Contingent Decision Making Under the Vertical System

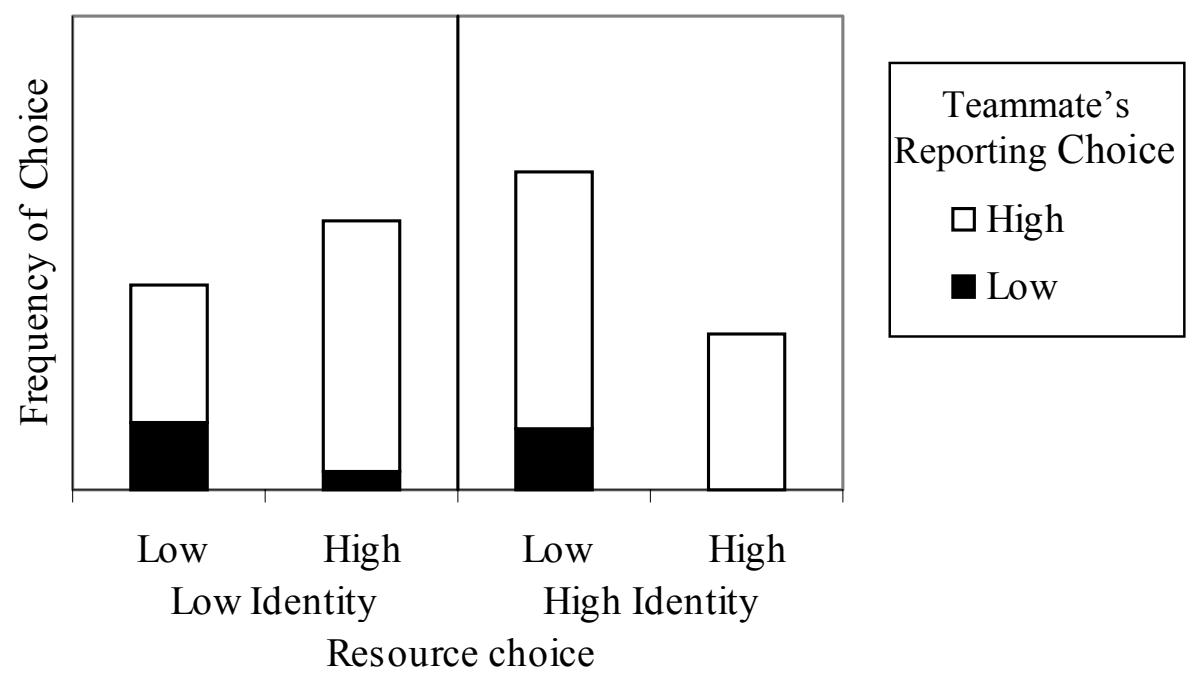

Note that the height of the bars represents a team member's resource choice in a given period, whereas the shading of the bars represents his/her teammate's reporting choice in the same period. 
Figure 14 - Contingent Decision Making Under the Horizontal System

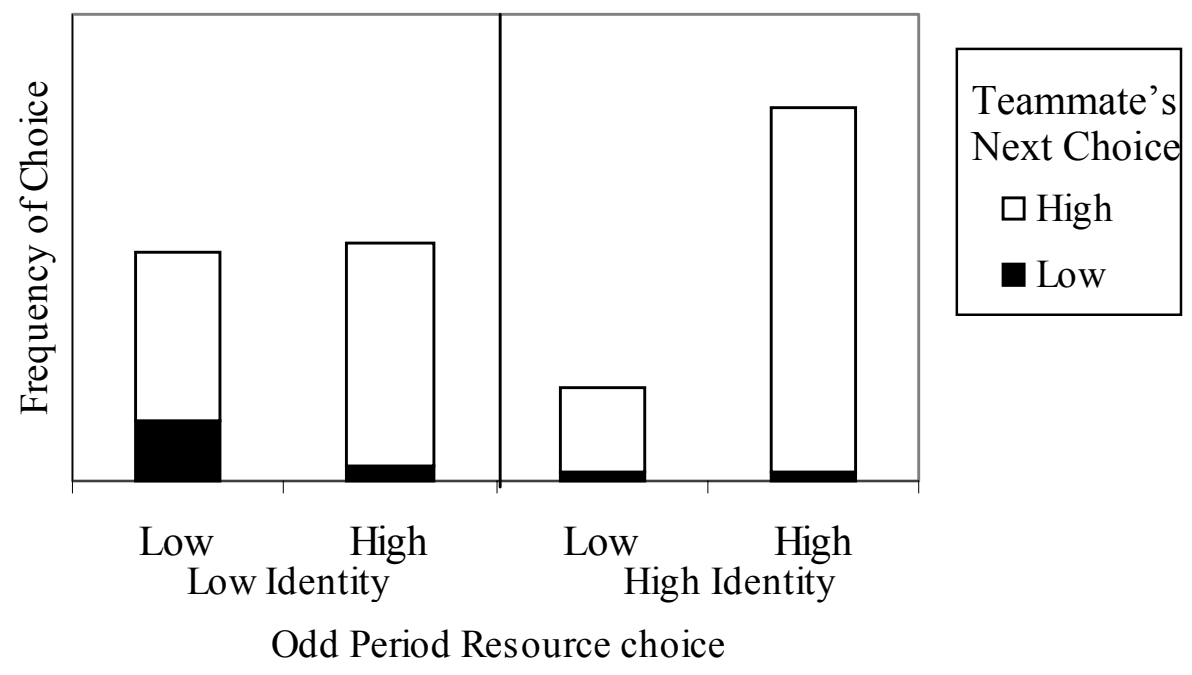

Note that the height of the bars represents a team member's choice in an odd period, whereas the shading of the bars represents his/her teammate's choice in the immediately following even period. 
Figure 15 - Trend Analysis

Panel A - Vertical Incentive System

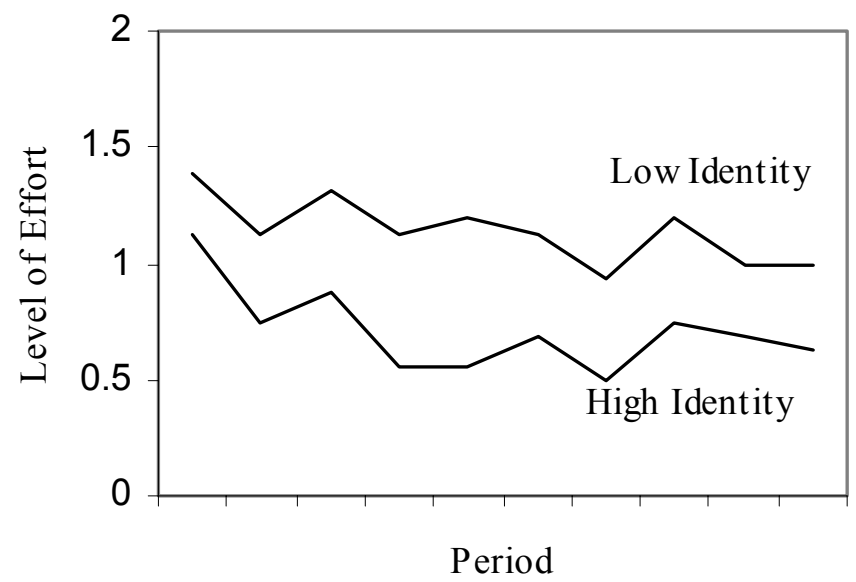

Panel B - Horizontal Incentive System

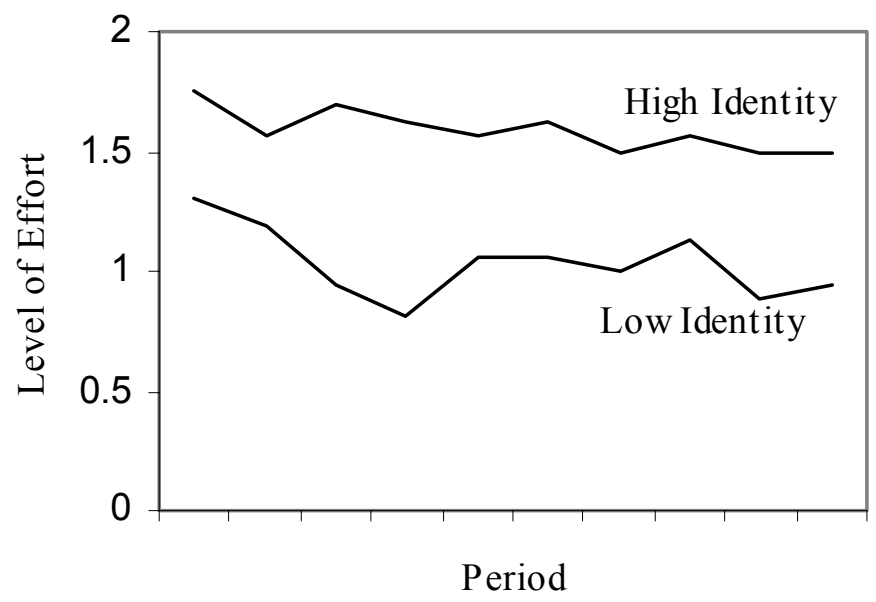




\section{Chapter 8: Summary and Conclusions}

This study presents evidence that the effectiveness of a financial incentive system can be either enhanced or degraded by a strong sense of identity, depending on specific characteristics of the incentive system. A vertical incentive system, in which the agents report observations of their teammates' efforts to the principal, becomes less effective in the presence of a strong team identity. Under this incentive system, a strong team identity leads individuals to collude against the principal, choosing low levels of effort and reporting falsely. Conversely, the effectiveness of a horizontal incentive system, based on peer-enacted control, is enhanced by a strong team identity. Because no collusive opportunities exist under this incentive system, a strong team identity serves to help teams to reach cooperative solutions, as desired by the principal. The evidence presented here

suggests that under both incentive systems, the effect of team identity on cooperation has both direct (based on a change of cognitive focus) and indirect (communication-mediated) components.

Finally, evidence suggests that team identity is partially endogenous, in that it is affected by the incentive system in place. After repeated interaction, the horizontal system, with its focus on team outcomes rather than individual contributions, leads to higher levels of team identity than does the vertical incentive system, where individuals act as whistle blowers for the principal.

This research provides useful insights for both theory and practice. From a practical standpoint, this study provides evidence on the usefulness of mutual 
monitoring as an alternative to traditional methods of measuring individual production inputs. In many joint production settings, workers hold high-quality information on co-workers' inputs, and firms can benefit by understanding how to use this knowledge base to make informed decisions in such areas as resource allocation, compensation, and promotion. I demonstrate that when the team has achieved a high level of identity, the best way to use this information may not be to extract it through reporting mechanisms. Instead, the most effective incentive system may be horizontal in nature, delegating responsibility for control to selfmanaged teams. This study thus helps explain why firms have more readily embraced horizontal incentive systems than vertical incentive systems.

Further, this study provides evidence on the types of incentive systems that are most likely to be effective for different types of teams. For example, Scott (1997) demonstrates that permanent teams tend to develop higher levels of identity than do part-time or temporary teams. One inference from the results presented here is that the horizontal approach is particularly appropriate for work teams involved in manufacturing or other permanent production-related tasks. Thus, by focusing on the consequences of team identification, this study aids in understanding the causal linkages among team characteristics, incentives, and performance.

From a theoretical standpoint, this study examines the intersection between economics and psychology, demonstrating that concepts from psychology may be useful in understanding the economic incentives addressed by agency theory. The study therefore adds to an expanding body of literature 
examining variables that interact with financial incentives to influence performance (Bonner et al. 2000, Bonner and Sprinkle 2001, Drake et al. 1999, Sprinkle 2000). The paper contributes more specifically to the relatively undeveloped literature on the effect of incentives in a team environment (Drake et al. 1999, Fisher et al. 2001, Rankin 2001, Rankin and Sayre 2000).

Certain factors limit the generalizability of these results. For example, one may view these results as implying that firms should always use the horizontal system, because it performs better than the vertical incentive system when the team identity is high and no worse when the team identity is low. However, this study was not designed to directly compare these two systems, and any such comparisons should be interpreted with caution, because of my treatment of risk preferences. To simplify the laboratory experiment, the stochastic element was removed, and the incentive systems were presented to participants in expected value terms. Such an abstraction is appropriate, because risk preferences are not relevant to the hypotheses investigated in this study. However, risk preferences are an outside factor that can affect the desirability of a vertical incentive system over a horizontal one. The vertical incentive system provides a first-best solution, meaning that the agents take on no output-based risk under this system. In contrast, the horizontal incentive system requires the agents to take on risk, for which they must be compensated. Thus, if risk preferences were considered, the cost of achieving the high levels of effort under the horizontal incentive system could be greater than the costs of achieving lower levels of effort under the vertical system. There are tradeoffs involved, and this paper cannot evaluate the 
absolute effectiveness of either system. The current findings show only that team identity enhances the effectiveness of the horizontal system, while degrading the effectiveness of the vertical system.

I also make the simplifying assumption that effort is discrete and perfectly observable, an attribute almost certainly not characteristic of real-world settings. While team members may observe the amount of time a coworker spends on a particular task, it is considerably more difficult to observe the intensity or creativity with which s/he works. ${ }^{36}$ This study compares two analytic approaches to incentive contracting, and these simplifying assumptions help to enhance comparability of results across the two incentive systems. However, it is unclear how the results would change if effort were imperfectly observable. For example, in their experimental investigation of several budget-based group incentive plans, Fisher et al. (2001) demonstrate different effects on effort duration, which is easily observed, and effort intensity, which is less easily observed. This limitation offers an opportunity for future research, and a body of psychology literature may prove helpful. Social Comparison Theory (Kunda 1999, 494) provides a rich theory for understanding the more subtle aspects of mutual monitoring. Thus, future work in this area may follow the approach used here of melding insights from both economics and psychology to understand complex managerial accounting issues.

36 These dimensions of effort are not only unobservable, but are also likely immeasurable. This leads to difficulty in meeting another assumption - common knowledge of the probability distribution of outcomes given effort. 


\section{Appendix A - Experimental Materials}

\section{High Identity, Vertical Incentive System}

You were each assigned to a color group when you arrived. Each of you will be paired with a member of your color group (who will be referred to as your teammate).

Assume that you and your teammate are two division managers working for Company XYZ. The company produces one product, but both of your divisions participate in the production of that product. You will be asked to make decisions for a number of periods, and your compensation will be based on the decisions made by both you and your teammate. You will accumulate points from your decisions. At the end of the session, your accumulated point balance from all periods will be paid to you in real cash at a rate of $\$ 1.00$ per 10 points. (For example, if your balance was 100 at the end of the session, you would receive $\$ 10.00$, which is 100 divided by 10.) The following instructions show how you accumulate points.

\section{Providing Resources}

Your services for Company XYZ require you to provide resources, which you can think of as work effort. Because effort is costly, providing high resources is more costly to you individually than providing low resources. You must choose between two alternatives, with the following consequences:

- High Resources - If you choose to provide high resources to the firm in any given period, your division's productivity will be high but you will incur a personal cost of $\mathbf{1 0}$ points.

- Low Resources - If you choose to provide low resources to the firm in any given period, your division's productivity will be low but you will not incur any personal cost.

Your teammate will be asked to make the same decision for his/her division. After independently making the decisions, you will be informed of the decision your teammate made.

\section{$\underline{\text { Reporting }}$}

You will be required to submit a report every period, in which you will document the level of resources your teammate provided in the period. Note that while you will know with certainty what level of resources your teammate provided, you are not required to report that level. You can choose to report either high or low, regardless of what your teammate actually did. 


\section{Compensation}

Your compensation will be based on the report filed by your teammate. Specifically,

- If your teammate reports that you provided high resources, you will receive 20 points.

- If your teammate reports that you provided low resources, you will receive 0 points.

The same compensation applies also to your teammate, who will be compensated based on the report you file. That is,

- If you report that your teammate provided high resources, your teammate will receive 20 points.

- If you report that your teammate provided low resources, your teammate will receive 0 points.

\section{Reporting Bonuses and Penalties}

You will also earn an extra bonus if you report that your teammate provided low resources, but only if s/he actually did provide low resources. Specifically,

- If you report that your teammate provided low resources, this will be verified, and if your teammate actually did provide low resources, you will receive a bonus of 10 points.

- However, if you report that your teammate provided low resources, and your teammate actually provided high resources, you will incur a penalty of 20 points.

The same reporting bonus and penalty applies also to your teammate with respect to your decision. That is,

- If your teammate reports that you provided low resources, and you actually did provide low resources, your teammate will receive a bonus of 10 points.

- However, if your teammate reports that you provided low resources, and you actually provided high resources, your teammate will incur a penalty of 20 points. 


\section{Record Keeping}

For each period, you will fill out the following table to keep track of your decisions and compensation.

\begin{tabular}{|c|c|}
\hline $\begin{array}{l}\text { Providing } \\
\text { Resources }\end{array}$ & $\begin{array}{l}\text { Circle the level of resources that you will provide. } \\
\text { HIGH } \\
\text { LOW } \\
\text { If you choose to provide high resources, deduct } 10 \\
\text { points. } \\
\text { If you choose to provide low resources, enter }-0 \text {-. }\end{array}$ \\
\hline $\begin{array}{l}\text { Observing } \\
\text { your } \\
\text { teammate's } \\
\text { Decision }\end{array}$ & $\begin{array}{l}\text { The administrator will circle the level of resources that } \\
\text { your teammate provided. } \\
\text { HIGH } \\
\text { LOW }\end{array}$ \\
\hline $\begin{array}{l}\text { Filing your } \\
\text { Report }\end{array}$ & $\begin{array}{l}\text { What report would you like to make regarding the } \\
\text { level of resources your teammate provided? } \\
\text { HIGH } \\
\text { LOW }\end{array}$ \\
\hline Compensation & $\begin{array}{l}\text { If your teammate reported that you provided high } \\
\text { resources, add } 20 \text { points. } \\
\text { If your teammate reported that you provided low } \\
\text { resources, enter -0- }\end{array}$ \\
\hline $\begin{array}{l}\text { Reporting } \\
\text { Bonus or } \\
\text { Penalty }\end{array}$ & $\begin{array}{l}\text { If you reported that your teammate provided high } \\
\text { resources, enter -0-. } \\
\text { If you reported that your teammate provided low } \\
\text { resources, the administrator will verify if your } \\
\text { teammate did in fact provide low resources, as you } \\
\text { reported. } \\
\quad \text { YES (enter a bonus of } 10 \text { points) } \\
\text { NO (enter a penalty of } 20 \text { points) }\end{array}$ \\
\hline Total & $\begin{array}{l}\text { Add / subtract the entries in each cell and write your } \\
\text { total compensation for this period here. Remember } \\
\text { that your compensation in dollars for this period is this } \\
\text { point total divided by } 10 \text {. }\end{array}$ \\
\hline
\end{tabular}




\section{Low Identity, Vertical Incentive System}

You were each assigned to a color group when you arrived. Each of you will be paired with a member of the other color group (who will be referred to as the other participant).

Assume that you and the other participant are two division managers working for Company XYZ. The company produces one product, but both of your divisions participate in the production of that product. You will be asked to make decisions for a number of periods, and your compensation will be based on the decisions made by both you and the other participant. You will accumulate points from your decisions. At the end of the session, your accumulated point balance from all periods will be paid to you in real cash at a rate of $\$ 1.00$ per 10 points. (For example, if your balance was 100 at the end of the session, you would receive $\$ 10.00$, which is 100 divided by 10.) The following instructions show how you accumulate points.

\section{Providing Resources}

Your services for Company XYZ require you to provide resources, which you can think of as work effort. Because effort is costly, providing high resources is more costly to you individually than providing low resources. You must choose between two alternatives, with the following consequences:

- High Resources - If you choose to provide high resources to the firm in any given period, your division's productivity will be high but you will incur a personal cost of $\mathbf{1 0}$ points.

- Low Resources - If you choose to provide low resources to the firm in any given period, your division's productivity will be low but you will not incur any personal cost.

The other participant will be asked to make the same decision for his/her division. After independently making the decisions, you will be informed of the decision the other participant made.

\section{Reporting}

You will be required to submit a report every period, in which you will document the level of resources the other participant provided in the period. Note that while you will know with certainty what level of resources the other participant provided, you are not required to report that level. You can choose to report either high or low, regardless of what the other participant actually did. 


\section{Compensation}

Your compensation will be based on the report filed by the other participant. Specifically,

- If the other participant reports that you provided high resources, you will receive 20 points.

- If the other participant reports that you provided low resources, you will receive 0 points.

The same compensation applies also to the other participant, who will be compensated based on the report you file. That is,

- If you report that the other participant provided high resources, the other participant will receive 20 points.

- If you report that the other participant provided low resources, the other participant will receive 0 points.

\section{Reporting Bonuses and Penalties}

You will also earn an extra bonus if you report that the other participant provided low resources, but only if s/he actually did provide low resources. Specifically,

- If you report that the other participant provided low resources, this will be verified, and if the other participant actually did provide low resources, you will receive a bonus of 10 points.

- However, if you report that the other participant provided low resources, and the other participant actually provided high resources, you will incur a penalty of 20 points.

The same reporting bonus and penalty applies also to the other participant with respect to your decision. That is,

- If the other participant reports that you provided low resources, and you actually did provide low resources, the other participant will receive a bonus of 10 points.

- However, if the other participant reports that you provided low resources, and you actually provided high resources, the other participant will incur a penalty of 20 points. 


\section{Record Keeping}

For each period, you will fill out the following table to keep track of your decisions and compensation.

\begin{tabular}{|c|c|}
\hline $\begin{array}{l}\text { Providing } \\
\text { Resources }\end{array}$ & $\begin{array}{l}\text { Circle the level of resources that you will provide. } \\
\qquad \text { HIGH } \\
\text { LOW } \\
\text { If you choose to provide high resources, deduct } 10 \\
\text { points. } \\
\text { If you choose to provide low resources, enter - } 0 \text {-. }\end{array}$ \\
\hline $\begin{array}{l}\text { Observing the } \\
\text { other } \\
\text { participant's } \\
\text { Decision }\end{array}$ & $\begin{array}{l}\text { The administrator will circle the level of resources that } \\
\text { the other participant provided. } \\
\text { HIGH } \\
\text { LOW }\end{array}$ \\
\hline $\begin{array}{l}\text { Filing your } \\
\text { Report }\end{array}$ & $\begin{array}{l}\text { What report would you like to make regarding the } \\
\text { level of resources the other participant provided? } \\
\text { HIGH } \\
\text { LOW }\end{array}$ \\
\hline Compensation & $\begin{array}{l}\text { If the other participant reported that you provided } \\
\text { high resources, add } 20 \text { points. } \\
\text { If the other participant reported that you provided low } \\
\text { resources, enter -0- }\end{array}$ \\
\hline $\begin{array}{l}\text { Reporting } \\
\text { Bonus or } \\
\text { Penalty }\end{array}$ & $\begin{array}{l}\text { If you reported that the other participant provided high } \\
\text { resources, enter - } 0 \text {-. } \\
\text { If you reported that the other participant provided low } \\
\text { resources, the administrator will verify if the other } \\
\text { participant did in fact provide low resources, as you } \\
\text { reported. } \\
\text { YES (enter a bonus of } 10 \text { points) } \\
\text { NO (enter a penalty of } 20 \text { points) }\end{array}$ \\
\hline Total & $\begin{array}{l}\text { Add / subtract the entries in each cell and write your } \\
\text { total compensation for this period here. Remember } \\
\text { that your compensation in dollars for this period is this } \\
\text { point total divided by } 10 \text {. }\end{array}$ \\
\hline
\end{tabular}




\section{High Identity, Horizontal Incentive System}

You were assigned to a color group when you arrived. Each of you will be paired with a member of your color group (who will be referred to as your teammate).

Assume that you and your teammate are two division managers working for Company XYZ. The company produces one product, but both of your divisions participate in the production of that product. You will be asked to make decisions for a number of periods, and your compensation will be based on the decisions made by both you and your teammate. You will accumulate points from your decisions. At the end of the session, your accumulated point balance from all periods will be paid to you in real cash at a rate of $\$ 1.00$ per 10 points. (For example, if your balance was 100 at the end of the session, you would receive $\$ 10.00$, which is 100 divided by 10.) The following instructions show how you accumulate points.

\section{Providing Resources}

Your services for Company XYZ require you to provide resources, which you can think of as work effort. Because effort is costly, providing high resources is more costly to you individually than providing low resources. You must choose between two alternatives, with the following consequences:

- High Resources - If you choose to provide high resources to the firm in any given period, your division's productivity will be high but you will incur a personal cost of $\mathbf{1 0}$ points.

- Low Resources - If you choose to provide low resources to the firm in any given period, your division's productivity will be low but you will not incur any personal cost.

Your teammate will be asked to make the same decision for his/her division. After independently making the decisions, you will be informed of the decision your teammate made.

\section{Compensation}

You and your teammate will receive the same compensation, and it will depend on the level of resources you both provide. Recall that you will be making decisions for a number of periods. The compensation plan will be different in even numbered and odd numbered periods. 


\section{Periods 1, 3, $5 \ldots$}

- If both you and your teammate provide high resources, you will each receive 20 points.

- If either you or your teammate (but not both of you) provides high resources, you will each receive 14 points.

- If neither you nor your teammate provides high resources, you will each receive 8 points.

Periods 2, 4, $6 \ldots$

- If both you and your teammate provide high resources, you will each receive 20 points.

- If either you or your teammate (but not both of you) provides high resources, you will each receive 10 points.

- If neither you nor your teammate provides high resources, you will each receive no points.

Note that a key difference between the compensation in odd and even-numbered periods is that in odd-numbered periods, your net number of points (Compensation minus Resource Costs) will be determined by both your decision and the other participant's decision. However, in the even-numbered periods, your net points will be determined entirely by the other participant's decision. This is because in even periods, if the other participant provides high resources, you will earn a net of 10 points irrespective of whether you provide high resources (because 20 points compensation -10 points cost $=10$ ) or low resources (because 10 points compensation -0 points cost $=10$ ). Similarly, if the other participant provides low resources, you will earn a net of 0 points irrespective of whether you provide high resources (because 10 points compensation -10 points cost $=0$ ) or low resources (because 0 points compensation -0 points cost $=0$ ). Thus, in even periods, your decision only affects the other person's payoffs, not your payoffs.

Note also that while the compensation will change every other period, you will be paired with the same person throughout the exercise. Therefore, it may be appropriate to think about the other participant's decisions in prior periods when making your decisions. 


\section{Record Keeping}

For each period, you will fill out the following table to keep track of your decisions and compensation.

\begin{tabular}{|c|c|}
\hline $\begin{array}{l}\text { Providing } \\
\text { Resources }\end{array}$ & $\begin{array}{l}\text { Circle the level of resources that you will provide. } \\
\qquad \text { HIGH } \\
\text { LOW } \\
\text { If you choose to provide high resources, deduct } 10 \\
\text { points. } \\
\text { If you choose to provide low resources, enter -0-. }\end{array}$ \\
\hline $\begin{array}{l}\text { Observing } \\
\text { your } \\
\text { teammate's } \\
\text { Decision }\end{array}$ & $\begin{array}{l}\text { The administrator will circle the level of resources that } \\
\text { your teammate provided. } \\
\text { HIGH } \\
\text { LOW }\end{array}$ \\
\hline \multirow[t]{2}{*}{ Compensation } & $\begin{array}{l}\text { Periods } 1, \mathbf{3}, \mathbf{5} \ldots \\
\text { - If both you and your teammate provided high } \\
\text { resources, add } 20 \text { points. } \\
\text { - If either you or your teammate (but not both) } \\
\text { provided high resources, add } 14 \text { points. } \\
\text { - If neither you nor your teammate provided high } \\
\text { resources, add } 8 \text { points. }\end{array}$ \\
\hline & $\begin{array}{l}\text { Periods } 2,4,6 \ldots \\
\text { - If both you and your teammate provided high } \\
\text { resources, add } 20 \text { points. } \\
\text { - If either you or your teammate (but not both) } \\
\text { provided high resources, add } 10 \text { points. } \\
\text { - If neither you nor your teammate provided high } \\
\text { resources, enter -0-. }\end{array}$ \\
\hline Total & $\begin{array}{l}\text { Add / subtract the entries in each cell and write your } \\
\text { total compensation for this period here. Remember } \\
\text { that your compensation in dollars for this period is this } \\
\text { point total divided by } 10 \text {. }\end{array}$ \\
\hline
\end{tabular}




\section{Low Identity, Horizontal Incentive System}

You were assigned to a color group when you arrived. Each of you will be paired with a member of the other color group (who will be referred to as the other participant).

Assume that you and the other participant are two division managers working for Company XYZ. The company produces one product, but both of your divisions participate in the production of that product. You will be asked to make decisions for a number of periods, and your compensation will be based on the decisions made by both you and the other participant. You will accumulate points from your decisions. At the end of the session, your accumulated point balance from all periods will be paid to you in real cash at a rate of $\$ 1.00$ per 10 points. (For example, if your balance was 100 at the end of the session, you would receive $\$ 10.00$, which is 100 divided by 10.) The following instructions show how you accumulate points.

\section{Providing Resources}

Your services for Company XYZ require you to provide resources, which you can think of as work effort. Because effort is costly, providing high resources is more costly to you individually than providing low resources. You must choose between two alternatives, with the following consequences:

- High Resources - If you choose to provide high resources to the firm in any given period, your division's productivity will be high but you will incur a personal cost of $\mathbf{1 0}$ points.

- Low Resources - If you choose to provide low resources to the firm in any given period, your division's productivity will be low but you will not incur any personal cost.

The other participant will be asked to make the same decision for his/her division. After independently making the decisions, you will be informed of the decision the other participant made.

\section{Compensation}

You and the other participant will receive the same compensation, and it will depend on the level of resources you both provide. Recall that you will be making decisions for a number of periods. The compensation plan will be different in even numbered and odd numbered periods. 


\section{Periods 1, 3, 5 ...}

- If both you and the other participant provide high resources, you will each receive 20 points.

- If either you or the other participant (but not both of you) provides high resources, you will each receive 14 points.

- If neither you nor the other participant provides high resources, you will each receive 8 points.

\section{Periods 2, 4, $6 \ldots$}

- If both you and the other participant provide high resources, you will each receive 20 points.

- If either you or the other participant (but not both of you) provides high resources, you will each receive 10 points.

- If neither you nor the other participant provides high resources, you will each receive no points.

Note that a key difference between the compensation in odd and even-numbered periods is that in odd-numbered periods, your net number of points

(Compensation minus Resource Costs) will be determined by both your decision and the other participant's decision. However, in the even-numbered periods, your net points will be determined entirely by the other participant's decision. This is because in even periods, if the other participant provides high resources, you will earn a net of 10 points irrespective of whether you provide high resources (because 20 points compensation -10 points cost $=10$ ) or low resources (because 10 points compensation -0 points cost $=10$ ). Similarly, if the other participant provides low resources, you will earn a net of 0 points irrespective of whether you provide high resources (because 10 points compensation -10 points cost $=0$ ) or low resources (because 0 points compensation - 0 points cost $=0$ ). Thus, in even periods, your decision only affects the other person's payoffs, not your payoffs.

Note also that while the compensation will change every other period, you will be paired with the same person throughout the exercise. Therefore, it may be appropriate to think about the other participant's decisions in prior periods when making your decisions. 


\section{Record Keeping}

For each period, you will fill out the following table to keep track of your decisions and compensation.

\begin{tabular}{|c|c|}
\hline $\begin{array}{l}\text { Providing } \\
\text { Resources }\end{array}$ & $\begin{array}{l}\text { Circle the level of resources that you will provide. } \\
\qquad \text { HIGH } \\
\text { LOW } \\
\text { If you choose to provide high resources, deduct } 10 \\
\text { points. } \\
\text { If you choose to provide low resources, enter -0-. }\end{array}$ \\
\hline $\begin{array}{l}\text { Observing the } \\
\text { other } \\
\text { participant's } \\
\text { Decision }\end{array}$ & $\begin{array}{l}\text { The administrator will circle the level of resources that } \\
\text { the other participant provided. } \\
\text { HIGH } \\
\text { LOW }\end{array}$ \\
\hline \multirow[t]{2}{*}{ Compensation } & $\begin{array}{l}\text { Periods } \mathbf{1}, \mathbf{3}, \mathbf{5} \ldots \\
\text { - If both you and the other participant provided high } \\
\text { resources, add } 20 \text { points. } \\
\text { - If either you or the other participant (but not both) } \\
\text { provided high resources, add } 14 \text { points. } \\
\text { - If neither you nor the other participant provided } \\
\text { high resources, add } 8 \text { points. }\end{array}$ \\
\hline & $\begin{array}{l}\text { Periods } 2,4,6 \ldots \\
\text { - If both you and the other participant provided high } \\
\text { resources, add } 20 \text { points. } \\
\text { - If either you or the other participant (but not both) } \\
\text { provided high resources, add } 10 \text { points. } \\
\text { - If neither you nor the other participant provided } \\
\text { high resources, enter -0-. }\end{array}$ \\
\hline Total & $\begin{array}{l}\text { Add / subtract the entries in each cell and write your } \\
\text { total compensation for this period here. Remember } \\
\text { that your compensation in dollars for this period is this } \\
\text { point total divided by } 10 \text {. }\end{array}$ \\
\hline
\end{tabular}




\section{Appendix B - Instructional Slides}

\section{All Conditions}

What is this?

This is a business decision making experiment in which each of you will act as a business manager of $\mathrm{XYZ}$ company, making a series of decisions.

Ground Rules

-No Talking.

-No Deception.

-No right or wrong answers.

\section{Agenda}

- Read a case study describing the decisions you will be asked to make.

-Business decision making exercise. -Compensation. 
High Identity, Vertical Incentive System

\section{Documentation for Each Period}

- Fill out a pink resource decision form.

- Enter your resource decision on the recordkeeping form.

- The administrator will then show you the resource decision record completed by your teammate and record this information on the record-keeping form.

- Fill out a green report form.

- The administrator will then show you the report record completed by your teammate and record this information on the recordkeeping form.

- Calculate your total points for the period on the record-keeping form.

- Write your total points on the gold point tally form. 
Low Identity, Vertical Incentive System

\section{Documentation for Each Period}

- Fill out a pink resource decision form.

- Enter your resource decision on the recordkeeping form.

- The administrator will then show you the resource decision record completed by the other participant and record this information on the record-keeping form.

- Fill out a green report form.

- The administrator will then show you the report record completed by the other participant and record this information on the record-keeping form.

- Calculate your total points for the period on the record-keeping form.

- Write your total points on the gold point tally form. 
High Identity, Horizontal Incentive System

\section{Documentation for Each Period}

- Fill out a pink resource decision form.

- Enter your resource decision on the recordkeeping form.

- The administrator will then show you the resource decision record completed by your teammate and record this information on the record-keeping form.

- Calculate your total points for the period on the record-keeping form.

- Write your total points on the gold point tally form. 
Low Identity, Horizontal Incentive System

\section{Documentation for Each Period}

- Fill out a pink resource decision form.

- Enter your resource decision on the recordkeeping form.

- The administrator will then show you the resource decision record completed by the other participant and record this information on the record-keeping form.

- Calculate your total points for the period on the record-keeping form.

- Write your total points on the gold point tally form. 


\section{Appendix C - Post-Experimental Questionnaire}

Please take a few minutes to answer a few brief questions. This will help us to interpret the results.

1. What program are you in? (Circle one) MBA MPA PPA Other

2. How many years of full-time work experience (internships or postundergraduate) do you have?

3. If you have full-time work experience, what type of work did you do?

For the following questions, please circle the numbers that correspond to your answer.

4. At the beginning of the session, to what extent did you perceive yourself to be a teammate of the person you were paired with?

$\begin{array}{ccccccc}\mathbf{1} & \mathbf{2} & \mathbf{3} & \mathbf{4} & \mathbf{5} & \mathbf{6} & \mathbf{7} \\ \begin{array}{c}\text { Definitely } \\ \text { Not a teammate }\end{array} & & \begin{array}{c}\text { Maybe a } \\ \text { teammate }\end{array} & & & \begin{array}{c}\text { Definitely } \\ \text { a teammate }\end{array}\end{array}$

5. At the end of the session, to what extent did you perceive yourself to be a teammate of the person you were paired with?

$\begin{array}{ccccccc}\mathbf{1} & \mathbf{2} & \mathbf{3} & \mathbf{4} & \mathbf{5} & \mathbf{6} & \mathbf{7} \\ \begin{array}{c}\text { Definitely } \\ \text { Not a teammate }\end{array} & & \begin{array}{c}\text { Maybe a } \\ \text { teammate }\end{array} & & & \begin{array}{l}\text { Definitely } \\ \text { a teammate }\end{array}\end{array}$

6. If you were to participate in a similar study in the future, to what extent would you like to be paired with the same person again?

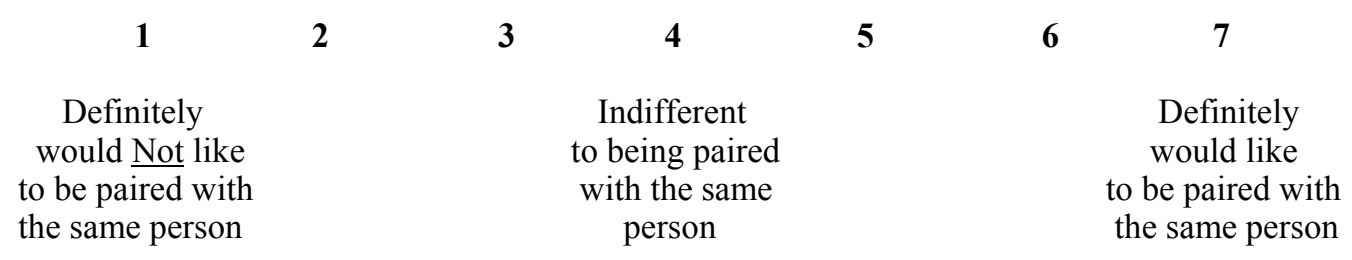


7. When you were considering your choices, were you more concerned with maximizing your own profit or maximizing the total profit to you and the person you were paired with?
1
2
3
4
5
6
7

Only interested

Interested in both

in my own profit

my own profit and the total profit

Only interested in the total profit

8. To what extent did you feel that your division's productivity was influenced by the effort of the person you were paired with?

$\begin{array}{llllllll}1 & 2 & 3 & 4 & 5 & 6 & 7\end{array}$

Not at all

Moderately

Influenced

Heavily

Influenced

9. How complex did you find the compensation method?

$\begin{array}{ccccccc}\mathbf{1} & \mathbf{2} & \mathbf{3} & \mathbf{4} & \mathbf{5} & \mathbf{6} & \mathbf{7} \\ \begin{array}{c}\text { Very } \\ \text { Simple }\end{array} & & \begin{array}{c}\text { Moderately } \\ \text { Complex }\end{array} & & & \begin{array}{c}\text { Very } \\ \text { Complex }\end{array}\end{array}$

10. To what extent did the following factors influence your decisions?

a) A desire to cooperate.

1

Not at all

\section{2}

3

Moderately
5

6

7

To a great Extent

b) A desire to do the right thing for your division.

1

Not at all
2

3

Moderately
5

6 7

To a great Extent

c) A desire to do the right thing for the other division.

1

Not at all
2

3

Moderately
5

6 7

To a great Extent 
d) A desire to do the right thing for the firm.

1

Not at all

e) A desire to be honest

1

2

Not at all

2
3

4

Moderately

5

6

7

To a great

Extent
5

Moderately

$\begin{array}{cc}3 & 4 \\ & \text { Moderately }\end{array}$

6

7

To a great

Extent

10. Briefly describe the strategy you used in making your decisions.

11. Please note any parts of the instructions you found confusing.

12. Other Comments.

Thank you very much for participating! Please do not discuss the study with others who may be participating until after September 21, 2001. 


\section{Appendix D - Communication Transcript Samples}

\section{High Identity, Vertical Incentive System}

\section{Period 1}

Blue 3: How are we gonna do this? Take turns maximizing? Comprende? I'm not sure how this is gonna work out. I'm trying to figure out how we'll make the most money.

\section{Period 2}

Blue 3: Let's try this. . say I did "high." We'll see how it works.Let me know what you think. I'm figuring the best way is just to take turns getting 30 .

Blue 4: Let's just keep taking turns doing this. Low, High.

\section{Period 3}

Blue 3: It's the best thing I can think of.

Blue 4: Yeah, me too

\section{Low Identity, Vertical Incentive System}

\section{Period 1}

Blue 1: If you provide low and I say you provided high every time (and vice versa), I think we'll both make the most money.

Yellow 1: One of us should choose to be low and the other high every time. Then both report high. You get 30 points each time. (I think!) I'll be high every time. You be low, then report high.

\section{Period 2}

Blue 1: If you do low, you won't have to pay 10 points for resources. 
Period 3

Blue 1: If we both report low, we can both say the other one of us reported high. Then we'd both get 20 points and neither one of us would lose 10 points. We'd both get 20 every time.

\section{High Identity, Horizontal Incentive System}

\section{Period 7}

Blue 1: There has to be a way to get more!

\section{Period 8}

Blue 1: I don't know. I guess just keep doing the same thing, but think about it.

Blue 2: I think that there's a way too for it to be higher hold on?

\section{Period 9}

Blue 2: I don't see it yet. You?

\section{Period 11}

Blue 1: Might as well stay with the same thing. I'll keep thinking.

\section{Low Identity, Horizontal Incentive System}

\section{Period 1}

Blue 3: High all the time?

Period 2

Yellow 3: OK - sounds fine. 


\section{References}

Abrams, D. and M. A. Hogg. 1990. An introduction to the social identity approach. In Social Identity Theory: Constructive and Critical Advances, edited by D. Abrams and M. A. Hogg. New York: Springer-Verlag New York, Inc.

Abosch, K. S. and D. B. Reidy. 1996. Supporting teams through rewards systems. ACA Journal 4(4): 72-81.

Arya, A., J. Fellingham and J. Glover. 1997. Teams, repeated tasks, and implicit incentives. Journal of Accounting and Economics 23: 7-30.

Arya, A. and J. Glover. 1995. A simple forecasting mechanism for moral hazard settings. Journal of Economic Theory 66: 507-521.

Arya, A. and J. Glover. 1996a. The role of budgeting in eliminating tacit collusion. Review of Accounting Studies 1: 191-205.

Arya, A. and J. Glover. 1996b. Verification of historical cost reports. The Accounting Review 71(2): 255-269.

Arya, A., J. Glover, and J. S. Hughes. 1997. Implementing coordinated team play. Journal of Economic Theory 74: 218-232.

Ashforth, B. E. and F. Mael. 1989. Social identity theory and the organization. Academy of Management Review 14(1): 20-39.

Baiman, S. 1982. Agency research in managerial accounting: a survey. Journal of Accounting Research 1: 154-213.

Barker, J. R. 1993. Tightening the iron cage: concertive control in self-managing teams. Administrative Science Quarterly 38: 408-437.

Barron, J. M. and K. P. Gjerde. 1997. Peer pressure in an agency relationship. Journal of Labor Economics 15(2): 234-254.

Bollen, K. A. and R. A. Stine. 1993. Bootstrapping goodness-of-fit measures in structural equation models. In Testing Structural Equation Models, edited by K. A. Bollen and J. S. Long. Newbury Park, CA: Sage Publications. 
Bonner, S. E., R. Hastie, G. B. Sprinkle, and S. M. Young. 2000. A review of the effects of financial incentives on performance in laboratory tasks: implications for management accounting. Journal of Management Accounting Research 12: 19-64.

Bonner, S. E. and G. B. Sprinkle. 2001. The effect of monetary incentives on effort and task performance: theories, evidence, and a framework for research. Forthcoming, Accounting, Organizations and Society.

Breakwell, G. M. 1983. Identities and conflicts. In Threatened Identities, edited by G.M. Breakwell. Chichester, UK: John Wiley \& Sons.

Brewer, M. B. 1979. In-group bias in the minimal intergroup situation: a cognitive-motivational analysis. Psychological Bulletin 86: 307-324.

Brewer, M. B. and R. M. Kramer. 1986. Choice behavior in social dilemmas: effects of social identity, group size, and decision framing. Journal of Personality and Social Psychology 50 (3): 543-549.

Brewer, M. B. and S. K. Schneider. 1990. Social identity and social dilemmas: a double-edged sword. In Social Identity Theory: Constructive and Critical Advances, edited by D. Abrams and M. A. Hogg. New York: SpringerVerlag New York, Inc.

Coates, D. E. 1998. Don’t tie 360 feedback to pay. Training 35(9): 68-78.

Cohen, S. G. and D. E. Bailey. 1997. What makes teams work: group effectiveness research from the shop floor to the executive suite. Journal of Management 23(3): 239-290.

Conover, W. J. and R. L. Iman. 1981. Rank transformations as a bridge between parametric and nonparametric statistics. The American Statistician 35: 124-129.

Cooper, R., D. V. DeJong, R. Forsythe, and T. W. Ross. 1992. Communication in coordination games. The Quarterly Journal of Economics 107(2): 739771 .

Dawes, R. M. 1980. Social Dilemmas. Annual Review of Psychology 31: 169-193.

De Cremer, D. and M. van Vugt. 1998. Collective identity and cooperation in a public goods dilemma: a matter of trust or self-efficacy? Current Research 
in Social Psychology 3(1).

$<$ http://www.uiowa.edu/ grpproc/crisp/crisp.html $>$

DeMatteo, J. S., L. T. Eby, and E. Sundstrom. 1998. Team-based rewards: current empirical evidence and directions for future research. Research in Organizational Behavior 20: 141-183.

Demski, J. 1997. Managerial Uses of Accounting Information. Norwell, MA: Kluwer Academic Publishers.

Demski, J. S., and D. Sappington. 1984. Optimal incentive contracts with multiple agents. Journal of Economic Theory 33: 152-171.

Demski, J. S., D. E. M. Sappington, and P. T. Spiller. 1988. Incentive schemes with multiple agents and bankruptcy constraints. Journal of Economic Theory 44: 156-167.

Diggle, P. J., K. Y. Liang, and S. L. Zeger. 1994. The Analysis of Longitudinal Data. New York: Oxford University Press.

Drake, A. R., S. F. Haka, and S. P. Ravenscroft. 1999. Cost system and incentive structure effects on innovation, efficiency and profitability in teams. The Accounting Review 74(3): 323-345.

Dumaine, B. 1990. Who needs a boss? Fortune 121(10): 52-60.

Dumaine, B. 1994. The trouble with teams. Fortune 130(5): 86.

Edwards, M. R. and A. J. Ewen. 1996. How to manage performance and pay with 360-degree feedback. Compensation \& Benefits Review 28(3): 41-46.

Everett, J. J., R. E. Smith, and K. D. Williams. 1992. Effects of team cohesion and identifiability on social loafing in relay swimming performance. International Journal of Sport Psychology 23: 311-324.

Ezzamel, M. and H. Willmott. 1998. Accounting for teamwork: a critical study of group-based systems of organizational control. Administrative Science Quarterly 43: 358-396.

Festinger, L. 1950. Informal social communication. Psychological Review 57: 271-282. 
Fischer, P. E. and J. S. Hughes. 1997. Mutual monitoring and best agency contracts. Journal of Institutional and Theoretical Economics 153: 334355 .

Fisher, J. G., S. A. Peffer, and G. B. Sprinkle. 2001. Budget-based contracts, budget levels, and group productivity: an experimental study. Working Paper, Kelley School of Business, Indiana University, Bloomington, IN.

Fishman, C. 1996. Whole Foods is all teams. Fast Company 2: 103.

Frederickson, J. R.. 1992. Relative performance information: the effects of common uncertainty and contract type on agent effort. The Accounting Review 67(4): 647-669.

Gibbons, R. 1992. Game Theory for Applied Economists. Princeton, NJ: Princeton University Press.

Gibbons, R. and K. J. Murphy. 1990. Relative performance evaluation for chief executive officers. Industrial and Labor Relations Review 43(S): 30-51.

Gillmor, D. 2000. Cisco's leader pushes his vision. The Inquirer, May 28, 2000, sec. E, p. 3.

Glover, J. 1994. A simpler mechanism that stops agents from cheating. Journal of Economic Theory 62: 221-229.

Haynes, C. M. and S. J. Kachelmeier. 1998. The effects of accounting contexts on accounting decisions: a synthesis of cognitive and economic perspectives in accounting experimentation. Journal of Accounting Literature 17: 97136.

Hewitt Associates, LLC. 1995. Salary Increase Report. Lincolnshire, IL: Hewitt Associates LLC.

Hogg, M. A. 1987. Social identity and group cohesiveness. In Rediscovering the Social Group: A Self-Categorization Theory, edited by J. C. Turner. Oxford, UK: Basil Blackwell Ltd.

Hogg, M. A. and D. J. Terry. 2000. Social identity and self-categorization processes in organizational contexts. Academy of Management Review 25(1): 121-141. 
Hogg, M. A. and D. Abrams. 1988. Social identification: A Social Psychology of Intergroup Relations and Group Processes. London: Routledge.

Holmstrom, B. 1979. Moral hazard and observability. Bell Journal of Economics 10: 74-91.

Holmstrom, B. 1982. Moral hazard in teams. Bell Journal of Economics 13: 324340 .

Institute of Management Accountants. 1999. Counting More, Counting Less, Transformations in the Management Accounting Profession, The1999 Practice Analysis. Montvale, NJ: Institute of Management Accountants.

Itoh, H. 1991. Incentives to help in multi-agent situations. Econometrica 59(3): 611-636.

Itoh, H. 1993. Coalitions, incentives, and risk sharing. Journal of Economic Theory 60: 410-427.

Kandel, E. and E. P. Lazear. 1992. Peer pressure and partnerships. Journal of Political Economy 100(4): 801-817.

Kahneman, D. and A. Tversky. 1984. Choices, values, and frames. American Psychologist 39: 341-350.

Kelley, M. 2000. Core values keep airline flying high. Harvard Business School Bulletin, December $2000<$ www.hbsworkingknowledge.hbs.edu>.

Kidwell, R. E., Jr. and N. Bennett. 1993. Employee propensity to withhold effort: a conceptual model to intersect three avenues of research. Academy of Management Review 18(3): 429-456.

King, R. 2002. An experimental investigation of self-serving biases in an auditing trust game: the effect of group affiliation. Forthcoming, The Accounting Review (April 2002).

Kline, R. B. 1998. Principles and Practice of Structural Equation Modeling. New York, NY: The Guilford Press.

Kramer, R. M. and M. B. Brewer. 1984. Effects of group identity on resource use in a simulated commons dilemma. Journal of Personality and Social Psychology 46(5): 1044-1057. 
Kunda, Z. 1999. Social Cognition - Making Sense of People. Cambridge, MA: The MIT Press.

Lawler, E. E., III and S. E.Cohen. 1992. Designing pay systems for teams. $A C A$ Journal 1(1): 6-9.

Lazega, E. 2000. Rule enforcement among peers: a lateral control regime. Organization Studies 21(1): 193-214.

Ledyard, J. O. 1995. Public goods: a survey of experimental research. In The Handbook of Experimental Economics, edited by J.H. Kagel and A.E. Roth, Princeton, NJ: Princeton University Press.

Lembke, S. and M. Wilson 1998. Putting the 'team' into teamwork: alternative theoretical contributions for contemporary management practice. Human Relations 51(7): 927-944.

Levene, H. 1960. Robust tests for equality of variances. In Contributions to Probability and Statistics: Essays in Honor of Harold Hotelling, edited by I. Olkin, 278-292. Stanford, CA: Stanford University Press.

Locksley, A., V. Oritz, and C. Hepburn. 1980. Social categorization and discriminatory behavior: Extinguishing the minimal intergroup discrimination effect. Journal of Personality and Social Psychology 39: 773-783.

Lorenzi-Cioldi, F. and W. Doise. 1990. Levels of analysis and social identity. In Social Identity Theory: Constructive and Critical Advances, edited by D. Abrams and M. A. Hogg. New York: Springer-Verlag New York, Inc.

Ma, C. 1988. Unique implementation of incentive contracts with many agents. Review of Economic Studies 55: 555-572.

Ma, C., J. Moore, and S. Turnbull. 1988. Stopping agents from 'cheating.' Journal of Economic Theory 46: 355-372.

Maxwell, S. E. and H. D. Delaney. 1989. Designing Experiments and Analyzing Data. Pacific Grove, CA: Brooks/Cole Publishing Company.

McGrath, J. E. 1984. Groups: Interaction and Performance. Englewood Cliffs, N.J.: Prentice Hall. 
Messick, D. M., H. Wilke, M. B. Brewer, R. M. Kramer, P. Zemke, and L. Lui. 1983. Individual adaptations and structural change as solutions to social dilemmas. Journal of Personality and Social Psychology 44: 294-309.

Mookherjee, D. 1984. Optimal incentive schemes with many agents. Review of Economic Studies 51: 433-446.

Moser, D. V. 1998. Using an experimental economics approach in behavioral accounting research. Behavioral Research in Accounting 10 (Supplement): 94-110.

Mullen, B. and C. Copper. 1994. The relation between group cohesiveness and performance: an integration. Psychological Bulletin 115(2): 210-227.

Nahavandi, A. and E. Aranda. 1994. Restructuring teams for the re-engineered organization. Academy of Management Review 8(4): 59-68.

Nikias, A. 2001. Implicit punishment strategies in a multi-period team setting. Working paper, The Ohio State University, Columbus, OH.

Prendergast, C. 1999. The provision of incentives in firms. Journal of Economic Literature 37: 7-63.

Radner, R. 1986. Repeated partnership games with imperfect monitoring and no discounting. Review of Economic Studies 53: 43-57.

Ramakrishnan, R. T. S. and A. V. Thakor. 1991. Cooperation versus competition in agency. Journal of Law, Economics, and Organization 7: 248-283.

Rankin, F. W. 2001. The effect of the mutual observability of information and performance measurement on the allocation of effort: an experimental analysis. Working Paper, Washington University, St. Louis, MO.

Rankin, F. and T. L. Sayre. 2000. The effects of performance separability and contract type on agent effort. Accounting, Organizations and Society 25: 683-695.

Rigdon, E. E., R. E. Schumacker, and W. Wothke. 1998. A comparative review of interaction and nonlinear modeling. In Interaction and Nonlinear Effects in Structural Equation Modeling, edited by R. E. Schumacker and G. A. Marcoulides, Mahwah, NJ: Lawrence Erlbaum Associates. 
Scott, S. G. 1997. Social identification effects in product and process development teams. Journal of Engineering Technology Management 14: 97-127.

Sewell, G. 1998. The discipline of teams: the control of team-based industrial work through electronic and peer surveillance. Administrative Science Quarterly 43: 397-428.

Slovic, P. and S. Lichtenstein. 1971. Comparison of Bayesian and regression approaches to the study of information processing in judgment. Organizational Behavior and Human Performance 6: 649-744.

Smith, V. L. 1982. Microeconomic systems as an experimental science. The American Economic Review 72: 923-955.

Sprinkle, G. B. 2000. The effect of incentive contracts on learning and performance. The Accounting Review 75(3): 299-326.

Tajfel, H. and J. Turner. 1986. The social identity theory of intergroup behavior. In The Social Psychology of Intergroup Relations ( $2^{\text {nd }}$ ed.), edited by S. Worchel and W. G. Austin. Chicago: Nelson-Hill Publishers.

Thatcher, M. 1996. Allowing everyone to have their say. Personnel Management 2(6): 28-30.

Tirole, J. 1988. The multicontract organization. Canadian Journal of Economics 21(3): 459-466.

Turner, J. C. 1987a. A self-categorization theory. In Rediscovering the Social Group: A Self-Categorization Theory, edited by J. C. Turner, Oxford, UK: Basil Blackwell Ltd.

Turner, J. C. 1987b. Rediscovering the social group. In Rediscovering the Social Group: A Self-Categorization Theory, edited by J. C. Turner, Oxford, UK: Basil Blackwell Ltd.

Varian, H. R. 1990. Monitoring agents with other agents. Journal of Institutional and Theoretical Economics 146: 153-174.

Villadsen, B. 1995. Communication and delegation in collusive agencies. Journal of Accounting and Economics 19: 315-344. 
Waller, W. S. 1995. Decision-making research in managerial accounting: return to behavioral-economics foundations. In Judgment and Decision-Making Research in Accounting and Auditing, edited by R. H. Ashton and A. H. Ashton. New York, NY: Cambridge University Press.

Waller, W. S. 2001. Behavioral accounting experiments in market and game settings. In Experimental Business Research, edited by R. Zwick and A. Rapoport. Dordrecht, The Netherlands: Kluwer Academic Publishers.

Wech, B. A., K. W. Mossholder, R. P. Steel, and N. Bennett. 1998. Does work group cohesiveness affect individuals' performance and organizational commitment? A cross-level examination. Small Group Research 29(4): 472-494.

Wellins, R. S., W. C. Byham and G. R. Dixon. 1994. Inside Teams: How 20 World-Class Organizations are Winning Through Teamwork. San Francisco, CA: Jossey-Bass.

Wit, A. P, and H. A. M. Wilke. 1992. The effect of social categorization on cooperation in three types of social dilemmas. Journal of Economic Psychology 13(1): 135-151. 


\section{Vita}

Kristy Lynne Towry, the daughter of H.N. and Inez Cherry Towry, was born on May 2, 1960 in Natchitoches, LA. After receiving a Bachelor of Science

in Mathematics from Northwestern State University of Louisiana in 1982, she worked as a programmer at First National Bank of Louisiana and as a systems analyst at Louisiana Tech University. Kristy was awarded a Master of Business Administration at Texas A\&M University in 1988, and accepted a position at Exxon Company, USA as a senior internal auditor. After holding a number of positions at Exxon over the next seven years, she joined Compaq Computer Corporation in 1995, where she worked as a financial analyst until beginning the Ph.D. program at The University of Texas at Austin in 1997. She has published articles in Issues in Accounting Education and The Accounting Review.

Permanent address: 1509 East Lakeshore Drive, Natchitoches, LA 71457

This dissertation was typed by the author. 